Aus der Abteilung für Neurogenetik

(Direktor: Prof. K.-A. Nave, PhD)

des Max-Planck-Instituts für experimentelle Medizin

in Göttingen

\title{
Der Einfluss von Neuregulin-1 auf die Remyelinisierung im peripheren Nervensystem
}

\author{
INAUGURAL-DISSERTATION \\ zur Erlangung des Doktorgrades \\ der Medizinischen Fakultät der \\ Georg-August-Universität zu Göttingen
}

vorgelegt von

Ruth Martha Stassart

aus

Aachen

Göttingen 2013

Dekan: Prof. Dr. rer. nat. H. K. Kroemer

I. Berichterstatter: Prof. Dr. med. M.W. Sereda

II. Berichterstatter/in: Prof. Dr. med. M. Simons

III. Berichterstatter/in: Prof. Dr. med. M. Oppermann

Tag der mündlichen Prüfung: 10.09.2013 


\section{INHALTSVERZEICHNIS}

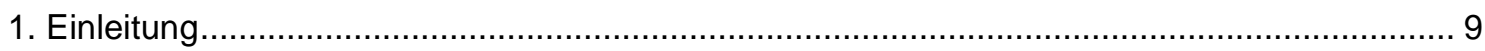

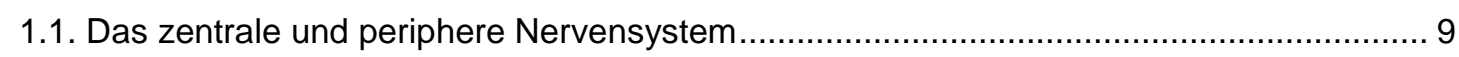

1.2. Die Struktur von Myelin und die Myelinisierung im PNS und ZNS .............................. 10

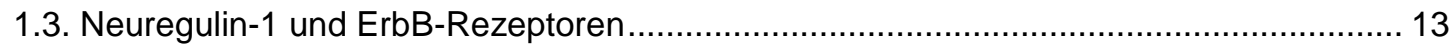

1.4. De- und Remyelinisierung im peripheren Nervensystem.......................................... 16

1.5. Zielsetzung und Hypothese der Promotionsarbeit ...................................................... 18

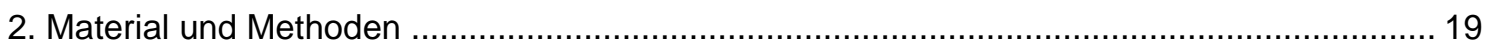

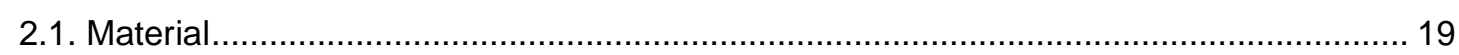

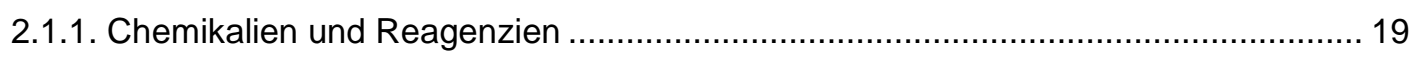

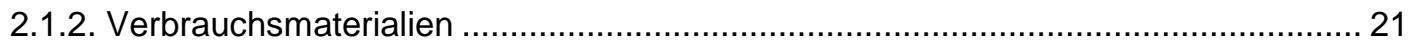

2.1.3. Enzyme, Nukleinsäuren und Reaktionskomplettsysteme ..................................... 21

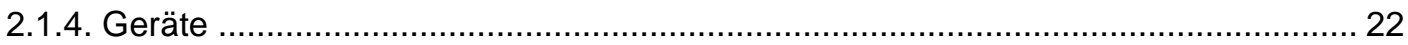

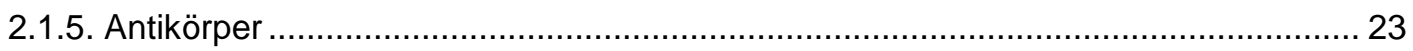

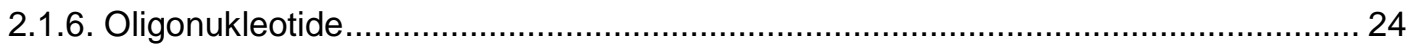

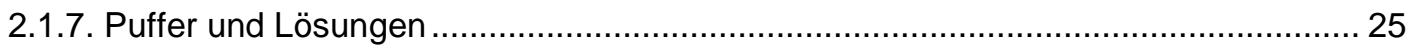

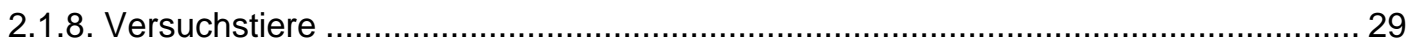

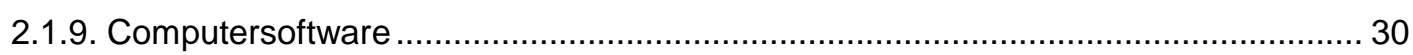

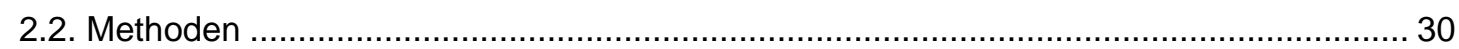

2.2.1. Handhabung und Analyse von Versuchstieren ................................................. 30

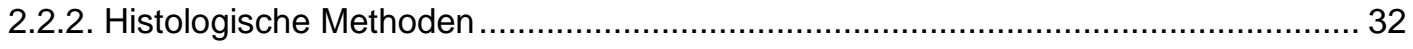

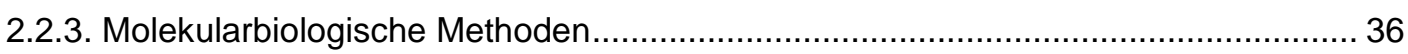

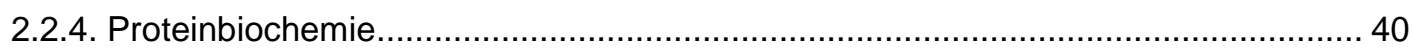

2.2.5. Isolierung und Kultivierung von primären Schwannzellen .................................... 41

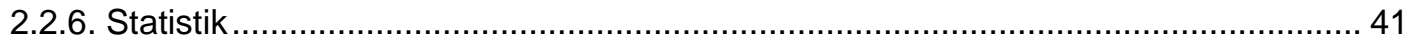

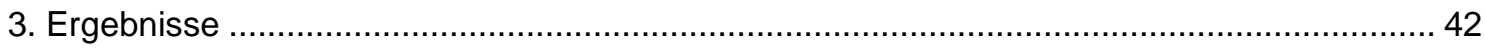

3.1. Neuronales Neuregulin-1 verbessert die Remyelinisierung im PNS ........................... 42

3.2. Schwannzellen exprimieren NRG1 Typ I nach einer Nervenschädigung ........................ 46

3.3. Die Expression von Schwannzell-NRG1 wird durch neuronales NRG1 reguliert............ 48

3.4. Die Rolle von Schwannzell-NRG1 für die Remyelinisierung im PNS ............................ 49

3.5. Axonales NRG1 Typ I kann den Verlust von Schwannzell-NRG1 nicht kompensieren .. 54 
4. Diskussion 56

4.1. Schwannzellen reagieren auch nach einer Nervenschädigung auf axonal

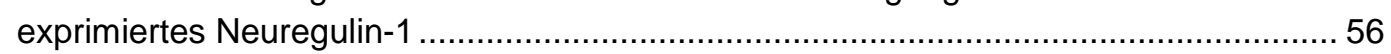

4.2. Schwannzellen exprimieren Neuregulin-1 Typ I nach einer Nervenverletzung ...............56

4.3. Schwannzell-NRG1 beeinflusst die Schwannzell-Redifferenzierung........................... 58

4.5. Die Funktion von glialem und neuronalem NRG1 Typ I während der Remyelinisierung. 59

5. Zusammenfassung 61

6. Abbildungsverzeichnis 63

7. Literaturverzeichnis 64 


\section{ABKÜRZUNGSVERZEICHNIS}

A

Abb.

ADAM17/ TACE

AKT

AP-1

APS

AraC

$A U$

BACE

bp

BPE

BRN2

BSA

ca.

CDNA

$\mathrm{C}_{6} \mathrm{H}_{5} \mathrm{Na}_{3} \mathrm{O}_{7}$

CIP

CRD

CREB

$\mathrm{CO}_{2}$

$\mathrm{Ct}$

DAB

DAPI

$\mathrm{ddH}_{2} \mathrm{O}$

DDSA

DDT

Dhh

DMEM

DMP30

DNA

dNTPs

DTT

ECL

EDTA

EGF

EGR2

EM

ErbB
Ampere

Abbildung

a disintegrin and metalloprotease 17

v-Akt-murine thymoma viral oncogene homolog 1

activator protein 1

Ammoniumperoxidsulfat

Cytosine-beta-d Arabinofuranosid

Arbitrary units

B-site amyloid precursor protein cleaving enzyme 1

Basenpaare

Bovine pituitary extract

POU domain, class 3 , transcription factor 2

Bovines Serumalbumin

circa

komplementäre DNA

Natriumcitrat

Alkalische Phosphatase

Cystein-reiche-Domäne

cAMP response element binding

Kohlendioxid

Threshold cycle

3-3'-Diaminobenzidin

4,6-Diamino-2-phenylindol

doppelt destilliertes Wasser

2-Duodecenyl-succinicacidanhydrid

Dichlordiphenyltrichlorethan

desert hedgehog

Dulbecco's Modified Eagle's Medium

2,4,6-tris-dimethylaminomethyl-Phenol

Desoxyribonukleinsäure

Desoxyribonukleosid-Triphosphate

1,4-Dithiotreitol

enhanced chemiluminescence

Ethylendiamintetraacetat

epidermal growth factor

early growth response 2

Elektronenmikroskop

erythroblastic leukemia viral oncogene homolog 


\begin{tabular}{|c|c|}
\hline ERK & extracellular signal regulated kinase \\
\hline f.c. & final concentration \\
\hline FCS & Fötales Kälberserum \\
\hline Fwd & Forward, Forwärtsprimer \\
\hline g & Gravitationskonstante \\
\hline g & gramm \\
\hline GPR126 & G-coupled-protein 126 \\
\hline $\mathrm{h}$ & Stunde \\
\hline $\mathrm{H}_{2} \mathrm{O}$ & Wasser \\
\hline HBSS & Hanks Balanced Salts Solution \\
\hline $\mathrm{HCl}$ & Salzsäure \\
\hline Hmgcr & 3-hydroxy-3-methylglutaryl-coenzyme-A-reductase \\
\hline HRP & Horseradish peroxidase \\
\hline $\lg$ & Immunglobulin \\
\hline IGF1 & insuline-like growth factor 1 \\
\hline $\mathrm{kb}$ & Kilobasen \\
\hline $\mathrm{KCl}$ & Kaliumchlorid \\
\hline $\mathrm{kDa}$ & kilo Dalton \\
\hline $\mathrm{kg}$ & Kilogramm \\
\hline $\mathrm{KHCO}_{3}$ & Kaliumhydrogencarbonat \\
\hline KI67 & antigen identified by monoclonal antibody Ki 67 \\
\hline 1 & Liter \\
\hline M & molar \\
\hline$\mu$ & Mikro \\
\hline$\mu l$ & Mikroliter \\
\hline MAPK & mitogen-activated protein kinase \\
\hline MBP & myelin basic protein \\
\hline $\mathrm{mg}$ & Milligramm \\
\hline$\mu \mathrm{g}$ & Mikrogramm \\
\hline $\mathrm{MgCl}_{2}$ & Magnesiumchlorid \\
\hline $\mathrm{MgSO}_{4}$ & Magnesiumsulfat \\
\hline $\min$ & Minute \\
\hline $\mathrm{ml}$ & Milliliter \\
\hline $\mathrm{mm}$ & Millimeter \\
\hline$\mu \mathrm{m}$ & Mikrometer \\
\hline$\mu \mathrm{M}$ & Mikromolar \\
\hline MNA & Methylnorbornen-2,3-dicarboxyl-anhydrid \\
\hline MOPS & 3-(N-Morpholino)-Propansulfonsäure \\
\hline mRNA & messenger RNA, Boten-Ribonukleinsäure \\
\hline $\mathrm{N}$ & Nervus \\
\hline $\mathrm{n}$ & Anzahl \\
\hline
\end{tabular}




\begin{tabular}{|c|c|}
\hline $\mathrm{n}$ & Nano \\
\hline $\mathrm{NaCl}$ & Natriumchlorid \\
\hline $\mathrm{NaHCO}_{3}$ & Natriumhydrogencarbonat \\
\hline $\mathrm{Na}_{2} \mathrm{HPO}_{4}$ & Dinatriumhydrogenphosphat \\
\hline $\mathrm{Na}_{2} \mathrm{HPO}_{4} \star 2 \mathrm{H}_{2} \mathrm{O}$ & Dinatriumhydrogenphosphat-2-hydrat \\
\hline $\mathrm{NaH}_{2} \mathrm{PO}_{4} \star 2 \mathrm{H}_{2} \mathrm{O}$ & Natriumdihydrogenphosphat-hydrat \\
\hline $\mathrm{NaOH}$ & Natriumhydroxid \\
\hline Nal & Natriumiodid \\
\hline NFAT & nuclear factor of activated T-cells \\
\hline NFKB & nuclear factor kappa B \\
\hline ng & Nanogramm \\
\hline NRG1 & Neuregulin-1 \\
\hline n.s. & nicht signifikant \\
\hline $\mathrm{OsO}_{4}$ & Osmiumtetroxid \\
\hline $\mathrm{p}$ & Wahrscheinlichkeit \\
\hline PAX3 & paired box gene 3 \\
\hline PBS & Phosphatpuffer \\
\hline PCR & Polymerasekettenreaktion \\
\hline PFA & Paraformaldehyd \\
\hline $\mathrm{Pl}_{3} \mathrm{~K}$ & Phosphatidylinositol-3-Kinase \\
\hline PLL & Poly-L-Lysin \\
\hline $\mathrm{PO} / \mathrm{MPZ}$ & myelin protein zero \\
\hline PNS & Peripheres Nervensystem \\
\hline POU3F1 & POU domain, class 3, transcription factor 1 \\
\hline PVDF & Polyvinylidenfluorid \\
\hline Ras & rat sarcoma superfamily \\
\hline Rev & Reverse, Rückwertsprimer \\
\hline RNA & Ribonukleinsäure \\
\hline rpm & rounds per minute \\
\hline rRNA & ribosomale RNA \\
\hline RT & Raumtemperatur \\
\hline RT & Reverse Transkriptase \\
\hline s & Sekunde \\
\hline S100 & S100 calcium binding protein A1 \\
\hline SC & Schwannzelle \\
\hline Scap & Sterol regulatory element-binding protein cleavage activating protein \\
\hline SDS & Sodium-Dodecyl-Sulfat \\
\hline SOX2 & SRY-box containing gene 2 \\
\hline sox10 & SRY-box containing gene 10 \\
\hline TAE & Tris/Acetat Puffer \\
\hline $\operatorname{Tg}$ & Transgen \\
\hline
\end{tabular}




$\begin{array}{ll}\text { Thy1 } & \text { thymus cell antigen } 1 \\ \text { tRNA } & \text { transfer RNA } \\ \mathrm{U} & \text { Units, Enzymeinheit } \\ \mathrm{UV} & \text { ultraviolett } \\ \mathrm{V} & \text { Volt } \\ \mathrm{Wt} & \text { Wildtyp } \\ \text { ZNS } & \text { Zentrales Nervensystem } \\ \text { Z.B. } & \text { zum Beispiel }\end{array}$




\section{EINLEITUNG}

\subsection{Das ZENTRALE UND PERIPHERE NERVENSYSTEM}

Der Begriff Nervensystem bezeichnet zwei spezialisierte Zelltypen, Neurone sowie Gliazellen, die in einem komplexen Zusammenspiel der Informationsaufnahme, -verarbeitung und -übertragung dienen. Bis auf einige Ausnahmen (z.B. Schwämme) weisen die meisten vielzelligen Organismen Nervensysteme auf. Die primitivste Form eines Nervensystems besitzen Hohltiere, darunter die Nesseltiere (Cnidaria). Hier ist das Nervensystem durch ein einfaches, diffuses Nervennetz charakterisiert, welches keine Zentralisierung in Form einer Gehirnausbildung (Cephalisierung) aufweist, obwohl einfache Sinnesorgane vorliegen können (Campbell und Reece 2003).

Die Nervensysteme von Wirbeltieren sind dagegen durch eine ausgeprägte Cephalisierung gekennzeichnet, und lassen sich in ein zentrales sowie ein peripheres Nervensystem unterteilen. Das zentrale Nervensystem (ZNS) bezeichnet Gehirn und Rückenmark, während das periphere Nervensystem (PNS) alle neuralen Strukturen außerhalb des ZNS umfasst (Campbell und Reece 2003). Weiterhin differenziert man sowohl im ZNS als auch im PNS ein somatisches von einem vegetativen Nervensystem (Trepel 1999). Das somatische Nervensystem dient der willkürlichen Kommunikation zwischen Organismus und Umwelt, wie z.B. der Innervation der Skelettmuskulatur. Dagegen arbeitet das vegetative Nervensystem überwiegend unbewusst, und reguliert die Funktionen der inneren Organe (Trepel 1999).

Die Hauptaufgaben des Nervensystems sind die Informationsaufnahme durch sensorische Endorgane, die Verarbeitung der Informationen im zentralen Nervensystem sowie die Ausbildung einer Antwort (wie zum Beispiel einer motorischen Reaktion) auf die empfangenen und verarbeiteten Reize (Campbell und Reece 2003). Das Nervensystem ermöglicht alle Aspekte unseres Bewusstseins sowie der Wahrnehmung, und steuert unser Verhalten (Campbell und Reece 2003).

Die kleinste strukturelle und funktionelle Einheit des Nervensystems stellt die Nervenzelle, das Neuron, dar. Dieses besteht aus einem Zellkörper (Perikaryon) und einerseits aus impulsempfangenden (afferenten) Fortsätzen, den Dendriten, sowie einem impulsweiterleitenden (efferenten) Fortsatz, dem Axon (Welsch 2003). Am distalen Axonende finden sich terminale Aufzweigungen, die synaptischen Endknöpfchen (Trepel 1999). Zusammen mit der nachfolgenden Zelle bilden diese eine sogenannte Synapse, an welcher die Erregungsüberleitung von einer Nervenzelle zur nächsten mit Hilfe chemischer Substanzen (Transmitter) stattfindet (Trepel 1999).

Die zweite Zellpopulation des Nervensystems sind Gliazellen, die auch bereits bei einfachen Organismen wie Anneliden oder Arthropoden in engem Kontakt zu Neuronen und ihren Fortsätzen stehen (Eckert et al. 2002). Im Rahmen der Evolution ist die Anzahl der Gliazellen 
im Nervensystem deutlich angestiegen, so dass beim Menschen ungefähr zehnmal mehr gliale als neuronale Zellen zu finden sind (Welsch 2003).

Gliazellen entstehen, ebenso wie Neurone, aus der ektodermalen Anlage des Nervensystems. Eine Ausnahme stellen die Mikrogliazellen dar, die sich aus dem Mesoderm entwickeln (Welsch 2003). Die Gliazellen des zentralen Nervensystems bilden sich im Neuralrohr, wogegen die periphere Glia aus der Neuralleiste entsteht (Welsch 2003). Zu den Gliazellen des zentralen Nervensystems werden Astrozyten, Mikroglia und Oligodendrozyten gezählt. Die peripheren Gliazellen sind die Schwannzellen (Welsch 2003).

Astrozyten sind reichverzweigte, oft sternförmig erscheinende Zellen, die je nach Gehirnregion unterschiedliche Morphologien und Funktionen ausbilden können (Protoplasmatische und Fibrilläre Astrozyten) (Oberheim et al. 2012). Während der Entwicklung spielen Astrozyten eine wichtige Rolle für die korrekte Migration von Neuronen (Haberland 2007). Zudem sind Astrozyten wichtig für den Schutz von Neuronen vor z.B. exzitotoxischen Neurotransmittern, für den Austausch von verschiedenen Energiemetaboliten mit Neuronen und ihrer Umgebung, wie auch für die Homöostase im Extrazellularraum (Oberheim et al. 2012). Astrozyten sind außerdem an der Ausbildung der Blut-Hirnschranke mitbeteiligt (Haberland 2007).

Mikroglia stellen die residenten Immunzellen des zentralen Nervensystems dar, und werden oft als die Makrophagen des ZNS bezeichnet (Hanisch und Kettenmann 2007). Mikroglia sind stark verzweigte Zellen und ihre Fortsätze zeichnen sich durch eine hohe Beweglichkeit aus. Sie überprüfen ihre Umgebung hinsichtlich potentieller Pathogene, und ein Kontakt mit einem Pathogen führt zu einer Aktivierung der Mikrogliazelle. Mikroglia können phagozytieren und verschiedenste proinflammatorische Moleküle bilden (Hanisch und Kettenmann 2007, Rivest 2009). Neuere Studien zeigen jedoch, dass Mikroglia in ihren Antworten auf pathologische Stimuli sehr viel vielfältiger reagieren als früher angenommen, und sowohl neuroprotektiv wie auch neurotoxisch wirken können (Hanisch und Kettenmann 2007).

Oligodendrozyten im ZNS und Schwannzellen im PNS umgeben die Axone entlang ihres Verlaufes vom neuronalen Zellkörper bis hin zur Synapse. Zudem können beide Gliazellen als sogenannte Satellitenzellen das Neuron selbst umringen. Oligodendrozyten und Schwannzellen bilden um Axone überhalb eines bestimmten Durchmessers eine Isolierschicht, das Myelin. Kleine Axone werden dagegen nur von glialem Zytoplasma sowie der glialen Zellmembran umgeben (Griffin und Thompson 2008). Unabhängig von ihrer Rolle als Myelin bildende Zellen kommen Oligodendrozyten und Schwannzellen auch wichtige „Unterstützungsfunktionen“ für die Integrität und den Erhalt von Axonen zu (Nave 2010).

\subsection{Die Struktur VON Myelin UND die Myelinisierung IM PNS UND ZNS}

Eine von Gliazellen gebildete Myelinschicht um das Axon kennzeichnet Vertebraten, wenn auch einzelne Invertebraten Myelin-ähnliche Strukturen aufweisen (Nave 2010). Die Evolution von Myelin war die Voraussetzung für die Entwicklung höherer kortikaler Funktionen, da sie eine deutlich schnellere Impulsweiterleitung auf kleinerem Raum ermöglichte. Als erstes hat die 
Ausbildung von Myelin höchstwahrscheinlich in einem Fisch, dem Plakoderm, stattgefunden (Nave 2010).

Die schnelle Impulsweiterleitung myelinisierter Axone ist die Folge der saltatorischen Erregungsleitung (Bähr et al. 2003). Jede Gliazelle ummantelt nur einen bestimmten Abschnitt (Internodium) eines Axons. Zwischen zwei myelinisierten Abschnitten entsteht ein nicht isolierter Zwischenraum, der Ranvier-Schnürring. Hier findet sich eine hohe Dichte spannungsabhängiger Ionenkanäle (Campbell und Reece 2003). Da die Myelinschicht den elektrischen Widerstand des Axons stark erhöht, kommt es nur im Bereich der RanvierSchnürringe zu der Ausbildung einer Depolarisation (Bähr et al. 2003). Die Aktionspotentiale „springen“ somit von Schnürring zu Schnürring und müssen nicht kontinuierlich entlang des Axons (wie bei kleinen unmyelinisierten Axonen) fortgeleitet werden. Während die Oligodendrozyte im zentralen Nervensystem bis zu fünfzig Internodien verschiedener Axone myelinisieren kann, ummantelt die Schwannzelle jeweils nur einen Abschnitt eines einzigen Axons (sog. 1:1 Verhältnis von Schwannzelle und Axon), (Peters et al. 1991).

Die Dicke der Myelinschicht ist proportional zum Axondurchmesser. Somit sind Axone mit einem kleinen Durchmesser von einer dünnen Myelinschicht umgeben, während große Axone eine verhältnismäßig dickere Myelinschicht aufweisen. Dieses Verhältnis wird durch das g-ratio (Axondurchmesser / Gesamtdurchmesser der Faser (Axon + Myelin)) ausgedrückt (Friede und Bischhausen 1982).

Das Myelin besteht zum größten Anteil (ca. 70\%) aus Lipiden (hiervon die Hälfte Cholesterin) und zu ungefähr dreißig Prozent aus Proteinen (Simons und Trotter, 2007, Quarles et al. 2006). Das von Oligodendrozyten und Schwannzellen gebildete Myelin ist grundsätzlich gleich aufgebaut, wenn auch die biochemische Zusammensetzung leicht verschieden ist (Quarles et al. 2006). Im zentralen Nervensystem ist das häufigste Myelinprotein das Proteolipidprotein (PLP), gefolgt vom Myelin-Basischen-Protein (MBP). Im peripheren Nervensystem stellt das Myelinprotein Zero (P0) den grössten Proteinanteil dar (Quarles et al. 2006). Der Aufbau der Myelinscheide erfordert eine sehr ausgeprägte Lipid- (und Protein)biosynthese in Gliazellen, gefolgt von dem Transport der einzelnen Bausteine an die Zelloberfläche und dem konzertierten Einbau in die Myelinschicht (Simons und Trotter 2007). In Säugetieren erfolgt die Myelinisierung überwiegend postnatal, und schreitet bis in das frühe Erwachsenenalter fort (Nave 2010).

Myelinisierende und nicht-myelinisierende Schwannzellen aller spinalen Nerven entstehen aus der Neuralleiste (Mirsky et al. 2008). Die Reifung von Schwannzellen erfordert drei Hauptentwicklungsschritte (Abb. 1; Mirsky et al. 2008). Zunächst entstehen aus migrierenden Neuralleistenzellen Schwannzellvorläuferzellen (Mirsky et al. 2008). Diese entwickeln sich zwischen Embryonaltag 15-17 in unreife Schwannzellen, die zunächst weiter stark proliferieren (Jessen und Mirsky 2005). Der Austritt aus dem Zellzyklus ist die Voraussetzung für die nachfolgende Differenzierung in reife Schwannzellen. Vor Beginn der Myelinisierung müssen Schwannzellen die in Bündeln liegenden Axone separieren, und ein 1:1-Verhältnis mit einem Axon herstellen (Jessen und Mirsky 2005). Nicht myelinisierende Schwannzellen umgeben mehrere kleine Axone in sogenannten Remak-Bündeln. 
Während ihrer Entwicklung sind Schwannzellen immer eng mit axonalen Strukturen assoziiert, und axonal exprimierte Faktoren (s.u.) tragen entscheidend zu der Regulation der Schwannzellentwicklung in allen drei Differenzierungsstadien bei (Abb. 1; Jessen und Mirsky 2005). Schwannzellen exprimieren während ihrer Entwicklung verschiedene molekulare Marker (wie z.B. Transkriptionsfaktoren), mit deren Hilfe man die einzelnen Reifungsstadien charakterisieren kann (Abb. 1; Jessen und Mirsky 2005).

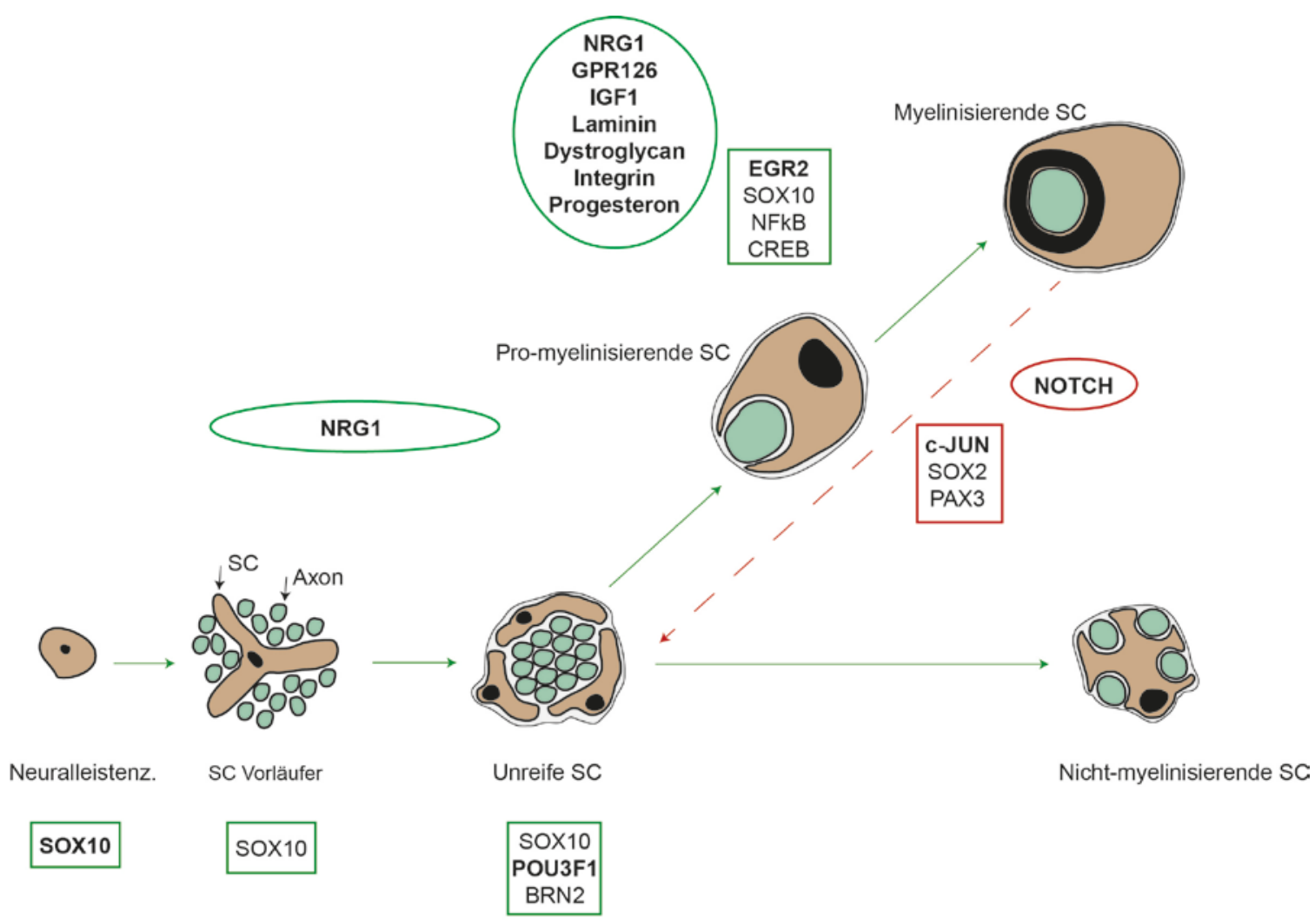

Abb. 1: Die Entwicklung von Schwannzellen im peripheren Nerv. Schwannzellen (SC) entwickeln sich aus Neuralleistenzellen in 3 Hauptentwicklungsschritten in reife, myelinbildende Zellen. In der Abb. dargestellt ist eine Auswahl der an der SC-Entwicklung beteiligten Transkriptions- (eckige Kästen) und extrinsischen Faktoren (ovale Kästen). Die Entstehung von SC-Vorläuferzellen erfordert den Transkriptionsfaktor SOX10, der auch für die weitere SC-Reifung wichtig bleibt (Mirsky et al. 2008). Für das Überleben der Vorläuferzellen sowie die Bildung von unreifen Schwannzellen ist axonal exprimiertes Neuregulin-1 (NRG1) essentiell. Unreife SC exprimieren neben SOX10 die Transkriptionsfaktoren POU3F1 und BRN2, die in die weitere SC-Reifung und die zeitliche Kontrolle des Myelinisierungsvorgangs involviert sind (Mirsky et al. 2008). Für die Reifung in myelinisierende SC ist der Transkriptionsfaktor EGR2 essentiell, weitere wichtige Transkriptionsfaktoren sind zudem NFkB und CREB (Mirsky et al. 2008). Neben NRG1, welches sowohl das Myelinisierungsschicksal von SC als auch die Regulation der Myelindicke kontrolliert, sind zahlreiche weitere extrinsische Faktoren identifiziert worden, die für die Entwicklung der unreifen in reife SC wesentlich sind (Taveggia et al. 2010). Unter anderem sind dies der Rezeptor GPR126 (G-coupled-protein 126), der extrazelluläre Faktor IGF1 (Insuline-like growth factor 1), Komponenten der extrazellulären Matrix wie Laminin, Dystroglycan und Integrin sowie das Hormon Progesteron (Taveggia et al. 2010, Stassart et al. 2012). Nach einer Nervenverletzung dedifferenzieren Schwannzellen und entwickeln sich zurück in unreife, proliferierende Zellen. Die Dedifferenzierung von Schwannzellen wird von dem Transkriptionsfaktor c-Jun reguliert, weiterhin beteiligt sind die Transkriptionsfaktoren SOX2 und PAX3. Der Rezeptor NOTCH inhibiert die Myelinisierung von SC und wird in dedifferenzierten SC induziert (Mirsky et al. 2008). Abbildung adaptiert von Jessen und Mirsky (2005), S. 673. 
Oligodendrozyten entstehen aus der Subventrikularzone im Telencephalon und entwickeln sich zunächst zu Oligodendrozytenvorläuferzellen, die proliferieren und in alle Regionen des ZNS migrieren (Emery 2010b). Anschließend differenzieren die Vorläuferzellen in postmitotische Zellen, sogenannte promyelinisierende Oligodendrozyten. Diese bilden einen engen Kontakt zu benachbarten Nervenfasern aus, um nach einer terminaler Reifung die Axone zu myelinisieren (Emery 2010a). Im Gegensatz zur Schwannzellentwicklung wird die Oligodendrozytendifferenzierung hauptsächlich von einem intrinsischen Netzwerk zahlreicher Transkriptionsfaktoren reguliert, und ist weniger abhängig von axonalen und extrazellulären Faktoren (Emery 2010b). Obwohl in den letzten Jahren einige extrinsische Faktoren (z.B. die axonale elektrische Aktivität) identifiziert worden sind, welche die Oligodendrozytendifferenzierung mitregulieren, sind bisher keine spezifischen axonalen Faktoren bekannt, die die Myelinisierung sowie die Myelindicke im ZNS kontrollieren (Emery 2010a; Taveggia 2010).

\subsection{NeUREgULIN-1 UND ERBB-REZEPTOREN}

Neuregulin-1 gehört zu einer Gruppe von Wachstumsfaktoren, die wichtige Zell-ZellInteraktionen für die Entwicklung sowie die Funktion verschiedener Organe wie Lunge, Herz und Nervensystem mediieren (Falls 2003). Neuregulin-1 wird von einem der grössten menschlichen Gene kodiert (ca 1.4 Megabasen), welches auf dem kurzen Arm von Chromosom acht lokalisiert ist (Falls 2003). Durch alternatives Spleißen und die Aktivierung verschiedener Promotoren können mehr als sechzehn verschiedene Neuregulin-1-Isoformen entstehen (Falls 2003). Allen Neuregulin-1-Isoformen gemeinsam ist eine EGF (epidermal growth factor)ähnliche Domäne (Falls 2003). Diese ist essentiell und alleine ausreichend für die Aktivierung der entsprechenden Rezeptoren aus der Gruppe der ErbB-Rezeptor-Tyrosinkinasen (Falls 2003). Anhand der N-terminalen Struktur werden die Neuregulin-1-Isoformen aktuell in sechs verschiedene Klassen eingeordnet (Nave und Salzer 2006). In den letzten fünfzehn Jahren wurden im Nervensystem insbesondere die Isoformen I - III in einer Vielzahl von Studien in vitro und in vivo untersucht (Falls 2003, Nave und Salzer 2006, Taveggia et al. 2010). Alle Isoformen werden zunächst als Transmembranproteine synthetisiert, welche dann durch Proteasen prozessiert und von der Zellmembran abgetrennt werden können (Falls 2003, Newbern und Birchmeier 2010, Stassart et al. 2012). Neuregulin-1 Typ I und II weisen eine Transmembrandomäne auf und sind zudem durch eine Immunglobulin ähnliche Domäne gekennzeichnet (Falls 2003; Abb.2). Die Typ-III-Isoform ist dagegen zweifach in der Zellmembran verankert, und muss daher mehrmals prozessiert werden, um von der Membran abgetrennt zu werden (Falls 2003, Stassart et al. 2012, Abb. 2).

Neuregulin-1 Typ III wird im Nervensystem hauptsächlich von Neuronen exprimiert, obgleich auch gliale Zellen Neuregulin-1 Typ III synthetisieren können (Nave und Salzer 2006). Mausmutanten mit einer fehlenden Expression von Neuregulin-1 Typ III sterben kurz nach der Geburt, da Entwicklungsdefekte der neuromuskulären Endplatte eine korrekte Innervation der Atemmuskulatur verhindern (Wolpowitz et al. 2000, Falls 2003). Zudem weisen diese Tiere eine deutlich reduzierte Anzahl spinaler Motoneurone und sensorischer Nervenzellen sowie eine 
Degeneration der Hirn- und Spinalnerven auf (Wolpowitz et al. 2000, Falls 2003). Weiterhin zeigen Neuregulin-1-Typ-III-defiziente Mäuse einen fast vollständigen Verlust von SchwannzellVorläuferzellen (Wolpowitz et al. 2000, Falls 2003). Diese und zahlreiche weitere Studien belegen, dass Neuregulin-1 alle drei Stadien der Schwannzellentwicklung entscheidend reguliert (Abb. 1; Falls 2003, Birchmeier und Nave 2008, Newbern und Birchmeier 2010). Während der Embryonalentwicklung kontrolliert Neuregulin-1 Typ III zunächst die Proliferation und Migration von Schwannzell-Vorläuferzellen, um anschließend als Differenzierungsfaktor die weitere Reifung der Schwannzelle zu determinieren (Birchmeier und Nave 2008).

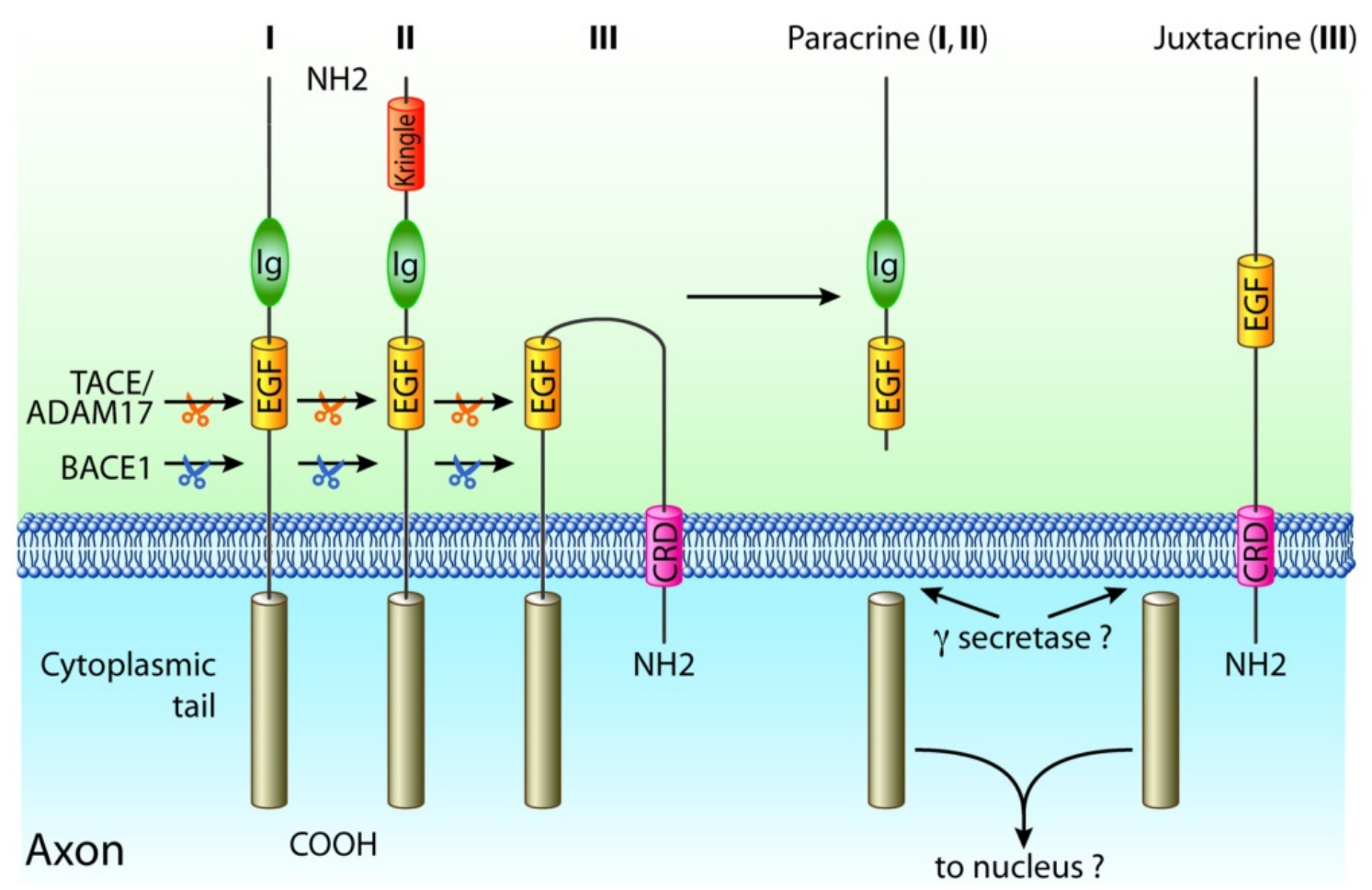

Abb.2: Die Struktur der Neuregulin-1-Isoformen Typ I - III. Die Neuregulin-1-Isoformen Typ I-III werden als Transmembranproteine synthetisiert und auf der axonalen Oberfläche exprimiert. Die einzelnen Isoformen unterscheiden sich im Bereich ihrer N-Termini, weisen jedoch alle eine EGF-ähnliche Domäne auf, die essentiell für die Aktivierung der ErbB-Rezeptoren auf der glialen Oberfläche ist (Falls 2003). Während Typ I und II eine Immunglobulin (Ig)-ähnliche Domäne aufweisen und nur einfach in der Membran verankert sind, zeichnet sich die Typ-III-Isoform durch eine Cystein-reiche-Domäne (CRD) aus, die eine zweite Transmembrandomäne darstellt (Falls 2003). Die proteolytische Spaltung durch die Sekretase BACE aktiviert alle 3 Isoformen, führt aber nur bei Typ I und II zu einer Ablösung des Nterminalen Bereiches von der Zellmembran, und somit zu einem parakrinen Signal (Taveggia et al. 2010). Die Prozessierung durch die TACE/ADAM17 dagegen inhibiert das Neuregulin-1-Signal (Taveggia et al. 2010). Die intrazelluläre Domaine kann durch y-Sekretasen abgetrennt werden und als retrogrades Signal für das Neuron wirken (Stassart et al. 2012). Abbildung entnommen aus Stassart et al. (2012), S.604 (adaptierte Grafik von Nave und Salzer (2006), S.493). 
Die Höhe der axonalen Neuregulin-1-Typ-III-Expression dient als Surrogatmarker für den axonalen Durchmesser und signalisiert der Schwannzelle, welche Fasern myelinisiert werden müssen (Taveggia et al. 2005, Birchmeier und Nave 2008). Eine Mindestexpressionshöhe von Neuregulin-1 Typ III auf der axonalen Oberfläche (physiologisch erreicht bei einem axonalen Durchmesser von $1 \mu \mathrm{m}$ ) ist erforderlich, um die Myelinisierung durch Schwannzellen zu initiieren (Taveggia et al. 2005, Birchmeier und Nave 2008). Kleine Axone exprimieren nur geringe Mengen an Neuregulin-1 Typ III und assoziierte Schwannzellen differenzieren somit in nicht myelinisierende Remak-Schwannzellen (Taveggia et al. 2005, Birchmeier und Nave 2008).

Neuregulin-1 Typ III stellt jedoch nicht nur das Schlüsselsignal für die Initiierung der Myelinisierung dar, sondern reguliert auch die Myelindicke (Nave und Salzer 2006, Birchmeier und Nave 2008). Dies konnte mit Hilfe von verschiedenen Mausmutanten bewiesen werden, die unterschiedliche Expressionshöhen von Neuregulin-1 Typ III in Neuronen aufweisen (Michailov et al. 2004). Transgene Tiere mit einer neuronalen Überexpression von Neuregulin-1 Typ III (unter dem Thy1-Promotor) zeigen proportional zum Axondurchmesser eine deutlich dickere Myelinscheide (Michailov et al. 2004). Die Axone von Mäusen mit einer Hemizygotie für Neuregulin-1 Typ III sind dagegen hypomyelinisiert (Michailov et al. 2004).

Die herausragende Rolle von Neuregulin-1 für die Schwannzellentwicklung und die Regulation der Myelinisierung im PNS ist spezifisch für die Typ-III-Isoform (Nave und Salzer 2006, Birchmeier und Nave 2008). Mäuse mit einer neuronalen Überexpression von Neuregulin-1 Typ I zeigen eine unveränderte Myelindicke im PNS (Michailov et al. 2004). Auch ist die Anzahl an Schwannzell-Vorläuferzellen sowie die weitere Schwannzellentwicklung in Mäusen mit einer reduzierten Neuregulin-1-Typ-I-Expression unverändert (Sandrock et al. 1997, Falls 2003). Dagegen zeigen diese Mausmutanten eine reduzierte Entwicklung von Acetylcholinrezeptoren an der neuromuskulären Endplatte (Sandrock et al. 1997, Falls 2003).

Die Rolle von Neuregulin-1 im zentralen Nervensystem ist wesentlich komplexer und weniger gut verstanden (Taveggia et al. 2010). Eine Deletion von Neuregulin-1 in kortikalen Neuronen oder von ErbB-Rezeptoren in Oligodendrozyten beeinflusst nicht die Myelinisierung im ZNS (Brinkmann et al. 2008). Dagegen kann durch eine neuronale Überexpression von Neuregulin-1 Typ III und - im Gegensatz zum PNS - auch von Typ I eine Zunahme der Myelindicke erreicht werden (Brinkmann et al. 2008). Zusammenfassend kann Neuregulin-1 die Myelinisierung im ZNS stimulieren, ist jedoch weder essentiell für die Oligodendrozytendifferenzierung noch für die korrekte Ausbildung der Myelinscheide im ZNS (Stassart et al. 2012, Taveggia et al. 2010).

An der weiteren posttranslationalen Modifikation der membranständigen Neuregulin-1Isoformen sind Sekretasen beteiligt, die den Aktivierungsstatus von Neuregulin-1 verändern, sowie Neuregulin-1 von der axonalen Membran abspalten können (Stassart et al. 2012, Taveggia et al 2010). So können aus initial membranständigen Neuregulin-1-Isoformen sekretierte Faktoren entstehen, die im Folgenden parakrin oder autokrin wirken (Abb.2; Newbern und Birchmeier 2010, Falls, 2003). In den letzten Jahren sind verschiedene Sekretasen identifiziert worden, die Neuregulin-1 prozessieren (Taveggia et al. 2010, Newbern 
und Birchmeier 2010). Die Sekretase BACE-1 ( $\beta$-site amyloid precursor protein cleaving enzyme 1) aktiviert Neuregulin-1 Typ III und fördert die Myelinisierung und Remyelinsierung im PNS (Abb.2; Stassart et al. 2012, Taveggia et al. 2010, Newbern und Birchmeier 2010). Die alpha Sekretase ADAM-17 (a disintegrin and metalloprotease 17) dagegen inhibitiert die Funktion von Neuregulin-1 Typ III (Abb.2; Stassart et al., 2012, Taveggia et al. 2010, Newbern und Birchmeier 2010). Des Weiteren ist die Metalloendopeptidase Nardilysin ( $\mathrm{N}$-arginine dibasic convertase) an der Prozessierung von Neuregulin-1 beteiligt (Ohno et al. 2009, Stassart et al. 2012, Taveggia et al. 2010, Newbern und Birchmeier 2010).

Die Aktivierung von auf der Gliazelle sitzenden ErbB-Rezeptoren durch Neuregulin-1 induziert eine Rezeptor-Homo- oder Heterodimerisierung (Nave und Salzer 2006, Falls 2003). Im PNS wird ein Heterodimer aus ErbB2 und 3 gebildet, wobei nur ErbB2 eine Kinasedomäne aufweist, während ausschließlich ErbB3 eine Rezeptorfunktion besitzt (Stassart et al. 2012, Falls 2003). Die wichtigsten nachgeschalteten Signaltransduktionskaskaden sind der PI3K/AKT (phosphatidylinositole-3-kinase/v-Akt murine thymoma viral oncogene homolog 1)Signalweg sowie die Ras/MAPK/ERK (Ras/mitogen-activated protein kinase/extracellular signal regulated kinase)-Kaskade und der NFAT (nuclear factor of activated $T$ cells)-CalcineurinSignalweg (Stassart et al. 2012; Taveggia 2010, Newbern und Birchmeier 2010). Die Aktivierung eines oder mehrerer dieser Signalwege führt zu einer Vielzahl zellulärer Antworten in der Gliazelle, die unter anderem Proliferation, Migration und Differenzierung vermitteln (Newbern und Birchmeier 2010). So ist der PI3K/AKT-Signalweg essentiell für die Myelinisierung im gesamten Nervensystem (Taveggia et al. 2010). Eine Aktivierung von ERK1/2 in Mausmutanten fördert die Schwannzellentwicklung sowie die Myelinisierung im peripheren Nervensystem (Newbern et al. 2011, Newbern und Birchmeier 2010). Der NFAT/CalcineurinSignalweg ist ebenfalls essentiell für die Schwannzelldifferenzierung und die Aktivierung der Myelingenexpression im PNS (Kao et al. 2009).

\subsection{De- UND Remyelinisierung im PERIPHEREN NERVENSYStem}

De- und remyelinisierende Prozesse des PNS entstehen als Folge von akuten Nervenverletzungen, z.B. in Folge von Traumen, durch endogene oder exogene toxische Substanzen sowie auch im Rahmen zahlreicher chronischer Erkrankungen, die direkt oder indirekt das Nervensystem betreffen (Jessen und Mirsky 2008, Chen et al. 2007). Das periphere Nervensystem zeichnet sich durch eine erstaunliche Regenerationsfähigkeit aus, die es von den meisten anderen ausgereiften Geweben unterscheidet (Bosse 2012, Chen et al. 2007, Jessen und Mirsky 2008). Jedoch wird eine volle Wiederherstellung der Nervenfunktion selbst nach einer akuten Nervenverletzung selten erreicht (Frostick et al. 1998).

Eine akute Nervenschädigung führt zunächst zu einem als Waller-Degeneration bezeichneten Vorgang (Stoll und Müller 1999). Hierbei degenerieren die Axone distal der Schädigung, während der proximale Nervenanteil intakt bleibt (Chen et al. 2007). Innerhalb von wenigen Stunden kommt es zu einer Fragmentierung der distalen Axone, gefolgt von einem Kollaps der 
Myelinscheiden (Bosse 2012). Diese werden zum Teil von Schwannzellen selbst, zum Teil von eingewanderten Makrophagen phagozytiert (Bosse 2012, Stoll und Müller 1999). Parallel beginnen Axone ab dem Schädigungsort wieder neu auszuwachsen, und werden anschließend von Schwannzellen remyelinisiert (Bosse 2012, Chen et al. 2007). Die axonale Regeneration findet mit ca. $3 \mathrm{~mm} / \mathrm{Tag}$ statt, so dass eine Reinnervation der Zielorgane je nach Distanz innerhalb von einigen Wochen stattfinden kann (Stoll und Müller 1999).

Schwannzellen zeigen während dieses Prozesses der De- und Regeneration eine herausragende Plastizität, und bilden die Basis für eine erfolgreiche Nervenregeneration im PNS (Bosse 2012, Jessen und Mirsky 2008). Schwannzellen reagieren auf eine akute Nervenverletzung und den resultierenden Verlust des axonalen Kontaktes zunächst mit einer Dedifferenzierung, d.h. sie entwickeln sich von einer reifen, ausdifferenzierten Zelle zurück zu einer proliferierenden Vorläuferzelle (Jessen und Mirsky 2008). Gleichzeitig werden Gene induziert, die das axonale Auswachsen und das neuronale Überleben unterstützen, sowie die Makrophageninfiltration in das verletzte Gewebe fördern (Arthur-Farraj et al. 2012, Jessen und Mirsky 2008). Die dedifferenzierten Schwannzellvorläuferzellen lagern sich im Folgenden parallel in sogenannten Büngner-Bändern an, die als eine Art Leitkanäle die Voraussetzung für das korrekte Auswachsen der Axone bilden (Chen et al. 2007).

Die Entwicklung von reifen Schwannzellen zurück zu Vorläuferzellen erfordert die Aktivierung intrazellulärer Faktoren, die als negative Regulationsfaktoren den Prozess der Dedifferenzierung steuern (Abb. 1; Jessen und Mirsky 2008). Diese Faktoren sind in der reifen Schwannzelle herunterreguliert, und höchstwahrscheinlich bilden positive und negative Regulationsfaktoren in der Schwannzelle ein Gleichgewicht, welches die Voraussetzung für eine erfolgreiche Myelinisierung darstellt (Jessen und Mirsky 2008). In den letzten Jahren konnten der Transkriptionsfaktor c-Jun sowie der Raf/MEK/ERK-Signalweg als wichtige Regulatoren der Dedifferenzierung von Schwannzellen identifiziert werden (Jessen und Mirsky 2008, Arthur-Farraj et al. 2012, Napoli et al. 2012). Der Transkriptionsfaktor c-Jun ist Teil des AP-1-Transkriptionsfaktorkomplexes und kontrolliert maßgeblich den Dedifferenzierungsprozess nach einem akuten Nervenschaden (Jessen und Mirsky 2008). Mausmutanten mit einer Schwannzell-spezifischen Deletion von c-Jun weisen eine Dysregulation der WallerDegeneration sowie der Nervenregeneration auf. Die gestörte Schwannzell-Dedifferenzierung in den Mutanten führt unter anderem zu einer fehlerhaften Ausbildung der Büngner-Bänder, verhindert einen korrekten Myelinabbau durch Schwannzellen und Makrophagen und hemmt eine erfolgreiche axonale Regeneration (Arthur-Farraj et al. 2012).

Mit Hilfe von transgenen Mäusen, in welchen der Raf/MEK/ERK-Signalweg spezifisch in reifen Schwannzellen aktiviert wurde, konnte eine wichtige Funktion des ERK-Signalweges in der Dedifferenzierung nachgewiesen werden (Napoli et al. 2012). Eine Aktivierung des Signalweges in transgenen Mäusen ist ausreichend, um einen Dedifferenzierungsphänotyp in Schwannzellen zu induzieren. In den transgenen Tieren kommt es zunächst zu einer Demyelinisierung von Schwannzellen, ohne dass ein axonaler Schaden induziert wurde. Anschließend proliferieren die Schwannzellen und sekretieren proinflammatorische Signale (Napoli et al. 2012). Wird die 
Aktivierung des Signalweges beendet, redifferenzieren und remyelinisieren die Schwannzellen in der Folge (Napoli et al. 2012).

Die Redifferenzierung der Schwannzellvorläuferzellen in unreife und schließlich reife, myelinisierende Schwannzellen ähnelt in vieler Hinsicht dem Differenzierungsprozess während der Entwicklung (Jessen und Mirsky 2008). Jedoch ist das Genexpressionsmuster redifferenzierender Schwannzellen nicht identisch mit dem während der Entwicklung, und es ist wahrscheinlich, dass nach einem Nervenschaden spezifische Faktoren exprimiert werden, die den denervierten Schwannzellphänotyp widerspiegeln (Jessen und Mirsky 2008). Bis her sind jedoch nur wenige Faktoren identifiziert worden, die spezifisch die Redifferenzierung von Schwannzellen regulieren (Jessen und Mirsky 2008).

Trotz der Fähigkeit von Schwannzellen, in myelinbildende Zellen zu redifferenzieren, erreicht die neu gebildete Myelinscheide nicht mehr den ursprünglichen Durchmesser (Schröder 1972). Die neu ausgewachsenen Axone bleiben hypomyelinisiert und die Internodienabstände verkürzt (Schröder 1972, Sherman und Brophy 2005, Chen et al. 2007). Die unvollständige Remyelinisierung führt zu einer verringerten Nervenleitgeschwindigkeit und somit zu einer eingeschränkten Funktionsfähigkeit des regenerierten peripheren Nerven (Chen et al. 2007, Bosse 2012).

\subsection{Zielsetzung Und Hypothese der Promotionsarbeit}

Die Ursachen für die unvollständige Remyelinisierung nach einer Nervenverletzung im PNS sind bisher unverstanden. Als mögliche kausale Faktoren werden insbesondere fehlende Stimulationsfaktoren für remyelinisierende Schwannzellen oder inhibitorische Signale diskutiert (Sherman und Brophy 2005). Weiterhin könnten Schwannzellen die Fähigkeit verlieren, auf myelinisierungsinduzierende Faktoren zu reagieren (Sherman und Brophy 2005).

Neuregulin-1 kontrolliert während der Entwicklung alle Stadien der Schwannzellentwicklung und reguliert die Myelindicke im PNS. In dieser Promotionsarbeit wurde die Hypothese verfolgt, dass eine veränderte Neuregulin-1-Expression oder ein dysregulierter Neuregulin-1-Signalweg für die unvollständige Remyelinisierung nach Nervenschaden verantwortlich sein könnte (Sherman und Brophy 2005, Fricker und Bennett 2011).

Vorherige Untersuchungen zu Neuregulin-1 nach einer Nervenschädigung konnten zeigen, dass sich die Funktion des Neuregulin-1 / ErbB-Signalwegs nach einer Nervenverletzung von der während der Entwicklung unterscheidet (Atanasoski et al. 2006, Fricker et al. 2011, Fricker und Bennett 2011). So bleibt Neuregulin-1 zwar nach einer Nervenschädigung essentiell für die Myelinisierung im PNS (Fricker et al. 2011), ist aber, im Gegensatz zur Entwicklung, nicht für das Überleben und die Proliferation von Schwannzellen nach einer Nervenverletzung notwendig (Atanasoski et al. 2006, Fricker et al. 2011, Fricker und Bennett 2011).

In der vorliegenden Arbeit wurde die Funktion von neuronal und glial exprimiertem Neuregulin-1 für die Remyelinisierung und die Regeneration des PNS mit Hilfe verschiedener Neuregulin-1transgener und -mutierter Mauslinien analysiert. 


\section{Material und Methoden}

\subsection{MATERIAL}

\subsubsection{ChemikALIEN UND REAGENZIEN}

Acrylamid

Agarose

Amylalkohol

Ammoniumperoxiddisulfat (APS)

Ammoniumacetat

Aqua Poly Mount (Einbettmedium)

AraC

Azur-II-Farbstoff

Beta-Mercaptoethanol

Bleicitrat

Bovines Pituitary Extract (BPE)

Bromphenolblau

BSA (bovines Serumalbumin)

Chloroform

Chlorhydrat

DAB (3-3'-Diaminobenzidin)

DAPI (4,6-Diamino-2-phenylindol)

DDSA (2-Duodecenyl-succinicacidanhydrid)

DMP30 (2,4,6-tris-dimethylaminomethyl-Phenol)

DTT (1,4-Dithiotreitol)

EDTA (Ethylendiamintetraacetat)

Essigsäure

Ethanol

Ethidiumbromid

Eukitt (Einbettmedium)

Fetales Kälberserum (FCS)

Formol

Formvar

Forskolin

Gelatine

Glutamax

Glutardialdehyd

Glyzerin

Glycidether
Sigma-Aldrich, Schnelldorf

Bio-Rad, Hercules, CA, USA

Merck, Darmstadt

Merck, Darmstadt

Merck, Darmstadt

Polysciences Inc., Eppelheim

Sigma-Aldrich, Schnelldorf

Merck, Darmstadt

Merck, Darmstadt

Merck, Darmstadt

Sigma-Aldrich, Schnelldorf

International Biotechnology Inc.

Sigma-Aldrich, Schnelldorf

Merck, Darmstadt

Merck, Darmstadt

Dako Cytomation, Hamburg

Boehringer, Mannheim

Serva, Heidelberg

Serva, Heidelberg

GibcoBRL, Karlsruhe

Merck, Darmstadt

Merck, Darmstadt

Merck, Darmstadt

Sigma-Aldrich, Schnelldorf

Kindler $\mathrm{GmbH}$, Freiburg

PAN Biotech, Aidenbach

Merck, Darmstadt

Merck, Darmstadt

Sigma-Aldrich, Schnelldorf

Sigma-Aldrich, Schnelldorf

Sigma-Aldrich, Schnelldorf

Merck, Darmstadt

Merck, Darmstadt

Serva, Heidelberg 


\section{Glyzin}

Hämalaun

HBSS (Hanks Balanced Salts Solution)

Isopropanol

Kalialaun (Kaliumaluminiumsulfat)

Kaliumchlorid (KCl)

Kaliumhydrogencarbonat $\left(\mathrm{KHCO}_{3}\right)$

Ketamin (Ketanest ${ }^{\circledR}$ )

Lidocain, Salbe 2\%

Magermilchpulver Naturaflor

Magnesiumsulfat $\left(\mathrm{MgSO}_{4}\right)$

Methanol

Methylenblau

MNA (Methylnorbornen-2,3-dicarboxyl-anhydrid)

MOPS (3-(N-Morpholino)-Propansulfonsäure)

Dinatriumhydrogenphosphat $\left(\mathrm{Na}_{2} \mathrm{HPO}_{4}\right)$

Dinatriumhydrogenphosphat-2-hydrat

$\left(\mathrm{Na}_{2} \mathrm{HPO}_{4} * 2 \mathrm{H}_{2} \mathrm{O}\right)$

Natriumchlorid ( $\mathrm{NaCl})$

Natriumcitrat $\left(\mathrm{C}_{6} \mathrm{H}_{5} \mathrm{Na}_{3} \mathrm{O}_{7}\right)$

Natriumdihydrogenphosphat-hydrat

$\left(\mathrm{NaH}_{2} \mathrm{PO}_{4} * \mathrm{H}_{2} \mathrm{O}\right)$

Natriumhydroxid $(\mathrm{NaOH})$

Natriumiodid (Nal)

Osmiumtetroxid

Paraformaldehyd (PFA)

Pellet Paint TM

Pferdeserum

PLL (Poly-L-Lysin)

Propylenoxid

Proteinase-Hemmer-Tabletten (Complete)

Salzsäure $(\mathrm{HCl})$

Schiff's Reagenz

Sodium-Dodecyl-Sulfat (SDS)

Streptomycin/Penicillin

Tribomethanol

Tris-HCl-Base

Trypsin

Uranylacetat

Xylencyanol

Xylol
Merck, Darmstadt

Merck, Darmstadt

GibcoBRL, Karlsruhe

Merck, Darmstadt

Merck, Darmstadt

Merck, Darmstadt

Merck, Darmstadt

Parke-Davis, Berlin

Merck, Darmstadt

Töpfer, Dietmannsried

Merck, Darmstadt

Merck, Darmstadt

Merck, Darmstadt

Sigma-Aldrich, Schnelldorf

Sigma-Aldrich, Schnelldorf

Merck, Darmstadt

Merck, Darmstadt

Merck, Darmstadt

Merck, Darmstadt

Merck, Darmstadt

Merck, Darmstadt

Merck, Darmstadt

Serva, Heidelberg

Serva, Heidelberg

Merck, Darmstadt

Sigma-Aldrich, Schnelldorf

Sigma-Aldrich, Schnelldorf

Serva, Heidelberg

Roche, Grenzach

Serva, Heidelberg

Merck, Darmstadt

Sigma-Aldrich, Schnelldorf

Sigma-Aldrich, Schnelldorf

Merck, Darmstadt

Sigma-Aldrich, Schnelldorf

Merck, Darmstadt

Merck, Darmstadt

Merck, Darmstadt

Merck, Darmstadt 
Xylazin (Rompun®)

Ziegenserum

Zitronensäure

\subsubsection{VERBRAUCHSMATERIALIEN}

Coverplates für Immunhistochemie

Deckgläschen

Diafilme

ECL-Filme

Einmalhandschuhe

Eppendorfgefäße

Falconröhrchen, Größe: 15ml, $50 \mathrm{ml}$

Filterpapier (3mm)

Injektionskanülen

Kosmetiktücher

Kupfergrids für Elektronenmikroskopie

Nahtmaterial

NuPage 4-12\% Bis-Tris Gele

Objektträger

PCR-Mikrotiterplatten

PCR-Plattenfolie „Air Pore Sheet”

Pipettenspitzen

Präparationsbesteck und Arterienklemme

PVDF-Membran Hybond-PTM

Spritzen „NormInjekt", Größe : 1ml

Sterilfiltrationseinheit $100 \mathrm{ml}, 500 \mathrm{ml}$

Stickstoff, flüssig

Transferpipetten

Trockeneis

Zellkulturplatten (6, 12, 24 Vertiefungen)

Zellkulturschalen $(3,5 \mathrm{~mm}, 6 \mathrm{~cm}, 10 \mathrm{~cm} \varnothing)$
Bayer, Leverkusen

Invitrogen, Darmstadt

Merck, Darmstadt

Dako Cytomation, Hamburg

Marienfeld, Lauda-Königshofen

Plano, Wetzlar

GE Healthcare, Freiburg

Hartmann, Heidenheim

Eppendorf, Hamburg

Becton \& Dickinson, Heidelberg

Whatman, GE Healthcare, Freiburg

Becton \& Dickinson, Freiburg

Wepa Professional, Arnsberg

Plano, Wetzlar

Braun, Tuttlingen

Invitrogen, Darmstadt

Menzel-Gläser, Braunschweig

Marienfeld, Lauda-Königshofen

ABgene, Surrey, UK

ABgene, Surrey, UK

Molecular Bioproducts,

San Diego, CA, USA

Fine Science Tools, Heidelberg

GE Healthcare, Freiburg

Henke Saas Wolf, Tuttlingen

Corning Life Sci., Amsterdam, NL

Messer-Griesheim, Krefeld

Bio-Rad, Hercules, CA, USA

Messer-Griesheim, Krefeld

Becton \& Dickinson, Freiburg

Becton \& Dickinson, Freiburg

\subsubsection{ENZYME, NUKLEINSÄUREN UND REAKTIONSKOMPLETTSYSTEME}

Alkalische Phosphatase (CIP)

Chemilumineszenzkit (Western Blot)

Desoxyribonukleosid-Triphosphate (dNTPs)

DNA-Größenmarker Lambda/HindIII
Boehringer, Mannheim

Perkin Elmer, Rodgau

Boehringer, Mannheim

Promega, Mannheim 
DNA-Größenmarker PhiX174/HaellI

DNeasy 96TM Kit für DNA-Isolation

Dulbecco's Modified Eagle's Medium (DMEM)

GoTaqTM DNS-Polymerase

Lowry Assay

LSAB2 Kit für Immunhistochemie

Power Sybr® Green PCR Master Mix

Precision Plus ProteinTM Standard Dual Color

Proteinase $\mathrm{K}$

Randomisierte Nonamerprimer

RNA 6000 Nano Assay

RNeasyTM Mini Kit für RNA Isolation

Superscript IIITM RT-Kit

SybrGreen

Taq-Polymerase Puffer

Taq-DNA-Polymerase (5 U/ $\mu \mathrm{l})$

TRIzol Reagent

\subsubsection{GERÄTE}

7500 Real-Time PCR System

Agarose-Gelekammer mit Kämmen

Agarosegeldokumentation ImageMaster VDS

Freiburg

Agilent Bioanalyzer 2100

Ausgießstation AP280

Blotkammern für Western Blots

Binokular

Coverplate-Kassetten

Diamantmesser Semithin Diamond Knife $45^{\circ}$

Elektronenmikroskop EM 900

Feinwaage, digital

Fräse für Epon-Präparate

Gefrierschrank $-20^{\circ} \mathrm{C}$

Gefrierschrank $-80^{\circ} \mathrm{C}$

Gelladestation für Agilent Bioanalyzer

Gelkammern für Polyacrylamidgele

Gewebe-Einbettautomat (EM) Lynx el
Promega, Mannheim

Qiagen, Hilden

Invitrogen, Darmstadt

Promega, Mannheim

Bio-Rad, Hercules, CA, USA

Dako Cytomation, Hamburg

Applied Biosystems, UK

Bio-Rad, Hercules, CA, USA

Boehringer, Mannheim

F. Benseler, MPI für exp. Med.

Agilent Technologies, Böblingen

Quiagen, Hilden

Invitrogen, Carlsbad, USA

Perkin Elmer, Rodgau

Promega, Mannheim

Boehringer, Mannheim

GibcoBRL, Karlsruhe

Applied Biosystems

Hauswerkstatt MPI exp. Med

Amersham Pharmacia Biotech,

Agilent Technologies, Böblingen

Microm, Walldorf

Invitrogen, Darmstadt

Zeiss, Jena

Dako Cytomation, Hamburg

Diatome U.S.,

Fort Washington, PA, USA

Zeiss, Jena

Heraeus Instruments,

Langenselbold

Reichert, Wien, Österreich

Liebherr, Ochsenhausen

New Brunswick Scentific, Nürtingen

Agilent Technologies, Böblingen

Invitrogen, Darmstadt

Vision BioSystems Inc,

Norwell, MA USA 
Gewebehomogenisierer Ultraturrax T8

Gewebeinfiltrationsautomat (Paraffin) HMP110

Glaswaren

Konfokales Mikroskop

Lichtmikroskop Leica DM RXA2

Magnetrührer

Mikrowelle Mikromat

PCR-Thermocycler T3

PCR-Versiegler Combi Thermosealer

Peristaltikpumpe

Pipetten, Größen: 10 $\mu l, 20 \mu l, 200 \mu l, 1000 \mu l$

Photometer Ultraspec 3000

Reinstwasseranlage SeralPur Pro $90 \mathrm{CN}$

Rotationsmikrotom Leica RM 2155

Schlittenmikrotom HM400

Spannungsgeräte Elektrophorese

Spektralphotometer

Sterilbank

Thermomixer

Trocknungszentrifuge Speed Vac

Ultramikrotom

UV-Illuminator

Videomikroskopie-Kamera

Probenmischgerät Vortexer

Zellkulturinkubator

Zentrifuge Laboratory Centrifuge 4K15

Zentrifuge Heraeus Biofuge 13

\subsubsection{ANTIKÖRPER}

Primärantikörper:

Anti-EGR2 (polyklonal Kaninchen, 1:400)

Anti-KI-67 (monoklonal Maus, 1:100)

Anti-MPZ (polyklonal Kaninchen, 1:250)

Anti-NRG1 (polyklonal Kaninchen, 1:250)
IKA Labortechnik, Staufen

Microm, Walldorf

Schott, Mainz

Leica, Wetzlar

Leica, Wetzlar

Omnilab, Bremen

AEG, Berlin

Biometra, Göttingen

Advanced Biotechnologies,

Surrey, UK

Heraeus Instruments, Langenselbold

Gilson, Villiers-le-Bel, Frankreich

Amersham Pharmacia Biotech,

Freiburg

Seral, Ransbach

Leica Microsystems, Wetzlar

Microm, Walldorf

Amersham Pharmacia Biotech,

Freiburg

Amersham Pharmacia Biotech,

Freiburg

Heraeus Instruments, Langenselbold

Eppendorf, Hamburg

Eppendorf, Hamburg

Leica, Wetzlar

Amersham Pharmacia Biotech,

Freiburg

Hamamatsu, Herrsching

Bender \& Hobein, München

Heraeus Instruments, Langenselbold

Sigma Laborzentrifugen,

Osterode am Harz

Heraeus Instruments, Langenselbold
Dies Meijer, Rotterdam

Dako Cytomation, Hamburg

J. Archelos, Würzburg

Santa Cruz SC-348, Heidelberg 
Anti-POU3F1 (polyklonal Kaninchen, 1:500)

Anti-S100 (monoklonal Maus, 1:250)

Anti-Tubulin (monoklonal Maus, 1:5000)

Sekundärantikörper:

Cy2-gekoppelt-anti-Kaninchen (Ziege, 1:1000)

Cy2-gekoppelt-anti-Maus (Ziege, 1:1000)

Cy3-gekoppelt-anti-Kaninchen (Ziege, 1:1000)

Cy3-gekoppelt-anti-Maus (Ziege, 1:1000)

HRP-anti-Kaninchen (Ziege, 1:1000)

HRP-anti-Maus (Ziege, 1:1000)
Dies Meijer, Rotterdam

Merck-Millipore, Darmstadt

Sigma-Aldrich, Schnelldorf

Jackson Immu. Res., Newmarket, UK Jackson Immu. Res., Newmarket, UK Jackson Immu. Res., Newmarket, UK Jackson Immu. Res., Newmarket, UK Jackson Immu. Res., Newmarket, UK Jackson Immu. Res., Newmarket, UK

\subsubsection{OLIGONUKLEOTIDE}

Die Primeroligonukleotide für die semiquantitative Expressionsanalyse mittels RT-PCR wurden mit der Internet-basierten Software Universal ProbeLibrary Assay Design Center von der Firma Roche Applied Science entworfen, mit Hilfe der Software Oligo Analyzer (Teemu Kuulasmaa 2009) gegengeprüft und von F. Benseler (Abt. 501 des MPI für exp. Medizin, Göttingen) synthetisiert.

Primer zur Genotypisierung der Nrg1 Typ I transgenen Mäuse:

Fwd: 5'-CTGGTAGAGCTCCTCCGCTTC -3'

Rev: 5'-TGGCAAAGGACCTTAGGCAGTGT -3'

Primer zur Genotypisierung der Nrg1 Typ III transgenen Mäuse:

Fwd: 5'-CGATAAGTTTAGGAGCAGTTTGCAG -3'

Rev: 5'-TGGCAAAGGACCTTAGGCAGTGT -3'

Primer zur Genotypisierung der Dhh-Cre Mauslinie:

Fwd: 5'-CAGCCCGGACCGACGATGAA -3'

Rev: 5'-CCTGCGGAGATGCCCAATTG -3'

Primer zur Genotypisierung der $\mathrm{Nrg}^{\text {loxP/loxP }}$ Mäuse:

Fwd: 5'-GCACCAAGTGGTTGCGATTGTTGCT -3'

Rev: 5'-TCCTTTTGTGTGTGTTCAGCACCGG -3'

Primer für die semiquantitative Expressionsanalyse von Nrg1 Typ I mittels RT-PCR:

Fwd: 5'-GGGAAGGGCAAGAAGAAGG -3'

Rev: 5'-TTTCACACCGAAGCACGAGC -3'

Primer für die semiquantitative Expressionsanalyse von Hmgcr mittels RT-PCR:

Fwd: 5'-CAACCTTCTACCTCAGCAAGC -3'

Rev: 5'-CACAGTGCCACATACAATTCG -3'

Primer für die semiquantitative Expressionsanalyse von Scap mittels RT-PCR:

Fwd: 5'-CTCAGGGGCAATCACAGC -3'

Rev: 5'-TGAGCAAATGTTTGGCTGAC -3' 
Primer für die semiquantitative Expressionsanalyse von Mbp mittels RT-PCR:

Fwd: 5'-GCCTGTCCCTCAGCAGATT -3'

Rev: 5'-GCCTCCGTAGCCAAATCC -3'

\subsubsection{PUFFER UND LÖSUNGEN}

2.1.7.1. DNA Aufreinigung und Genotypisierungs PCR:

TAE-Puffer (50x, 1000ml):

$242 \mathrm{~g} \quad$ Tris- $\mathrm{HCl}$ Base

$57,1 \mathrm{ml} \quad$ Essigsäure 100\%

$100 \mathrm{ml} \quad$ EDTA $(0,5 \mathrm{M} \mathrm{pH} \mathrm{8)}$

auf $1000 \mathrm{ml}$ mit $\mathrm{H}_{2} \mathrm{O}$ auffüllen

\subsubsection{IMMUNHISTOCHEMIE}

Blockierungslösung:

$2 \mathrm{~g} \quad \mathrm{BSA}$

$2 \mathrm{~g} \quad$ Pferdeserum

$0,1 \mathrm{~g} \quad$ Gelatine

In 100 ml d-PBS unter Erwärmen lösen.

Hämalaun:

$1 \mathrm{~g} \quad$ Hämalaun

$0,1 \mathrm{~g} \quad$ Natriumiodid

$50 \mathrm{~g} \quad$ Kalialaun

unter Schütteln in 1 I Aqua bidest. lösen.

$50 \mathrm{~g} \quad$ Chlorhydrat

$1 \mathrm{~g} \quad$ Zitronensäure

zugeben und mischen.

Phosphatpuffer (PBS):

Stammlösung A: 0,2 M Natriumdihydrogenphosphat

Stammlösung B: 0,2 M Dinatriumhydrogenphosphat

Gebrauchslösung (0,1M, pH 7,4):

$20 \mathrm{ml}$ Stammlösung $A$

$80 \mathrm{ml}$ Stammlösung $B$

$100 \mathrm{ml}$ Aqua bidest. 
Fixierungslösung (1000 ml):

$100 \mathrm{ml} \quad$ PBS Stammlösung A

$400 \mathrm{ml} \quad$ PBS Stammlösung $B$

$100 \mathrm{ml} \quad$ Formol 37\% (filtriert)

$400 \mathrm{ml} \quad$ Aqua bidest.

PBS/BSA:

$20 \mathrm{ml} \quad$ PBS Stammlösung $A$

$80 \mathrm{ml} \quad$ PBS Stammlösung $B$

$1,8 \mathrm{~g} \quad \mathrm{NaCl}$

$1 \mathrm{~g} \quad$ BSA

$100 \mathrm{ml} \quad$ Aqua bidest.

Scotts Lösung:

$2 \mathrm{~g} \quad$ Kaliumhydrogencarbonat

$20 \mathrm{~g} \quad$ Magnesiumsulfat

Aqua bidest. ad $1000 \mathrm{ml}$.

Trispuffer:

Stammlösung $(0,5 \mathrm{M}, \mathrm{pH} 7,6)$ :

60, $75 \mathrm{~g}$ TRIS(hydroxymethyl)-aminomethan in $500 \mathrm{ml}$ Aqua bidest. lösen, mit $1 \mathrm{M} \mathrm{HCl}$ auf pH 7,6 einstellen und mit $\mathrm{H}_{2} \mathrm{O}$ auf $1000 \mathrm{ml}$ auffüllen.

Gebrauchslösung $(0,05 \mathrm{M}, \mathrm{pH} 7,6)$ :

$100 \mathrm{ml} \quad$ Stammlösung

$9 \mathrm{~g} \quad \mathrm{NaCl}$

Mit $\mathrm{H}_{2} \mathrm{O}$ auf $1000 \mathrm{ml}$ auffüllen.

Zitratpuffer:

Stammlösung A: 0,1M Zitronensäure

Stammlösung B: 0,1M Natriumcitrat

Gebrauchslösung (0,01 M, pH 6):

$9 \mathrm{ml} \quad$ Stammlösung $\mathrm{A}$

$41 \mathrm{ml} \quad$ Stammlösung $B$

Aqua bidest. ad $500 \mathrm{ml}$

\subsubsection{ELEKTRONENMIKROSKOPIE}

Bleicitrat nach Reynolds (1963):

$1,33 \mathrm{~g} \quad$ Bleinitrat

$1,76 \mathrm{~g} \quad$ Natriumcitrat

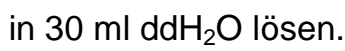


Stark schütteln, nach ca 30 min Umwandlung von Bleinitrat in Bleicitrat. Anschließend max. $8 \mathrm{ml}$ $1 \mathrm{~N} \mathrm{NaOH}$ hinzugeben, mit Aqua dest. auf $50 \mathrm{ml}$ auffüllen und schwenken bis sich das Bleicitrat aufgelöst hat ( $\mathrm{pH}$ Wert 12). Vor Gebrauch zentrifugieren.

Fixanz nach Karnovsky, pH 7,5 (1965):

$0,36 \mathrm{~g} \quad$ Natriumdihydrogenphosphat $\mathrm{x}_{2} \mathrm{O}$

$3,1 \mathrm{~g} \quad$ Dinatriumhydrogenphosphat $\times 2 \mathrm{H}_{2} \mathrm{O}$

$1 \mathrm{NaCl}$

$20 \mathrm{ml} \quad$ Glutardialdehydlösung

$8 \mathrm{~g} \quad$ Paraformaldehyd (PFA)

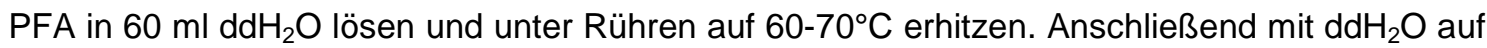
$80 \mathrm{ml}$ auffüllen. Tröpfchenweise $1 \mathrm{M} \mathrm{NaOH}$ zugeben, bis die Lösung klar wird. Anschließend

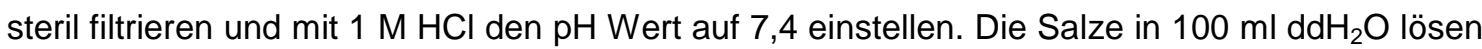
und zu dem PFA geben. Glutardialdehydlösung zugeben.

Formvar-Lösung zum Befilmen von Kupfergitter:

0,25 g Formvar in eine dunkle, trockene Flasche geben. $100 \mathrm{ml}$ Chloroform durch einen Papierfilter laufen lassen und zum Formvar geben. Die Flasche gut verschließen und mindestens $24 \mathrm{~h}$ lang bis zur kompletten Auflösung des Formvars stehen lassen. Die Lösung ist dunkel gelagert mindestens ein Jahr haltbar.

Kunstharzmischung Epon (Luft 1961):

Lösung A:

$67,5 \mathrm{~g} \quad$ Glycidether

$88,2 \mathrm{~g} \quad$ DDSA

eine Stunde mit Magnetrührer rühren

Lösung B:

82,3 $\mathrm{g} \quad$ Glycidether

73,3 g MNA

eine Stunde mit Magnetrührer rühren

Gebrauchslösung Epon:

Epon Lösungen A + B im Verhältnis 1 : 1 mischen; 1,8\% DMP30 zugeben

Methylen-Azur-II-Färbelösung (Richardson et al. 1960):

Methylenblau-Lösung: 1\% Methylenblau in 1\% wässriger Boraxlösung

Azur-II-Lösung: 1\% Azur II in $\mathrm{H}_{2} \mathrm{O}$

beide Lösungen in einem Verhältnis von 1:1 mischen. 


\subsubsection{PRoteinbiochemie}

Laufpuffer für Polyacrylamidgele (20x):

$\begin{array}{ll}1 \mathrm{M} & \text { MOPS } \\ 1 \mathrm{M} & \text { Tris Base } \\ 69,3 \mathrm{mM} & \text { SDS } \\ 20,5 \mathrm{mM} & \text { EDTA }\end{array}$

Lysepuffer für Proteinlysaten aus Ischiasnerven:

$\begin{array}{ll}320 \mathrm{mM} & \text { Sucrose } \\ 10 \mathrm{mM} & \text { Tris } \\ 1 \mathrm{mM} & \mathrm{NaHCO}_{3} \\ 1 \mathrm{mM} & \mathrm{MgCl}_{2}\end{array}$

Proteinase-Hemmer (Complete, Roche), 1 Tablette für 50 ml Lösung.

Lysepuffer für Proteinlysaten aus primären Rattenschwannzellen:

$\begin{array}{ll}1 \% & \text { SDS } \\ 0,1 \mathrm{M} & \text { PBS }\end{array}$

Proteinase-Hemmer (Complete, Roche), 1 Tablette für 50 ml Lösung.

Protein-Probenpuffer (2x):

$\begin{array}{ll}20 \% & \text { Glyzerin } \\ 4,6 \% & \text { SDS } \\ 0,4 \% & \text { Bromphenolblau } \\ 125 \mathrm{mM} & \text { Tris-Base }\end{array}$

auf $50 \mathrm{ml}$ mit dd $\mathrm{H}_{2} \mathrm{O}$ auffüllen $\mathrm{pH} \mathrm{6,8}$

zu $20 \mu$ I Probenpuffer vor Probenzugabe $1 \mu$ ß-Mercaptoethanol (5\%) zugeben

SDS-Sammelgelpuffer $(250 \mathrm{ml})$ :

$15,15 \mathrm{~g}(0,5 \mathrm{M})$ Tris-Base

$5 \mathrm{ml}(0,4 \%) \quad$ SDS (20\%)

auf $250 \mathrm{ml}$ mit dd $\mathrm{H}_{2} \mathrm{O}$ auffüllen, $\mathrm{pH}$ 6,8 mit $\mathrm{HCl}$ einstellen

SDS-Trenngelpuffer $(250 \mathrm{ml})$ :

45,42 g (1,5 M) Tris-Base

$5 \mathrm{ml}(0,4 \%) \quad$ SDS (20\%)

auf $250 \mathrm{ml}$ mit dd $\mathrm{H}_{2} \mathrm{O}$ auffüllen, $\mathrm{pH} 8,8$ mit $\mathrm{HCl}$ einstellen

Waschpuffer:

$1 \mathrm{x}$

PBS

$5 \%$

Tween 20 
Western Blot-Puffer (1000 ml):

$20 \% \mathrm{v} / \mathrm{v} \quad$ Methanol pH 9,2

48mM Tris-Base

$39 \mathrm{mM} \quad$ Glyzin

$0,1 \% \quad$ SDS

auf $1000 \mathrm{ml}$ mit Aqua bidest. auffüllen

\subsubsection{SCHWANNZELLKULTUR}

Lysepuffer:

$\begin{array}{ll}100 \mu \mathrm{l} & \text { Kollagenase } \\ 200 \mu \mathrm{l} & \text { Trypsin } \\ 1700 \mu \mathrm{l} & \text { DMEM }\end{array}$

Ruhemedium:

DMEM

$10 \%$ FCS

Glutamax

Penicillin/Streptomycin

\subsubsection{NARKOSE UND TÖTUNG VON MÄUSEN}

Ketamin-Xylazin:

$\begin{array}{ll}0,6 \mathrm{ml} & \text { Ketamin (10\%) } \\ 0,2 \mathrm{ml} & \text { Xylazin }(2 \%)\end{array}$

Avertin:

$1 \mathrm{~g} \quad$ Tribomethanol

$0,81 \mathrm{~g} \quad$ Amylalkohol

$71,49 \mathrm{ml} \quad$ Aqua bidest.

$\mathrm{H}_{2} \mathrm{O}$ auf $40^{\circ} \mathrm{C}$ (max) erwärmen und zu Tribromethanol und Amylalkohol langsam hinzupipettieren. Etwa 10 min. unter Rühren lösen. Anschließend steril filtrieren $(0,2 \mu \mathrm{m})$ und bis zur Verwendung in dunklen Gefäßen einfrieren.

\subsubsection{VERSUCHSTIERE}

Alle Tiere wurden gemäß dem deutschen Tierschutzgesetz im Tierhaus des Max-PlanckInstitutes für experimentelle Medizin, Göttingen, gehalten. Es wurden Neuregulin-1 Typ I und Typ III transgene Tiere (C57Bl6-Tg(Thy1-Nrg1*III)1Kan+/- und C57BI6-Tg(Thy1Nrg1*l)1Kan+/-, in Text und Abbildung bezeichnet als $\mathrm{Nrg1}(\mathrm{I}) \operatorname{tg}$ und $\mathrm{Nrg}$ (III) tg) verwendet (Michailov et al. 2004). Des Weiteren wurden Dhh ${ }^{\text {Cre }}$ (C57Bl6-Tg(Dhh-cre)1Mejr)-positive Tiere 
mit $\mathrm{Nrg} 1^{\text {loxPlloxP }}$ (C57Bl6-(Nrg1tm2Cbm))-Mäusen verpaart (Jaegle et al. 2003, Li et al. 2002). In diesen Versuchen dienten $\mathrm{Nrg}^{\text {loxPlloxP}}$-Mäuse als Kontrollen. Diese Tiere unterschieden sich morphologisch und phänotypisch nicht von Wildtypmäusen.

\subsubsection{COMPUTERSOFTWARE}

7500 Fast System SDS Software

Excel 2003

Illustrator 13.0.2

Image J $1.40 \mathrm{~g}$

Oligo Analyzer 1.1.2

Openlab 2.1

Photoshop 10.0.1

qBase 1.3.5

Statistica 6.0

Universal Probe Library

Assay Design Center

Word 2003
Applied Biosystems, UK Microsoft Europe, Berlin

Adobe Systems Software

Saggart, Irland

$\mathrm{NIH}$, USA

Teemu Kuulasmaa, Kuopio, Finnland

Improvision, Heidelberg

Adobe Systems Software

Saggart, Irland

Center for Medical Genetics, Belgium

Ghent, Belgien (Hellemans et al. 2007)

StatSoft Europe, Hamburg

Roche Applied Science, Mannheim

Microsoft Europe, Berlin

\subsection{Methoden}

\subsubsection{HANDHABUNG UND ANALYSE VON VERSUCHSTIEREN}

Alle in der vorliegenden Arbeit verwendeten Mäuse (siehe 2.1.8.) wurden in der lokalen Tierhaltungseinheit des Max-Planck-Institutes für experimentelle Medizin, Göttingen, gezüchtet und gehalten. Die Haltung erfolgte gemäß den Richtlinien der deutschen Gesellschaft für Versuchstierkunde.

\subsubsection{IDENTIFIKATION DER MÄUSE}

Zur eindeutigen Identifikation der Mäuse wurden die Tiere im Alter von 3-4 Wochen mit Hilfe eines Ohrlochstanzgerätes mit einem Lochkode versehen. Dieser erlaubt die Nummerierung der Mäuse von 1-99. Die weitere Zuordnung erfolgte durch an den Käfigen angebrachte Identifikationskarten, auf denen die Mauslinie mit Name und Numernkode sowie das Geburtstdatum, das Geschlecht und die Identifikationsnummern der Elterntiere notiert sind. Zur Verwaltung der Zucht wurde das Tierdatenbankprogramm PyRAT (Scionics Computer Innovation $\mathrm{GmbH}$ ) verwendet. 
Zur Genotypisierung der Mäuse wurde zum Zeitpunkt der Ohrlochkodierung eine ca. $5 \mathrm{~mm}$ lange Schwanzbiopsie entnommen, die bis zur weiteren Verwendung (Isolierung der genomischen DNA) in einem Eppendorfgefäß auf $-20^{\circ} \mathrm{C}$ gelagert wurde.

\subsubsection{NARKOTISIERUNG UND TÖTUNG VON VERSUCHSTIEREN}

Für die Durchführung der Nervenkompressionsoperationen wurden die Tiere mit einer Injektionsnarkose betäubt. Die Mäuse erhielten hierfür eine intraperitoneale Injektion einer Kombination auf $5 \mathrm{mg} / \mathrm{kg}$ Körpergewicht $5 \mathrm{mg} / \mathrm{kg}$ Körpergewicht Ketamin (Ketanest ${ }^{\circledR}$ ) und 2 $\mathrm{mg} / \mathrm{kg}$ Körpergewicht Xylazin (Rompun $\left.{ }^{\circledR}\right)$. Für die Entnahme von Gewebe und die Perfusion von Tieren wurden die Mäuse mit Hilfe einer intraperitonealen Injektion von Avertin (0,2 $\mathrm{ml}$ pro $10 \mathrm{~g}$ Körpergewicht) betäubt.

\subsubsection{NERVENKOMPRESSIONSMODELL}

Das Nervenkompressionsmodell wurde bei allen verwendeten Mäusen im Alter von drei Monaten durchgeführt. Zunächst wurden die Tiere mit einer Injektionsnarkose (siehe 2.2.1.2.) betäubt. Anschließend wurden die Hinterläufe der Mäuse leicht fixiert, und die Hautfläche im Bereich des rechten proximal lateralen Oberschenkels (ca $1 \times 1 \mathrm{~cm}$ ) rasiert. Die Haut wurde dann insgesamt 3-mal desinfiziert. Mit Hilfe eines Skalpells wurde die Haut in Verlaufsrichtung des N. ischiadicus über eine Länge von ca. $0,8 \mathrm{~cm}$ eröffnet. Das subkutante Fettgewebe wurde stumpf präpariert und minimalinvasiv der Bereich zwischen Musculus gluteus maximus und Musculus semimembranosus freigelegt, um so einen Zugang zum Nervus ischiadicus zu erhalten. Mit Hilfe eines nicht resorbierbaren Fadens (Dafilon DSMP13 3/8c, Braun) wurde das Endoneurium mit einem Knoten versehen, und direkt proximal dieser Markierung der $\mathrm{N}$. ischiadicus mit einer Arterienklemme (Breite $3 \mathrm{~mm}$ ) für $40 \mathrm{~s}$ komprimiert. Anschließend wurde die Haut mit zwei bis drei Einzelknopfnähten verschlossen, erneut desinfiziert und mit Lidocainsalbe bestrichen. Die Tiere wurden nach der Operation bis zum vollen Erwachen halbstündlich überwacht, und in der Folge 2-mal täglich kontrolliert.

$\mathrm{Zu}$ verschiedenen Zeitpunkten nach der Nervenkompressionsoperation (4 Tage, 2 Wochen und 4 Wochen) wurden die Mäuse getötet und der N. ischiadicus entnommen. Für Transkriptionsund Proteinanalysen wurde der $\mathrm{N}$. ischiadicus nativ entnommen und in einem Eppendorf-Gefäß bei $-80^{\circ} \mathrm{C}$ bis zur Verwendung gelagert. Für diese Experimente wurde der gesamte $\mathrm{N}$. ischiadicus distal der endoneuralen Markierung verwendet. Alle $\mathrm{N}$. ischiadici die für histologische Analysen verwendet wurden, wurden nach der Fixation der Mäuse durch Perfusion (2.1.1.4.) entnommen. Hierbei wurde der $\mathrm{N}$. ischiadicus immer $4 \mathrm{~mm}$ distal des endoneuralen Knotens histologisch untersucht. 


\subsubsection{FIXATION DURCH PERFUSION}

Für die histologische Analyse des N. ischiadicus wurden die Mäuse mittels einer Ganzkörperperfusionstechnik fixiert, um die Struktur des zu analysierenden Gewebes besser zu erhalten. Zunächst wurden die Tiere mit einer Avertin Injektionnarkose betäubt und anschließend Bauch- und Brustraum ohne die Verletzung größerer Gefäße eröffnet. Nach Freilegung des Herzens wurde eine Kanüle in den linken Ventrikel eingeführt, welche mit einer Peristaltikpumpe (Heraeus SR70) verbunden wurde. Vor Beginn der Blutgerinnung wurde das Kreislaufsystem mit einem isotonischen Blutersatz (HBSS) (30 ml) über ca. 5 min gespült. Anschließend wurde das Tier mit $50 \mathrm{ml}$ Fixans nach Karnovsky (1965) für Elektronenmikroskopie oder mit $50 \mathrm{ml}$ 4\% PFA für Immunhistochemie perfundiert. Anschließend wurde der Nervus ischiadicus präpariert und das Tier danach in der Fixanslösung dauerhaft konserviert.

\subsubsection{Histologische Methoden}

\subsubsection{Einbetten in Kunstharz und Herstellung von Semi- Und ULTRADÜNNSCHNITTEN}

Die N. ischiadici wurden nach der Perfusion und Präparation für mind. $24 \mathrm{~h}$ in Fixans nach Karnovsky (1965) postfixiert. Für die Herstellung von Semidünnschnitten (0,5 $\mu \mathrm{m})$ für Lichtmikroskopie sowie von Ultradünnschnitten $(50-70 \mathrm{~nm})$ für Elektronenmikroskopie wurden die Nerven Anschließend in ein Kunstharz, Epon, eingebettet. Die Einbettung erfolgte über $24 \mathrm{~h}$ vollautomatisch in einem Einbettautomaten der Firma Leica (Lynx el). Dabei werden die Nerven mit Osmium infiltriert und über Entwässerungsschritte mit Hilfe von aufsteigenden Alkoholkonzentrationen erfolgt die Fixierung in Epon nach unten aufgeführtem Schema. Anschließend wurden die Nerven in Ausgießformen mit reinem Epon gegeben. Die Proben wurden durch Erhitzen auf $60^{\circ} \mathrm{C}$ für $24 \mathrm{~h}$ polymerisiert, um feste Kunstharzblöcke zu erhalten. Die fertigen Eponblöcke wurden danach mit einer Diamantenfräse getrimmt. Dabei wurde der Block so angespitzt, dass eine kleine trapezförmige Fläche entstand, die den Nerv mittig enthielt. Die Herstellung von Semidünn- und Ultradünnschnitten erfolgte mit einem Diamantenmikrotom.

Die 0,5 $\mu \mathrm{m}$ dicken Semidünnschnitte wurden auf Objektträger gegeben und mit einer AzurMethylenblau-Lösung für eine Minute gefärbt und auf einer Heizplatte bei $60^{\circ} \mathrm{C}$ getrocknet. Zuletzt wurden die Schnitte mit Eukitt fixiert und mit einem Deckglas geschützt.

Die Ultradünnschnitte $(50-70 \mathrm{~nm})$ wurden auf mit Formvar befilmte Kupfergritter gezogen (2.2.2.2.) und getrocknet. Anschließend wurden die Schnitte für ca. 30 min auf einem Tropfen $2 \%$ Uranylacetatlösung kontrastiert und mit danach mit $\mathrm{H}_{2} \mathrm{O}$ gespült. Die zweite Kontrastierung erfolgte über 6 min mit Bleicitrat nach Reynolds. 


$\begin{array}{lll}\frac{\text { Reagenz }}{\text { 1. Puffer }} & \underline{\text { Dauer }} & \underline{\text { Temperatur }} \\ \text { 2. } 2 \% \mathrm{OsO}_{4} & 15 \mathrm{~min} & \mathrm{RT} \\ \text { 3. } 3 \mathrm{mal} \mathrm{A.} \mathrm{dest.} & 4 \mathrm{~h} & \mathrm{RT} \\ \text { 6. } 30 \% \text { Ethanol } & 3 \mathrm{mal} 20 \mathrm{~min} & \mathrm{RT} \\ \text { 7. } 50 \% \text { Ethanol } & 30 \mathrm{~min} & \mathrm{RT} \\ \text { 8. } 70 \% \text { Ethanol } & 30 \mathrm{~min} & \mathrm{RT} \\ \text { 9. } 90 \% \text { Ethanol } & 30 \mathrm{~min} & \mathrm{RT} \\ \text { 10. } 4 \text { mal } 100 \% \text { Ethanol } & 4 \mathrm{mal} 15 \mathrm{~min} & \mathrm{RT} \\ \text { 14. } 3 \text { mal Propylenoxid } & 3 \mathrm{mal} 15 \mathrm{~min} & \mathrm{RT} \\ \text { 17. Propylenoxid/Epon 2:1 } & 2 \mathrm{~h} & \mathrm{RT} \\ \text { 18. Propylenoxid/Epon 1:1 } & 2 \mathrm{~h} & \mathrm{RT} \\ \text { 19. Propylenoxid/Epon 1:2 } & 4 \mathrm{~h} & \mathrm{RT} \\ \text { 20. Epon rein Dauer } & 4 \mathrm{~h} & \mathrm{RT}\end{array}$

\subsubsection{BEFILMEN VON KUPFERNETZEN}

Sorgfältig gesäuberte Objektträger wurden in eine spezielle Glasküvette mit einer Ablaufvorrichtung gestellt. Die Glasküvette wurde mit 0,25 \% Formvar befüllt. Das Ventil der Küvette wurde Anschließend geöffnet, so dass der Objektträger langsam und gleichmäßig mit der Formvarlösung benetzt wurde. Nach dem Trocknen wurde der Formvar Film auf dem Objekträger an allen Seiten mit einer Rasierklinge abgeschnitten und Anschließend angehaucht. Der Objektträger wurde dann in einem kleinen Winkel vorsichtig an die Wasseroberfäche eines voll mit Wasser befüllten Gefäßes gehalten, so dass der Formvarfilm auf die Wasserobfläche abschwimmen konnte. Die Kupfergitter wurden mit der Unterseite auf den Formvarfilm gelegt. Zuletzt wurde ein mit Papier beklebter Objektträger in das Wasser getaucht und so der Formvarfilm mit den Kupfergittern aufgenommen. Nach Trocknung konnten die Kupfergitter von dem Objektträger gelöst werden und verwendet werden.

\subsubsection{Analyse DER histologischen PRÄparate}

Auf lichtmikroskopischer Ebene wurde die Gesamtanzahl der myelinisierten Axone, die Anzahl der Schwannzellen in 1:1 Verhältnis mit Axonen sowie die Häufigkeitsverteilung der Axondurchmesser quantifiziert. Hierfür wurden von den gefärbten Semidünnschnitten mikroskopische Bilder bei 1000x mit einem Lichtmikroskop (Leica DM RXA2) angefertigt. Von jedem verwendeten Tier wurde ein gesamter Nervenquerschnitt mit Hilfe einer Videomikroskopie-Kamera und dem Programm Openlab 2.1 abfotographiert. Die weitere Verarbeitung erfolgte mit den Programmen Photoshop 10.0.1 und ImageJ 1.40g. Mit Hilfe von ImageJ wurden verblindet alle myelinisierten Axone pro Nervenquerschnitt sowie alle Schwannzellen in einem 1:1 Verhältnis mit Axonen ausgezählt. Für die Häufigkeitsverteilung 
der Axondurchmesser wurden je 300 Axone mittels eines Plugins zufällig ausgewählt und der Umfang mit ImageJ gemessen.

Die elektronenmikroskopischen Analysen umfassten die Bestimmung der Myelindicke (mittels gratio) zu verschiedenen Zeitpunkten nach Nervenkompression sowie die Quantifizierung der Myelinovoide, der myelinisierten und degenerierten Axone nach 4 Tagen und die Analyse der Schwannzellanzahl. Für die g-ratio Analyse wurden randomisiert ca. 30 elektronenmikroskopische Bilder mit einer Vergrösserung von 3000x aufgenommen und mit ImageJ analysiert. Hierzu wurde der Umfang des Axons (ohne Myelin) und der Umfang des Axons mit Myelinscheide bei mindestens 100 Nervenfasern pro Tier gemessen. Anschließend wurde der Quotient aus dem ersten und dem zweiten Wert gebildet, um das g-ratio zu erhalten. Für die Zählungen von Axonen und Schwannzellen erfolgte eine Auswertung auf 10 randomisierten EM Bildern (entspricht einer Fläche von 8,247 $\mu \mathrm{m}^{2}$ ).

\subsubsection{PARAFFINEINBETTUNG}

Die N. ischiadici für die immunhistochemischen Untersuchungen wurden in 4\% PFA für mind. $24 \mathrm{~h}$ nachfixiert. Anschließend wurde das Gewebe mit Hilfe eines Gewebeinfiltrationsautomaten (MICROM HMP 110) nach untem aufgeführten Schema paraffiniert.

Danach wurden die Nerven an einer Ausgießstation mit Paraffin in entsprechende Formen ausgegossen. Nach Aushärtung des Paraffins wurden Paraffinschnitte mit einer Dicke von $5 \mu \mathrm{m}$ angefertigt. Die Schnitte wurden auf beschichtete Objektträger (Histobond) aufgezogen und danach bei $37^{\circ} \mathrm{C}$ über Nacht getrocknet.

\begin{tabular}{ll} 
Reagenz & Dauer \\
\hline $50 \%$ Ethanol & $1 \mathrm{~h}$ \\
$70 \%$ Ethanol & $2 \mathrm{~h}$ \\
$70 \%$ Ethanol & $2 \mathrm{~h}$ \\
$96 \%$ Ethanol & $1 \mathrm{~h}$ \\
$96 \%$ Ethanol & $1 \mathrm{~h}$ \\
$100 \%$ Ethanol & $1 \mathrm{~h}$ \\
$100 \%$ Ethanol & $1 \mathrm{~h}$ \\
Isopropanol & $1 \mathrm{~h}$ \\
Xylol & $2 \mathrm{~h}$ \\
Xylol & $2 \mathrm{~h}$ \\
Paraffin & $2 \mathrm{~h}$ \\
Paraffin & $2 \mathrm{~h}$
\end{tabular}




\subsubsection{DAKO-LSAB2 UND DOPPELIMMUNFLUORESZENZFÄRBUNGEN DER PARAFFINSCHNITTE}

Die getrockneten Paraffinschnitte wurden zunächst entparaffiniert, indem sie für 10 min bei $60^{\circ} \mathrm{C}$ Anschließend in einer absteigenden Alkoholreihe inkubiert wurden. Danach wurden die Schnitte für $10 \mathrm{~min}$ in Zitratpuffer inkubiert und für weitere $10 \mathrm{~min}$ in dem Puffer bei 650 Watt in der Mikrowelle gekocht. Nach erfolgter Abkühlung (20 min) wurden die Objektträger kurz in TrisPuffer mit Milchpulver (2 \%) gewaschen.

Für die DAKO-LSAB2 Färbung wurden die Schnitte dann in das Coverslip System von DAKO eingesetzt und erneut mit dem Tris-Puffer gespült. Die endogene Peroxidase wurde durch eine 5 min. Inkubation mit $100 \mu \mathrm{l} 3 \% \mathrm{H}_{2} \mathrm{O}_{2}$ inaktiviert. Danach wurden die Schnitte wieder mit dem Tris-Puffer gewaschen.

Die Schnitte für die DAKO-LSAB2 Färbung wie auch für die Doppelimmunofluoreszenz wurden Anschließend für 10 min mit Ziegenserum (1:5 verdünnt, $100 \mu \mathrm{l}$ pro Schnitt) inkubiert, um die Hintergrundfärbung zu minimieren. Danach wurde der Primärantikörper in PBS/BSA verdünnt aufgetragen und über Nacht bei $4^{\circ} \mathrm{C}$ inkubiert. Die Schnitte wurden Anschließend mit dem TrisPuffer mehrmals gewaschen.

Für das DAKO-LSAB2 System wurden die Schnitte danach für 10 min mit dem biotinylierten Brückenantikörper von DAKO inkubiert (bei Raumtemperatur) und Anschließend erneut mit TrisPuffer gewaschen. Das Gewebe auf dem Objektträger wurde dann mit dem „Cytomation Pen“ von DAKO umrandet und Anschließend wurden für die enzymhistochemische Reaktion $100 \mu \mathrm{l}$ $D A B$ in DAKO Puffer auf die Schnitte gegeben. Nach 2-maligem waschen mit $\mathrm{H}_{2} \mathrm{O}$ wurden die Schnitte für 30 min mit Hämalaun gefärbt, dann in $\mathrm{HCl}$-Alkohol differenziert und mit Hilfe von Scotts-Lösung gebläut und zuletzt durch eine aufsteigende Alkoholreihe geführt. Die Schnitte wurden dann mit Eukitt und Deckgläsern verschlossen.

Für die Doppelimmunofluoreszenzfärbungen erfolgte nach dem Waschen die Inkubation mit dem fluoreszenzmarkierten Sekundärantikörper für $1 \mathrm{~h}$ bei Raumtemperatur. Nach 3 maligem Waschen mit dem Trispuffer wurde Anschließend die DAPI-Lösung $(0,5 \mu \mathrm{g} / \mu \mathrm{l})$ für die Kernfärbung aufgetragen. Die Schnitte wurden danach erneut mit dem Tris-Puffer gespült und mit Immu-Mount eingedeckt.

Die Analyse der immunhistochemischen Färbungen erfolgte pro Fläche entweder mit einem Lichtmikroskop oder mit Hilfe konfokaler Mikroskopie. 


\subsubsection{MolekUlarbiologische Methoden}

\subsubsection{ISOLATION VON DNA AUS SCHWANZBIOPSIEN}

Für die Genotypisierung der verschieden transgenen und mutierten Mäuse wurde DNA aus den Schwanzbiopsien der Tiere isoliert. Hierfür wurde das DNeasy 96 Kit der Firma Qiagen und das entsprechende Protokoll des Herstellers verwendet. Zunächst wurden die Proben in einer Mischung aus dem Puffer ALT $(180 \mu \mathrm{l})$ und Proteinase K $(20 \mu \mathrm{l})$ über Nacht bei $55^{\circ} \mathrm{C}$ lysiert. Am nächsten Tag wurde $400 \mu \mathrm{l}$ des Puffers AL/E hinzugegeben und nach Mischen und kurzer Zentrifugation (bei 3000 rpm) wurde der Überstand auf die Silicamembran der DNeasy Säulchen pipettiert. Anschließend wurden die Proben für $10 \mathrm{~min}$ bei $6000 \mathrm{rpm}$ zentrifugiert. Danach wurden die Säulchen mit $500 \mu$ des Puffers AW1 und AW2 inkubiert, jeweils gefolgt von einem Zentrifugationsschritt (5 min bei $6000 \mathrm{rpm}$ ). Die Proben wurden Anschließend für 15 min bei $70^{\circ} \mathrm{C}$ inkubiert. Die an die Silicamembran der Säulen gebundene DNA wurde zuletzt mit dem Puffer AE (200 $\mu$ l, vorgewärmt) eluiert. Nach dem der Puffer auf die Säulchen gegeben wurde, wurden die Proben für $5 \mathrm{~min}$. bei $60^{\circ} \mathrm{C}$ inkubiert und $2 \mathrm{~min}$ bei $6000 \mathrm{rpm}$ zentrifugiert. Der gleiche Vorgang wurde mit weiteren $100 \mu$ Puffer AE wiederholt. Die eluierte genomische DNA wurde bei $4^{\circ} \mathrm{C}$ gelagert.

\subsubsection{Die POlymeraseketTENREAKTION ZUR GENOTYPISIERUNG VON GENOMISCHER DNA}

Die Bestimmung des Genotyps der transgenen und mutierten Mäuse erfolgte mit Hilfe der Polymerasekettenreaktion (PCR), (Mullis et al. 1986). Die PCR erlaubt die exponentielle Vervielfältigung spezifischer DNA-Abschnitte, sofern die Sequenzen der beiden Enden bekannt sind. Die Ausgangskonzentration an DNA, das template, kann dabei sehr gering sein (z.B. 300 ng genomische DNA). Ein PCR-Programm besteht in der Regel aus drei unterschiedlichen Schritten, einem Denaturierungsschritt, einem Annealing-schritt und einem Elongationsschritt. Die Reaktion wird zunächst mit einer Temperatur-erhöhung auf $92-95^{\circ} \mathrm{C}$ gestartet, so dass die DNA in ihre Einzelstränge aufgetrennt wird. Im Folgenden fügt man DNA-Fragmente von ca. 20 Nucleotiden Länge, die Primer, hinzu. Diese sind zu den 3’Enden des zu amplifiziernden DNAAbschnittes des Sense- und des Antisense-Stranges komplementär und lagern sich bei einer Temperatur von $50-60^{\circ} \mathrm{C}$ spezifisch an die DNA an (Annealing). Die so flankierte Zielsequenz wird danach durch Elongation der Primer kopiert. Hierzu verwendet man das hitzestabile Enzym Taq-DNA-Polymerase (aus dem Bakterienstamm Thermus aquaticus), welches bei $72^{\circ} \mathrm{C}$ die Primer durch Polymerisierung der zugegebenen Desoxynucleotidtriphosphate (dNTPs) an beiden Strängen komplementiert. Mit jedem Zyklus von Neusynthese und Denaturierung erhält man so eine Verdopplung des DNA-Abschnittes (Fig.1). Die PCR führt zu einer exponentiellen Amplifikation, da auch die jeweils neu gebildeten Stränge als Matrize zur Verfügung stehen. Für die meisten Anwendungen liegt nach 35-40 Zyklen genügend Produkt zur weiteren Analyse vor. Ein programmierbares Heizprogramm, der Thermocycler, ermöglicht den automatischen Ablauf der PCR-Zyklen. Das Temperatur / Zeit Profil der PCR wurde an die 
Reaktionserfordernisse des jeweiligen Experimentes angepasst, im Prinzip erfolgte die Amplifikation jedoch immer nach folgendem Protokoll:

Die DNA-Amplifikation:

$3 \mathrm{~min} \quad 95^{\circ} \mathrm{C}$

$30 \mathrm{~s} \quad 57,5^{\circ} \mathrm{C}$

$90 \mathrm{~s} \quad 72^{\circ} \mathrm{C} \quad 35$ Zyklen

$60 \mathrm{~s} \quad 95^{\circ} \mathrm{C}$

$60 \mathrm{~s} \quad 57,5^{\circ} \mathrm{C}$

$10 \min 72^{\circ} \mathrm{C}$

Für die Reaktionen wurde ein Reaktionskit der Firma Promega verwendet mit einem Reaktionsvolumen von $20 \mu$ l pro DNA-Probe. Der Reaktionsansatz bestand aus:

$\begin{array}{ll}1 \mu \mathrm{l} & \text { Matritzen-DNA } \\ 2 \mu \mathrm{l} \mathrm{10x} & \text { PCR-Puffer Promega } \\ 2 \mu \mathrm{l} & \text { dNTPs (je Nukleotid f.c. } 200 \mu \mathrm{M} \text { ) } \\ 0,5 \mu \mathrm{l} & \text { Forward-Primer (f.c. } 300 \mathrm{nM} \text { ) } \\ 0,5 \mu \mathrm{l} & \text { Reverse-Primer (f.c. } 300 \mathrm{nM} \text { ) } \\ 1 \mu \mathrm{l} & \text { Taq DNA-Polymerase (f.c.1,6 U / } 50 \mu \mathrm{l} \text { ) } \\ \mathrm{dd}_{2} \mathrm{O} \text { ad 20 } 20 \mathrm{l} & \end{array}$

\subsubsection{AgARose-GeLELEKTROPHORESE VON GENOMISCHER DNA}

Die mittels PCR amplifizierten DNA-Fragmente wurden Anschließend per Gelelektrophorese im elektrischen Feld nach ihrer Grösse aufgetrennt. Prinzipiell ist die elektrische Mobilität für alle Nucleinsäuren - unabhängig von ihrem Molekulargewicht - gleich groß. Unterschiede in der Mobilität kommen erst durch die Siebstruktur der Gelmatrix zustande, da kleinere Moleküle im Vergleich zu größeren Nucleinsäuremolekülen das Gelsieb schneller durchwandern können. Agarose ist das wichtigste Trägermaterial für die Elektrophorese von Nucleinsäuren. Für die Auftrennung der DNA wurden 1,5\%-Agarosegele verwendet. Die Agarose wurde in 1X-TAEPuffer durch Erhitzen in der Mikrowelle gelöst. Anschließend wurde Ethidiumbromid $(1 \mu \mathrm{g} / \mu \mathrm{l})$ hinzugegeben, welches die Nucleinsäurebanden durch Interkalation in die DNA Anschließend unter einem UV-Illuminator sichtbar macht. Die Flüssigkeit wurde dann in Gelkammern mit Gelkämmen gegeben. Nach dem Aushärten des Gels wurden die Gelkämme entfernt, das Gel in einer Laufkammer platziert und mit 1X-TAE-Laufpuffer überdeckt. Die DNA-Proben wurden mit 1/10 Volumen Probenpuffer versetzt und in die Geltaschen eingefüllt und Anschließend zum Auftrennen der DNA eine Spannung zwischen 30-180 V (5-10 V/cm) angelegt. Die entstandenen Banden wurden danach photographiert und ausgewertet. Als Größenmarker dienten je nach Größe des untersuchten Fragments entweder 100 bp oder 1-kb-Marker der Firma Promega. 


\subsubsection{Isolation von RNA aus NERVEngeWEBE}

Bei der RNA-Extraktion wird zunächst die gesamte RNA (rRNA, mRNA, tRNA) aus dem mechanisch zerkleinerten Nerven-Gewebe herausgelöst und stabilisiert. Hierzu wurde ein Standardprotokoll (RNeasy Lipid Tissue Mini Kit, Quiagen) und Reagenzien der Firma Qiagen verwendet. Die bei $-80^{\circ} \mathrm{C}$ gelagerten Proben wurden zunächst in Falconröhrchen mit $1 \mathrm{ml}$ TRIzol Lysereagenz überführt und mit Hilfe des Gewebehomogenisierers Ultraturrax homogenisiert und danach für fünf Minuten bei Raumtemperatur inkubiert. Anschließend wurden je $200 \mu \mathrm{l}$ Chloroform hinzugegeben und die Proben ca. 3 min inkubiert, gefolgt von einem 15-minütigen Zentrifugationsschritt bei $12000 \mathrm{~g}$ (bei $4^{\circ} \mathrm{C}$ ). Die obere Phase wurde danach in ein neues Eppendorfgefäß überführt und eine Volumeneinheit 70\%igen Alkohol hinzugegeben. Das Gemisch wurde Anschließend auf eine Säule mit Silikatmembran (RNeasy Mini Spin) gegeben und die Probe bei 8000 g für $15 \mathrm{~s}$. zentrifugiert. Danach wurden insgesamt drei Waschschritte mit dem Waschpuffer RW1 (2 mal je $700 \mu \mathrm{l}$, immer gefolgt von einem Zentrifugationsschritt (15 s., 8000 g) und dem RPE-Puffer in Ethanol (1 mal mit $500 \mu$ l, gefolgt von einer 3 minütigen Zentrifugation bei $8000 \mathrm{~g}$ ) durchgeführt. Zuletzt wurde die RNA mit zwei Zentrifugationsschritten bei $8000 \mathrm{~g}$ mit jeweils $50 \mu \mathrm{l}$ RNase-freiem Wasser eluiert. Die aufgereinigte RNA wurde Anschließend bei $-80^{\circ} \mathrm{C}$ gelagert. Die Konzentration der RNA wurde spektrometrisch bei OD260 vermessen.

\subsubsection{CDNA-SYNTHESE DURCH REVERSE TRANSKRIPTION VON RNA}

Für die cDNA-Synthese wird die gesamt RNA, mit RNAse Inhibitoren behandelt, eingesetzt. Im Verlauf der Synthese verwendet man jedoch möglichst mRNA spezifische Primer, so dass nur diese in cDNA umgeschrieben wird und die Genexpression analysiert werden kann. Die komplementäre DNA wurde mit dem „Superscript-III-RT“ Kit (Invitrogen) synthetisiert. Es wurden Primer mit einem Poly-T-Schwanz (dT-Primer, 0,6 $\mu \mathrm{M}$ ) verwendet, um spezifisch mRNA (welche einen Poly-A-Schwanz hat) in cDNA umzuschreiben. Zusätzlich wurden randomisierte Nonamer-Primer (N9-Primer, $120 \mu \mathrm{M}$ ) zugesetzt, so dass auch eine Umschreibung in die Gegenrichtung (antisense) erfolgen konnte. Je 500 ng RNA Transkript wurden mit $1 \mu$ der dTund N9-Primer für 2 min bei $70^{\circ} \mathrm{C}$ inkubiert, und die Proben danach auf Eis gelagert. Anschließend wurden zu den Proben ein Reaktionsgemisch bestehend aus dem 1st StrandPuffer $(5 x, 12 \mu l)$, Dichlordiphenyltrichlorethan (DDT, $100 \mathrm{mM}, 6 \mu \mathrm{l})$, gemischten Nukleotiden (10 mM, $3 \mu \mathrm{l}$ ) und Superscript-III-Polymerase (3 $\mu \mathrm{l}$, Wechselzahl von $200 \mathrm{U} / \mu \mathrm{l}$ ) hinzugegeben. Die cDNA Synthese erfolgte dann bei einer Inkubation von $10 \mathrm{~min}$ bei $25^{\circ} \mathrm{C}, 45 \min$ bei $45^{\circ} \mathrm{C}$ und $45 \mathrm{~min}$ bei $55^{\circ} \mathrm{C}$. .

\subsubsection{Semiquantitative ReAl-TIME-PCR Mit Sybr®-GREEN}

Bei der Real-Time semiquantitativen PCR vergleicht man über fluoreszierende Signale die PCR-Kinetik einer unbekannten Probe mit einem endogenen Standard, und kann so die relative Konzentration der Probe berechnen. Die Methode erlaubt somit die mRNA 
Expressionsbestimmung verschiedener Gene. In den in der vorliegenden Arbeit durchgeführten Expressionsanalysen wurde die Real-Time semiquantitative PCR mit dem Fluorochrom Sybr®Green durchgeführt. Sybr®-Green bindet an doppelsträngige DNA, und fluoresziert im gebundenen Zustand nach Anregung mit Licht entsprechender Wellenlänge. Die Fluoreszenz korreliert dabei proportional mit der Menge an doppelsträngigen Nukleinsäuren. Sybr®-Green bindet an jeden DNA-Doppelstrang, so dass der Farbstoff universell eingesetzt werden kann. Beachten muss man jedoch die mangelnde Spezifität, da z.B. auch Primer Dimere und unspezifische PCR-Produkte gebunden werden. Bei jeder PCR-Reaktion werden sowohl die zu untersuchende Probe als auch ein Standardgen amplifiziert. Dieses Standardgen, auch Haushaltsgen genannt, ist für die spätere Auswertung der PCR notwendig. Nach der PCR Reaktion werden die Fluoreszenzkurven der Probe und des Standards ermittelt, indem die Fluoreszenzintensität gegen die Zyklenzahl aufgetragen wurde. Danach wird die Zyklenzahl bestimmt, bei der sich das Reportersignal um die zehnfache Standardabweichung von den Störsignalen unterscheidet und die Amplifikation exponentiell verläuft. Diese Zahl gibt den Schwellenwert oder Ct-Wert an und ist von der ursprünglichen Konzentration der amplifizierten Sequenz abhängig. Anschließend werden die Ct-Werte der Probe mit den Ct-Werten des Haushaltsgens verglichen, welches die relative Quantifizierung der Proben-Sequenz ermöglicht. Als Standard werden Gene verwendet, von denen man annimmt, dass sie in dem zu untersuchenden Gewebe nicht reguliert sind. Das heisst, diese Gene sollten im Idealfall unter allen Bedingungen eine konstante Expression, und damit den gleichen Ct-Wert aufweisen. Die Auswertung wurde nach folgendem Rechenschema angefertigt ( $\Delta \Delta$ Ct-Methode):

1. Berechnung der Differenz zwischen dem Ct-Wert der Probensequenz und dem Ct-Wert des Haushaltsgens:

$\Delta$ Ct-Wert (Zielgen) $=$ Ct-Wert (Probe) - Ct-Wert (Standard)

2. Bestimmung des $\Delta \Delta$ Ct-Wertes, welcher die Ct-Wertdifferenz des Zielgens relativ zu einer als Kalibrator gewählten Probe angibt:

$\Delta \Delta \mathrm{Ct}$-Wert $=\Delta \mathrm{Ct}$-Wert (Zielgen) $-\Delta \mathrm{Ct}$-Wert (Kalibrator)

Für die Auswertung und die Normalisierung der Ct-Werte wurde die auf Excel basierende Software qBase verwendet.

Für die Real-Time semiquantitativen PCR mit Sybr®-Green wurde der folgende Reaktionsansatz sowie das folgende Amplifikationsprotokoll verwendet:

Reaktionsansatz:

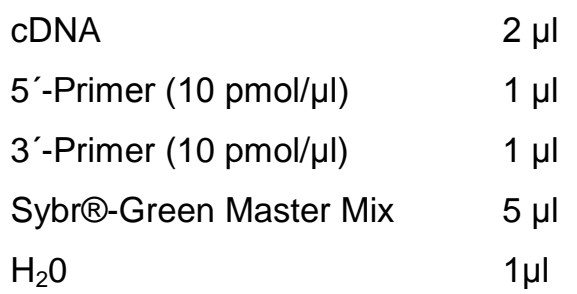


Amplifikationsprotokoll:

10 min bei $95^{\circ} \mathrm{C}$

$15 \mathrm{sec}$ bei $95^{\circ} \mathrm{C}$

$20 \mathrm{sec}$ bei $60^{\circ} \mathrm{C} \quad 40$ Zyklen

$40 \mathrm{sec}$ bei $72^{\circ} \mathrm{C}$

\subsubsection{PROTEINBIOCHEMIE}

\subsubsection{Proteinisolation aus GeWebe}

Die auf minus $80^{\circ} \mathrm{C}$ eingefrorenen Nerven wurden in dem Lysepuffer für Ischiasnerven mit dem Gewebehomogenisator Ultraturrax lysiert. Für die primären Rattenschwannzellkulturen wurde der entsprechende Lysepuffer für Zellen verwendet, und diese ebenfalls mit Hilfe des Ultraturrax lysiert.

\subsubsection{Konzentrationsbestimmung DER PROteine}

Die Bestimmung des Proteingehaltes verschiedener Proben erfolgte mit Hilfe des Lowry-Assays (Reagenzien und Protokoll der Firma Biorad), einem kolorimetrischem Verfahren, bei welchem die Proteine aufgrund der Farbreaktion im alkalischen wässrigen Milieu irreversibel denaturiert werden. Zunächst bildet sich ein Proteinkomplex mit Kupfersulfat, der dann die Reaktion mit einem zweiten Farbstoff, einem Folinreagenz, unterstützt. Die Konzentrationsbestimmung wurde anschließend mit einem Photometer durchgeführt, indem die gemessene Absorption der Probe mit der einer Standardproteinreihe (hergestellt mit Bovinem Serumalbumin) verglichen wurde.

\subsubsection{SDS-POLYACRYLAMID-GELELEKTROPHORESE (SDS PAGE)}

SDS (Natriumdodecylsulfat) ist ein anionisches Detergenz und überdeckt die Eigenladung von Proteinen, so dass Micellen mit konstanter negativer Ladung pro Masseneinheit entstehen. Die Proteine werden so nur nach einem Parameter, dem Molekulargewicht, getrennt. Für die Gelelektrophorese nach Laemmli (1970) wurden selbst gegossene Gele mit einem Sammelgel und einem Trenngel (mit 12\% SDS) verwendet. Die Elektrophorese wurde bei $200 \mathrm{~V}$ und 0,12 A pro Gel durchgeführt.

\subsubsection{Western-Blot Und immunologische Detektion der Proteine}

Beim Western-Blot werden die aufgetrennten Proteine aus der Polyacrylamidmatrix über das senkrecht zum Gel angelegte elektrische Feld eluiert und auf eine Membran transferiert. Dabei

bleibt die Bandenstruktur des SDS-Gels erhalten. Als Blot-Membranen wurden Polyvinylidendifluorid (PVDF) Membranen verwendet. Die Membran wurde zunächst in 20\% 
Methanol aktiviert. Anschließend wurden die Proteine über einen Zeitraum von einer Stunde in der Blotkammer bei $30 \mathrm{~V}$ und 0,17 A von dem Gel auf die Membran transferiert.

Bevor die Membran für eine Immundetektion genutzt werden kann, müssen die restlichen Proteinbindungsstellen der Membran gesättigt werden. Hierzu wurde ein Puffer aus PBS mit Tween 20 (PBS-T) und $2 \%$ Magermilchpulver verwendet. Anschließend wurde die Membran mit dem Primärantikörper über Nacht auf $4^{\circ} \mathrm{C}$ inkubiert. Nach 3-maligem Waschen mit dem entsprechenden Washpuffer wurde der Horseradish-Peroxidase (HRP) gekoppelte Sekundärantikörper für eine Stunde bei Raumtemperatur inkubiert. Zuletzt wurde die Membran erneut gründlich gewaschen.

Die Detektion der Proteine erfolgte mit einer Chemilumineszenzdetektionslösung der Firma Amersham. Diese enthält das Substrat ECL, welches fluoresziert nachdem es durch das Enzym HRP umgesetzt worden ist. Nach Applikation der Detektionslösung wurden Photofilme der Membran nach unterschiedlich langen Belichtungszeiten angefertigt.

\subsubsection{ISOLIERUNG UND KULTIVIERUNG VON PRIMÄREN SCHWANNZELLEN}

Für die Herstellung von primären Rattenschwannzellkulturen wurden die $\mathrm{N}$. ischiadici neugeborener Ratten (zwischen 1 und 3 Tage alt) präpariert. Im Durchschnitt wurden ca. 13 Ratten auf einmal präpariert. Die Ischiasnerven wurden Anschließend in einen Lysepuffer (100 $\mu \mathrm{l}$ Kollagenase, $200 \mu \mathrm{l}$ 2,5 \% Trypsin und $1700 \mu \mathrm{l}$ DMEM) überführt und für 45 min bei $37^{\circ} \mathrm{C}$ angedaut. Der Lysevorgang wurde danach mit 4 ml DMEM mit $10 \%$ FCS gestoppt und die Probe für 5 min bei $800 \mathrm{rpm}$ zentrifugiert. Das entstandene Pellet wurde in $8 \mathrm{ml}$ Ruhemedium resuspendiert und auf eine mit PLL beschichtete Zellkulturschale (10 cm Durchmesser) ausplattiert. Die Kultivierung der Zellen erfolgte bei $37^{\circ} \mathrm{C}$ und $5 \% \mathrm{CO}_{2}$. Nach $24 \mathrm{~h}$ wurde zu dem Ruhemedium für 3 Tage $0,01 \mathrm{mM}$ das Antimitotikum AraC hinzugegeben, um schnell proliferierende Zellen wie Fibroblasten zu eliminieren. Die Behandlung der Schwannzellen erfolgte nach 5 Tagen in Kultur mit 20 ng/ml Medium mit rekombinantem humanen Neuregulin-1 beta (EGF-like domain) der Firma Reprokine.

\subsubsection{STATISTIK}

Die im Rahmen der vorliegenden Arbeit erhobenen Daten wurden zunächst mit Excel 2003 weiterbearbeitet. Die statistische Auswertung erfolgte mit Statistica 6.0. Es wurde der students t-test für unverbundene Stichproben sowie Wilcoxon-Mann-Whitney-Test als statistische Tests verwendet. Ein Ergebniss mit einem P-Wert $<0,05$ wurde als signifikant bewertet. In allen Balkendiagrammen sind der Mittelwert (Balken) und der Standardfehler (T-Graph) angegeben. In den Box-Plot-Diagrammen sind der Mittelwert (kleines Kästchen), der Standardfehler (großer Kasten) und die Standardabweichung (T-Graph) angegeben. 


\section{ERGEBNISSE}

\subsection{NeURonales NeUREgUlin-1 VERBESSERT die ReMyelinisiERUNG IM PNS}

Die Funktion von neuronalem Neuregulin-1 für die Remyelinisierung des peripheren Nervensystems wurde mit Hilfe verschiedener transgener Mauslinien untersucht (Michailov et al. 2004). In Mäusen mit einer neuronalen Überexpression (unter dem Thy1.2 Promoter) von Neuregulin-1 Typ I und III (Nrg1 Typ I und III transgene Tiere; Michailov et al. 2004) wurde eine akute Schädigung des Nervus ischiadicus mit Hilfe eines standardisierten Nervenkompressionsmodells induziert. In diesem Modell sind die axonale Regeneration sowie die Remyelinisierung nach vier Wochen weitgehend abgeschlossen.

Zunächst wurde die Remyelinisierung in Nrg1 Typ III transgenen Mäusen untersucht. Hierzu wurden elektronenmikroskopische Aufnahmen von Nervenquerschnitten $4 \mathrm{~mm}$ distal der Schädigung angefertigt und die Remyelinisierung analysiert, in dem die Myelindicke quantifiziert wurde. Während Kontrollmäuse vier Wochen nach einer Nervenkompression in der g-ratio Analyse eine deutlich zu dünne Myelinscheide aufweisen, zeigen Nrg1 Typ III transgene Mäuse eine Hypermyelinisierung des N.ischiadicus, welche ungefähr der Hypermyelinisierung während der Entwicklung entspricht (Abb. 3a,b).

Die Hypermyelinisierung in Nrg1 Typ III transgenen Tieren nach Nervenkompression lässt sich dabei insbesondere bei Axonen mit einem kleinen bis mittleren Axondurchmesser beobachten (Abb. 3b).

a

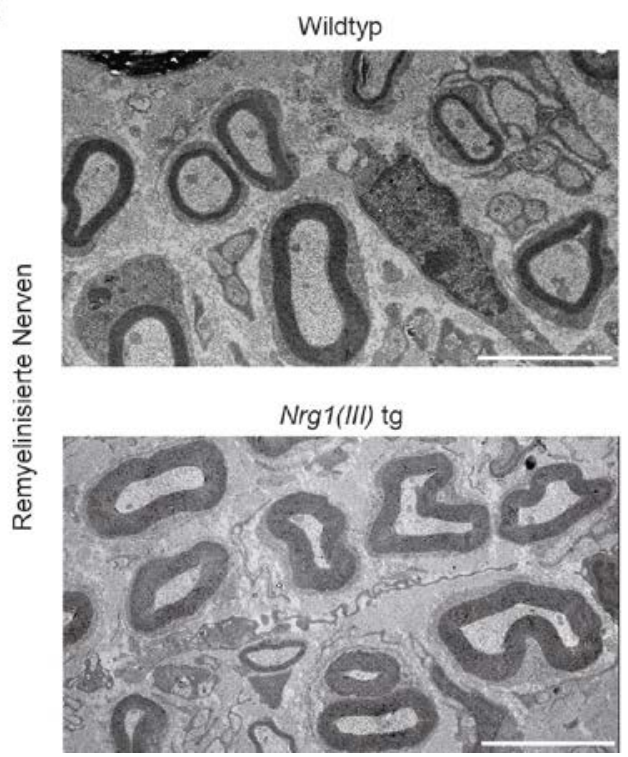

b

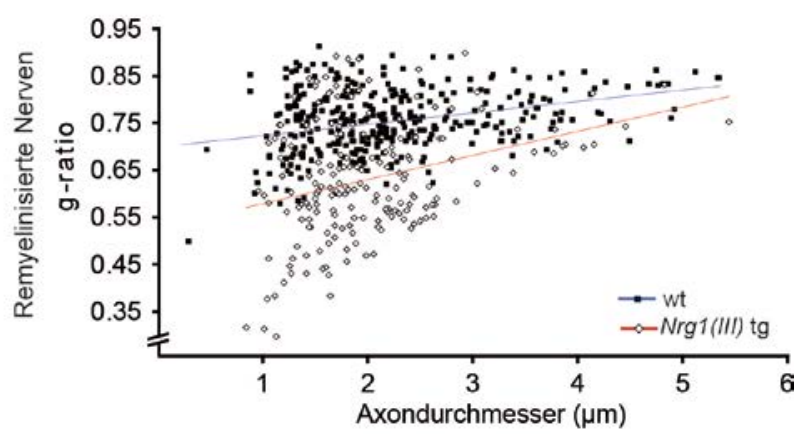

Abb. 3: Die neuronale Überexpression von NRG1 Typ III führt zu einer Hypermyelinsierung nach Nervenkompression. a: Repräsentative elektronenmikroskopische Aufnahme eines querangeschnittenen $\mathrm{N}$. ischiadicus eines Wildtyp und eines Nrg1 Typ III transgenen Tieres (Nrg1(III) tg) 4 Wochen nach Nervenkompression (Messbalken $5 \mu \mathrm{m}$ ). b: Die Quantifizierung der Myelindicke (g-ratio) im Verhältnis zum Axondurchmesser lässt eine Hypermyelinsierung insbesondere der klein- mittelkalibrigen Axone in Nrg1(III) tg Tieren im Vergleich zu Wildtyp (wt) Kontrollen erkennen. N=3 pro Gruppe. 
Während der Entwicklung reguliert spezifisch die Neuregulin-1 Typ-III-Isoform die Myelindicke im PNS (Michailov et al. 2004). Mäuse mit einer neuronalen Überexpression von Neuregulin-1 Typ I hingegen weisen keine Zunahme der Myelindicke in peripheren Nerven während der Entwicklung auf (Michailov et al. 2004).

Vier Wochen nach einer Nervenkompression dagegen lassen elektronenmikroskopische Aufnahmen des $\mathrm{N}$. ischiadicus eine deutlich verbesserte Remyelinisierung in Nrg1 Typ I transgenen Tieren im Vergleich zu Wildtypkontrollen erkennen (Abb. 4a). Die Ergebnisse der gratio Analyse zeigen entsprechend eine signifikante Zunahme der Myelindicke in Nrg1 Typ I transgenen Mäusen im Vergleich zu Kontrollen (Abb. 4b,c). Die Myelindicke remyelinisierter Nerven von Neuregulin-1 Typ I überexprimierenden Tiere erreicht dabei das Normalmaß, d.h. das g-ratio von geschädigten Nerven transgener Mäuse entspricht dem nicht geschädigter Kontrollnerven (Abb. 4a,b).

Die Zunahme der Myelindicke lässt sich für alle Axonkaliber gleichermaßen beobachten (Abb. 4c). Auch besteht kein Unterschied in der Grössenverteilung der axonalen Durchmesser zwischen geschädigten Nerven von Nrg1 Typ I transgenen Mäusen und Kontrolltieren. Nach der Nervenkompression weisen beide Gruppen eine reduzierte Anzahl grosskalibriger Axone im Vergleich zu nicht geschädigten N. ischiadici auf (Abb. 4d,e).

Die verbesserte Remyelinisierung Nrg1 Typ / transgener Tiere spiegelt sich auch auf transkriptioneller Ebene wieder (Abb. 4f). Vier Wochen nach Nervenkompression lässt sich eine erhöhte mRNA Expression myelinsierungs-assoziierter Gene in RNA Extrakten geschädigter Nerven Nrg1 Typ I transgener Tieren im Vergleich zu Kontrollen feststellen. (Abb. 4f). Neuregulin Typ I überexprimierende Mäuse weisen eine erhöhte mRNA Abundanz des umsatzbestimmenden Enzyms für die Cholesterinsynthese, der HMG-CoA-Reduktase (Hmgcr, 3-Hydroxy-3-Methylglutaryl-Coenzym-A-Reduktase) auf (Abb. 4f). Auch andere am Lipidmetabolismus von Schwannzellen beteiligte Gene, wie Scap (Sterol regulatory elementbinding protein cleavage-activating protein) werden in geschädigten Nerven Nrg1 Typ I transgener Tiere induziert (Abb. 4f). Ebenfalls lässt sich eine Induktion des Myelin basischen Proteins (Mbp) beobachten (Abb. 4f). 
a

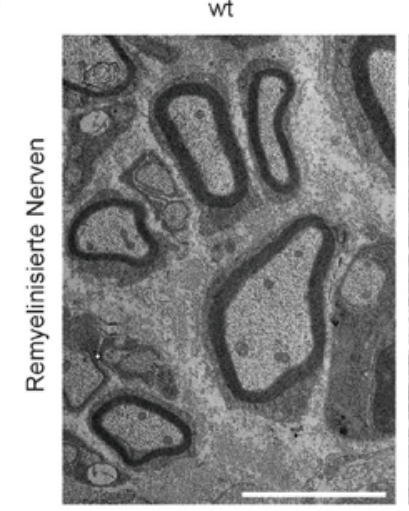

C

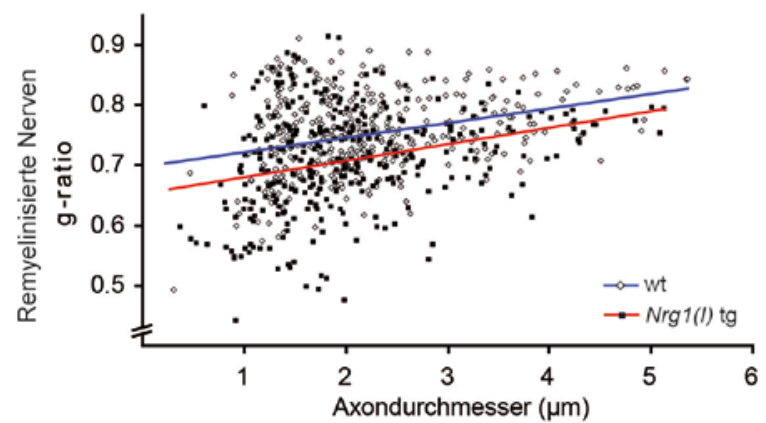

e

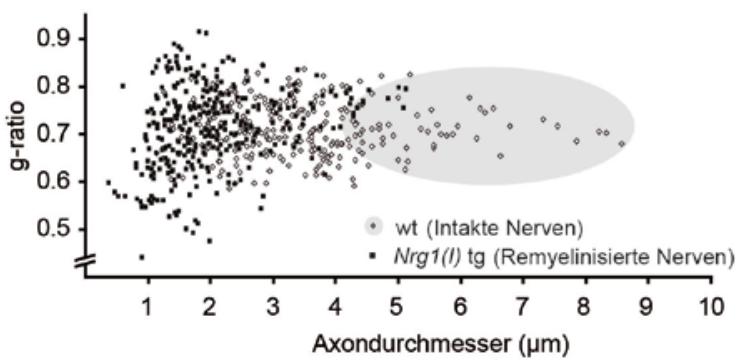

b

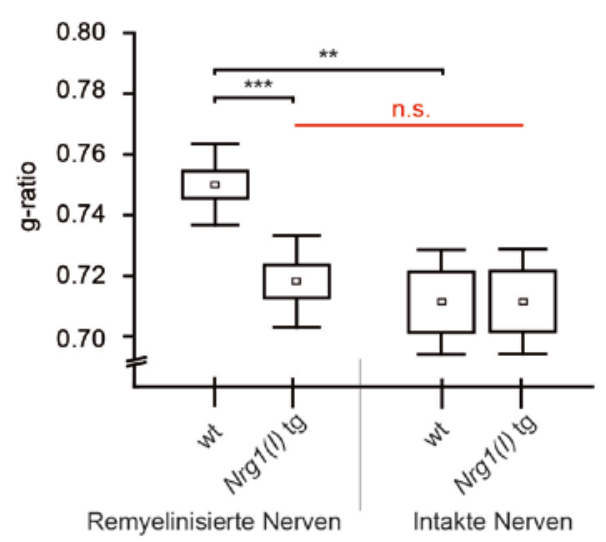

d

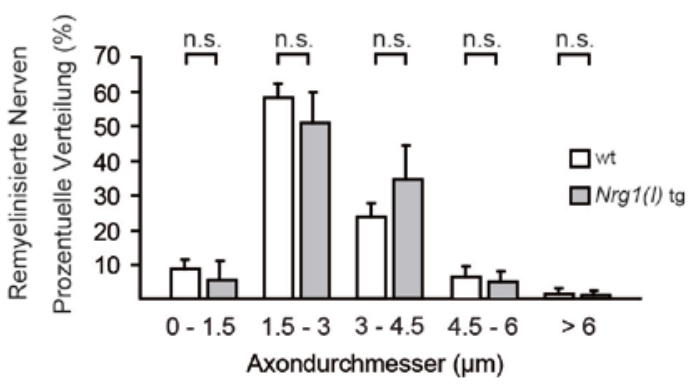

f

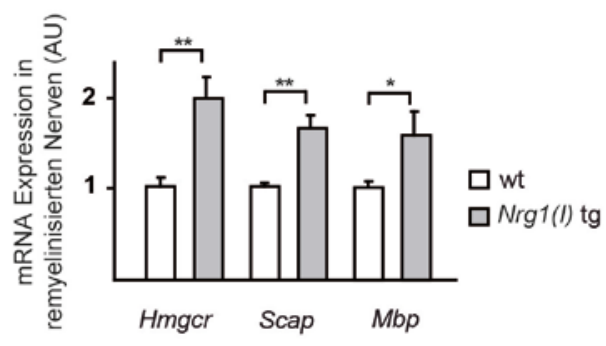

Abb. 4: Neuronales NRG1 Typ I verbessert die Remyelinisierung im PNS. a: Repräsentative elektronenmikroskopische Aufnahmen querangeschnittener N. ischiadici Nrg1 Typ I (Nrg1(I) $\operatorname{tg})$ transgener Tiere und Wildtyp Kontrollen (wt) 4 Wochen nach Nervenkompres-sion. Die Sterne markieren Axone mit „normaler" Myelindicke; (Messbalken $5 \mu \mathrm{m}$ ). b: Dargestellt ist ein Boxplot mit der g-ratio Analyse von wt $(n=9)$ und $\operatorname{Nrg} 1(I) \operatorname{tg}$ Tieren $(n=8) 4$ Wochen nach Nervenkompression (Remyelinisierte Nerven) und in nicht geschädigten Kontrollen (Intakte Nerven, $\mathrm{n}=3$ pro Gruppe). Die Remyelinisierung Nrg1(I) tg Nerven erreicht das Normalmaß nicht geschädigter Nerven. c: Das Verhältnis von g-ratio und Axondurchmesser in remyelinisierten Nerven von $\operatorname{Nrg} 1(I)$ tg und wt Tieren; ( $n=3$ pro Gruppe). d: Die prozentuelle Häufigkeitsverteilung der Axondurchmesser in $\operatorname{Nrg} 1(I) \operatorname{tg}$ und wt Nerven ( $\mathrm{n}=3$ pro Gruppe). e: Das Verhältnis von g-ratio und Axondurchmesser zeigt eine Reduktion des Axondurchmessers (grau unterlegter Bereich) in $\operatorname{Nrg1}(I) \operatorname{tg}$ Tieren nach Nervenkompression im Vergleich zu intakten wt Nerven ( $\mathrm{n}=3$ pro Gruppe). f: Die mRNA Expression (AU = arbitary units) myelinisierungsinduzierter Gene ist in $\operatorname{Nrg1}(I)$ $\operatorname{tg}$ Tieren ( $n=4)$ im Vergleich zu Wildtypmäusen $(n=5) 4$ Wochen nach Nervenkompression erhöht $(\mathrm{Hmgcr}$ = 3-Hydroxy-3-Methylglutaryl-Coenzym-A-Reduktase, Scap = Sterol regulatory element-binding protein cleavage-activating protein, $M b p=$ Myelin basische Protein). ${ }^{*} \mathrm{P}<0,05 ;{ }^{*} \mathrm{P}<0,01 ;{ }^{\star \star *} \mathrm{P}<0,001 ;$ n.s. $=$ nicht signifikant.

Beeinflusst axonales Neuregulin-1 Typ I spezifisch die Myelinbildung nach Nervenschädigung, oder ist es ebenfalls an der Proliferation und Redifferenzierung von Schwannzellen beteiligt? Die Anzahl der Schwannzellen, die in einem 1:1 Verhältnis mit Axonen assoziiert sind, ist vier Wochen nach Nervenkompression in Nrg1 Typ I transgenen Mäusen unverändert (Abb. 5a). 
Die Schwannzellproliferation und Differenzierung wurden zu einem früheren Zeitpunkt nach Nervenkompression (zwei Wochen nach Nervenkompression) untersucht, da die Redifferenzierung der Schwannzellen vier Wochen nach Nervenkompression bereits weitgehend abgeschlossen ist.

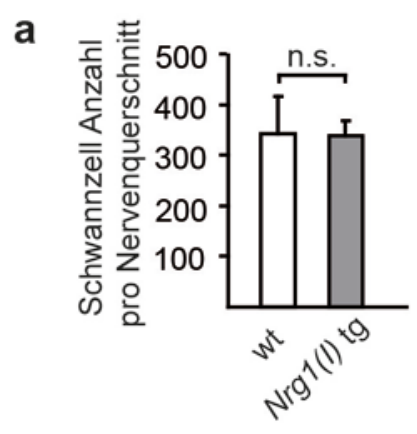

b

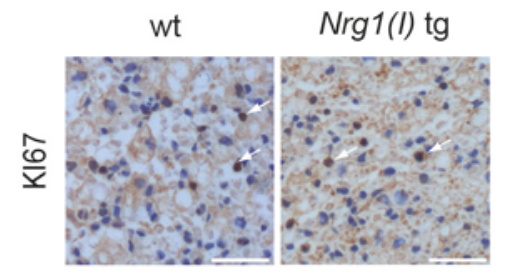

d
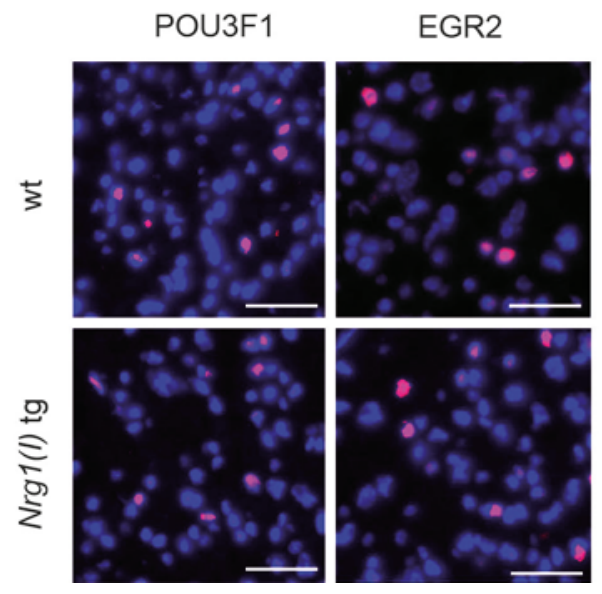

e
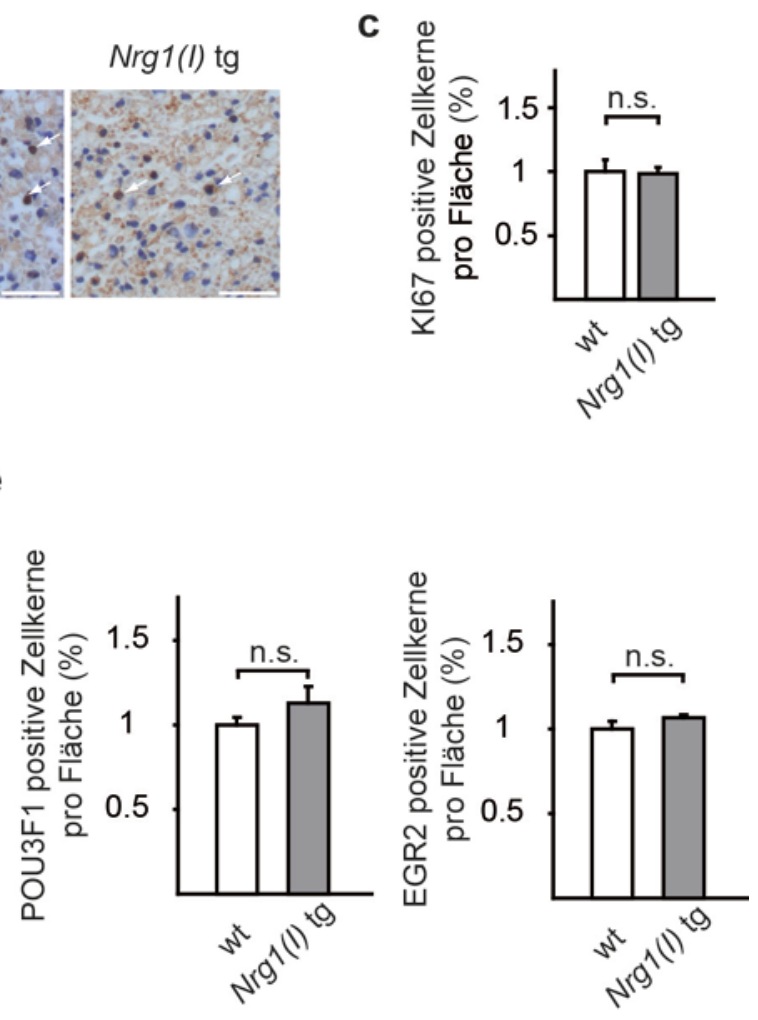

Abb. 5: Die Schwannzellproliferation und Differenzierung ist nach Nervenkompression in Nrg1 Typ I transgenen Tieren unverändert. a: Die Anzahl der Schwannzellen in einem 1:1 Verhältnis mit Axonen pro Nervenquerschnitt in $\operatorname{Nrg} 1$ Typ I transgenen $(\operatorname{Nrg} 1(I) \operatorname{tg}, \mathrm{n}=3$ ) und Wildtyp (wt, $\mathrm{n}=3$ ) Tieren 4 Wochen nach Nervenkompression. b: Lichtmikroskopische Aufnahmen querangeschnittener Nerven mit einer immunhistochemischen Färbung gegen KI67. Die Pfeile markieren KI67 positive Zellkerne. c: Quantifizierung der KI67 positiven Zellen in $\operatorname{Nrg1}(I) \operatorname{tg}$ und wt Tiere 2 Wochen nach Nervenkompression $(n=3$ pro Gruppe). d: Lichtmikroskopische Aufnahmen querangeschnittener Nerven mit immunhistochemischen Fluoreszenzfärbungen gegen POU3F1 und EGR2. In blau DAPI gefärbte Zellkerne, in pink Zellkerne die POU3F1 oder EGR2 exprimieren. E: Die Quantifizierung POU3F1 (links) und EGR2 (rechts) positiver Zellkerne pro Fläche in wt und $\operatorname{Nrg} 1(I) \operatorname{tg}$ Tieren ( $\mathrm{n}=3$ pro Gruppe). $\mathrm{n} . \mathrm{s} .=$ nicht signifikant.

Die Schwannzellproliferation wurde auf immunhistochemischer Ebene mit Hilfe eines Antikörpers gegen KI67, einem nukleären Protein, welches selektiv von mitotischen Zellen exprimiert wird, analysiert. Nrg1 Typ / transgene Tiere weisen keine erhöhte Anzahl Ki67 exprimierender Zellen im Vergleich zu Kontrollen zwei Wochen nach Nervenkompression auf (Abb. 5b,c). Diese Ergebnisse sind gut vereinbar mit anderen Studien, die ebenfalls keinen Einfluss von Neuregulin-1 auf die Schwannzellproliferation nach einer Nervenschädigung feststellen konnten (Atanosoki et al. 2006, Fricker et al. 2011).

Immunhistochemische Färbungen gegen die Transkriptionsfaktoren POU3F1 und EGR2 wurden im Folgenden verwendet, um die Schwannzelldifferenzierung nach Nervenkompression 
zu analysieren. POU3F1 markiert dabei unreife Schwannzellen, während EGR2 von myelinisierenden Schwannzellen exprimiert wird (Jessen und Mirsky 2005). Zwei Wochen nach Nervenkompression zeigt sich kein Unterschied in der Anzahl POU3F1 und EGR2 exprimierender Schwannzellen zwischen Nrg1 Typ I transgenen Tieren und Kontrollen. Diese Ergebnisse deuten darauf hin, dass axonal exprimiertes NRG1 Typ I die frühe Redifferenzierung von Schwannzellen nach einer Nervenkompression nicht maßgeblich beeinflusst (Abb. $\mathbf{5 d}, \mathbf{e})$.

Zusammenfassend führt sowohl die transgene Überexpression von Neuregulin-1 Typ III als auch von Neuregulin-1 Typ I in Neuronen zu einer verbesserten Remyelinisierung nach Nervenkompression. Die Überexpression von Neuregulin-1 Typ III induziert dabei eine Hypermyelinisierung der regenerierten Axone. Nrg1 Typ / transgene Tiere zeigen hingegen eine Rekonstitution der ursprünglichen Myelindicke mit einem g-ratio Wert, welcher im Mittel dem Wert nicht geschädigter Nerven entspricht.

Diese Ergebnisse führten zu der Hypothese, dass ein unzureichendes axonales Neuregulin-1Signal nach einem Nervenschaden die unvollständige Remyelinsierung im peripheren Nervensystem bedingen könnte.

\subsection{SCHWANNZELLEN EXPRIMIEREN NRG1 TYP I NACH EINER NERVENSCHÄDIGUNG}

Nach einer Nervenschädigung verlieren Schwannzellen aufgrund der Wallerischen Degeneration zunächst den Kontakt zum Axon, und somit ebenfalls den Kontakt zu axonal exprimierten Wachstumsfaktoren wie Neuregulin-1. Untersuchungen zur neuronalen Expression von Neuregulin-1 nach einem Nervenschaden ergaben zudem, dass die Neuregulin-1Expression nach einer Nervenschädigung deutlich reduziert ist, und erst vier Wochen nach Nervenkompression wieder die ursprüngliche Höhe erreicht (Bermingham-McDonogh et al. 1997, Stassart et al. 2012a). Diese Beobachtungen führten zu der Frage, ob denervierte Schwannzellen selbst die Expression von Wachstumsfaktoren induzieren, um so die Reduktion des axonalen Neuregulin-1-Signals zu kompensieren.

Tatsächlich konnte gezeigt werden, dass nach einem Nervenschaden die Expression von Neuregulin-1 in Schwannzellen stark induziert wird (Abb. 6a; Carroll et al. 1997, Stassart et al. 2012a). In nicht geschädigten Nerven dagegen ist die Expression von Neuregulin-1 in Schwannzellen extrem gering (Abb. 6a, Stassart et al. 2013). 
Die transkriptionelle Analyse der Neuregulin-1-Isoformen Typ I-III in geschädigten Ischiasnerven zu verschiedenen Zeitpunkten ergab, dass spezifisch die Nrg1 Typ-I-Isoform (und nicht Typ II oder III) in geschädigten Schwannzellen, insbesondere zwischen Tag 1 und 14 nach Nervenkompression, induziert wird (Stassart et al. 2013).

a

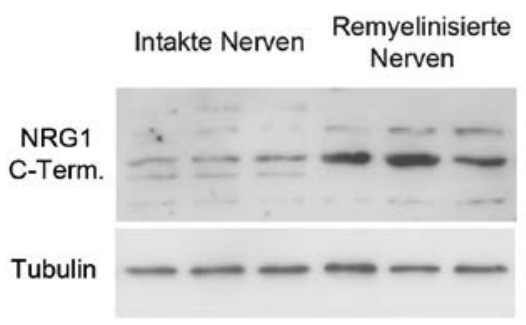

b

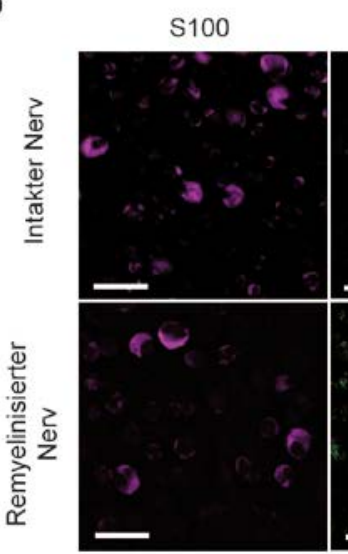

NRG1 C-Term

DAPI

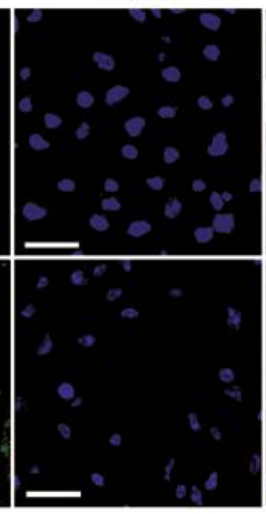

Zusammengeführte Bilder

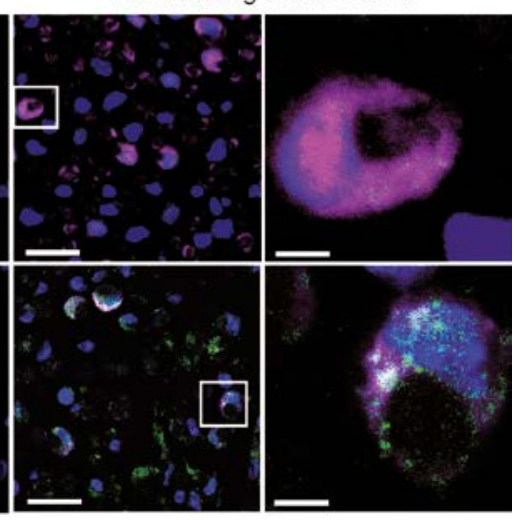

Zusammengeführte Bilder

C

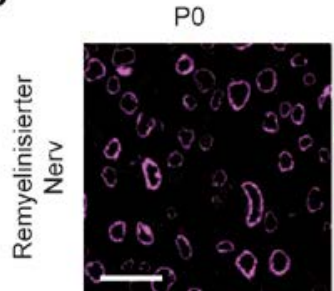

NRG1 C-Term.
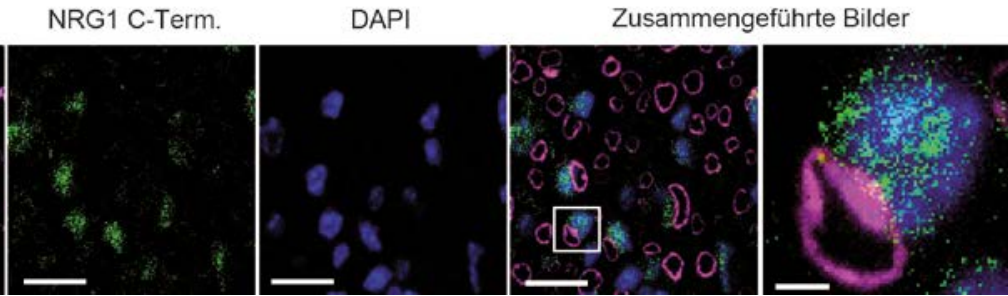

Abb. 6: Schwannzellen exprimieren Neuregulin-1 nach Nervenkompression im PNS. a: Western Blot Analyse von Ischiasnerven 4 Wochen nach Nervenkompression (Remyelinisierte Nerven) und von nicht geschädigten, intakten Nerven. Verwendet wurde ein Antikörper gegen den C-Terminus von Neuregulin-1 (Höhe der Bande: $70 \mathrm{kDa}$ ) sowie Tubulin als Ladekontrolle (Höhe der Bande: 55 kDa). b,c: Konfokale Mikroskopie Aufnahmen von querangeschnittenen Ischiasnerven gefärbt mit Antikörpern gegen S100 (einem von Schwannzellen exprimierten Protein), gegen den C-Terminus von Neuregulin-1 und gegen das Myelinprotein PO. Eine Kernfärbung erfolgte mit DAPI. Messbalken $20 \mu \mathrm{m}$ sowie 3,5 $\mu \mathrm{m}$ in den vergrößerten Aufnahmen ganz rechts.

Die Induktion der Schwannzell Neuregulin-1-Expression ist jedoch auf Proteinebene auch vier Wochen nach Nervenkompression noch deutlich sichtbar (Abb. 6a). Für die Analyse der Neuregulin-1 Proteinexpression wurde ein Antikörper verwendet, der gegen die C-terminale Region von allen Neuregulin-1-Isoformen gerichtet ist (Abb. 6a). Hierbei ist zu beachten, dass mit diesem Antikörper die axonale Neuregulin-1-Expression kaum detektierbar ist (Velanac et al. 2012). 
Um nachzuweisen, dass die Expression von Neuregulin-1 im geschädigten $\mathrm{N}$. ischiadicus in der Tat von Schwannzellen induziert wird, wurden immunhistochemische Färbungen gegen Neuregulin-1 und das von Schwannzellen exprimierte Protein S100 vier Wochen nach Nervenkompression durchgeführt (Abb. 6b). Die Analyse mittels konfokaler Mikroskopie konnte bestätigen, dass Neuregulin-1 mit S100 in Schwannzellen kolokalisiert (Abb. 6b). Doppelfluoreszenzfärbungen von Neuregulin-1 und dem Myelin Protein Zero (P0) zeigen weiterhin, dass Neuregulin-1 exprimierende Schwannzellen an der Bildung von Myelin während der Remyelinisierung beteiligt sind (Abb. 6c).

\subsection{DIE EXPRESSION VON SCHWANNZELL-NRG1 WIRD DURCH NEURONALES NRG1 REGULIERT}

Eine Nervenschädigung im PNS führt temporär zu einer Reduktion des axonalen Neuregulin-1Signals (Stassart et al. 2012a). Während dieser Zeit wird die Neuregulin-1-Expression in Schwannzellen induziert (Abb. 6a, b; Stassart et al. 2012a). Axonal exprimiertes Neuregulin-1 könnte daher die Schwannzell Neuregulin-1-Expression negativ regulieren.

Um diese Hypothese mit Hilfe eines einfachen experimentellen Schemas zu untersuchen, wurden primäre Ratten-Schwannzellkulturen verwendet (Abb. 7a). Die Schwannzellkulturen wurden für fünf Tage in einem Minimalmedium kultiviert, um den denervierten Schwannzellphänotyp zu imitieren. Anschließend wurden die Schwannzellen mit rekombinantem Neuregulin-1 (d.h. mit der EGF-like domain von Neuregulin-1) behandelt, um so das axonale Neuregulin-1-Signal zu simulieren (Abb. 7a). Nachfolgend wurde die mRNA Expression von Nrg1 Typ I in den mit Neuregulin-1 behandelten primären Schwannzellen und in unbehandelten Kontroll-Schwannzellkulturen analysiert (Abb. 7a). Diese Ergebnisse zeigen, dass die exogene Zugabe von rekombinantem Neuregulin-1 innerhalb von sechs Stunden eine signifikante Herrunterregulation der Nrg1 Typ I mRNA in primären Schwannzellen induziert (Abb. 7a). Die Reduktion der Nrg1 Typ I mRNA ist dabei mindestens für 24 Stunden in den behandelten Kulturen nachweisbar (Abb. 7a). Als Kontrollexperiment wurde in allen untersuchten Schwannzellkulturen die mRNA Expression von Hmgcr gemessen, da aus der Literatur bekannt ist (Pertusa et al. 2007), dass die Behandlung mit Neurgegulin1 zu einer Induktion dieses Genes in Schwannzellen führt (Abb. 7a). Die Heraufregulation der Hmgcr mRNA nach Behandlung belegt, dass die Transkriptionsleistung nach Zugabe von Neuregulin-1 in Schwannzellen nicht generell eingeschränkt ist (Abb. 7a).

Die Reduktion der Nrg1 Typ I mRNA nach Neuregulin-1 Behandlung konnte mittels einer Western Blot Analyse auf Proteinebene bestätigt werden (Abb. 7b). Drei Tage nach der Behandlung mit rekombinantem Neuregulin-1 zeigen primäre Schwannzellkulturen eine deutliche Reduktion der Neuregulin-1 Protein Expression im Vergleich zu unbehandelten Kontrollen (Abb. 7b). 
a

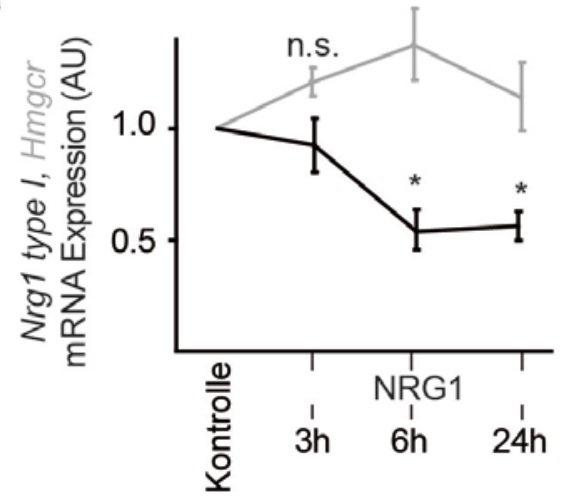

b

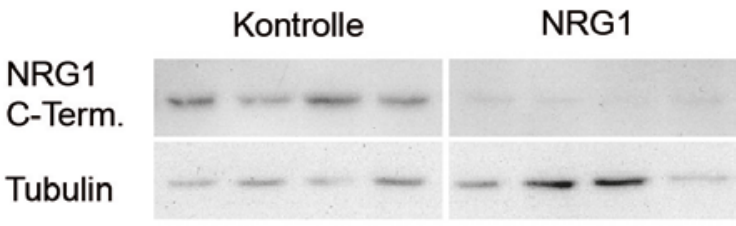

Abb. 7: Die Behandlung von primären Schwannzellkulturen mit rekombinantem NRG1 inhibiert die NRG1 Expression in Schwannzellen. a: Primäre Ratten-Schwannzellkulturen wurden mit $20 \mathrm{ng} / \mathrm{ml}$ rekombinantem NRG1 (EGF-ähnliche Domaine) behandelt. Nicht behandelte Kontrollen sowie Schwannzellkulturen 3,6 und 24 h nach Neuregulin-1 Behandlung wurden hinsichtlich ihrer Nrg1 Typ 1 mRNA Expression untersucht. Dabei wurde die Hmgcr mRNA Expression als Positivkontrolle verwendet, da die Stimulation von Schwannzellen mit Neuregulin-1 die mRNA Expression von Hmgcr induziert (Pertusa et al. 2007). (AU: arbitary units, n.s. = nicht signifikant, angegeben ist der Mittelwert und der Standardfehler, $\left.{ }^{*} \mathrm{P}<0,05\right)$. b: Dargestellt ist eine Western Blot Analyse von primären Schwannzellkulturen mit einem Antikörper gegen den C-Terminus von Neuregulin-1 (Bande auf Höhe $70 \mathrm{kDa}$ ) sowie mit einem Antikörper gegen Tubulin als Ladekontrolle (Bande auf Höhe $55 \mathrm{kDa}$ ). Verglichen wurden nicht behandelte Kontrollschwannzellen (Kontrolle) mit Schwannzellen 3 Tage nach Behandlung mit rekombinantem Neuregulin-1 (NRG1).

Weitere Analysen in vitro ergaben zudem, dass primäre Schwannzellkulturen eine signifikant geringere Expression von Neuregulin-1 aufweisen, wenn sie mit Axonen zusammen kultiviert werden (Stassart et al. 2012a). Umgekehrt zeigen Schwannzellen von Mausmutanten mit einer Hemizygotie für Neuregulin-1 Typ III eine höhere Nrg1 Typ I mRNA Expression in vivo (Stassart et al. 2012a). Verschiedene zusätzliche in vitro und in vivo Untersuchungen konnten nachweisen, dass die Regulation der Schwannzell Neuregulin-1-Typ-I-Expression durch exogenes Neuregulin-1 über die ErbB2/3 Rezeptoren und den ERK1/2 Signalweg in Schwannzellen vermittelt wird (Stassart et al. 2012a).

\subsection{DiE ROLLE VON SCHWANNZELL-NRG1 FÜR DIE REMYELINISIERUNG IM PNS}

Um die Funktion von Schwannzell Neuregulin-1 in vivo untersuchen zu können, wurden Mausmutanten mit einer spezifischen Deletion von Neuregulin-1 in Schwannzellen generiert. Mausmutanten mit einer Expression der Cre-Rekombinase unter dem Desert hedgehog Promotor wurden hierzu mit Mäusen mit einem von zwei loxP-Stellen flankierten Neuregulin-1 Gen verpaart ( $D h h^{C r e} \times \mathrm{Nrg}^{\text {loxP/loxP }}$ Mäuse), (Jaegle et al. 2003, Li et al. 2002).

Die $D h h^{\mathrm{Cre}} \times \mathrm{Nrg}^{\text {loxP/loxP }}$ Mausmutanten wurden zunächst im Alter von drei Monaten analysiert (Abb. 8a, b). Phänotypisch weisen die Tiere zu diesem Zeitpunkt keine Auffälligkeiten auf. Lichtmikroskopische Aufnahmen von Nervenquerschnitten des $\mathrm{N}$. ischiadicus lassen ebenfalls keine Unterschiede zwischen drei Monate alten $\mathrm{Dhh}^{\mathrm{Cre}} \times \mathrm{Nrg}^{\text {loxP/loxP }}$ Mäusen und 
entsprechenden Kontrollen erkennen (Abb. 8a). Die Ergebnisse der Quantifizierung des gratios (auf elektronenmikroskopischer Ebene) im Verhältnis zum Axondurchmessers zeigen eine unveränderte Myelindicke in $D h h^{C r e} \times \mathrm{Nrg}^{\text {loxP/loxP }}$ Mäusen (Abb. 8b).

a

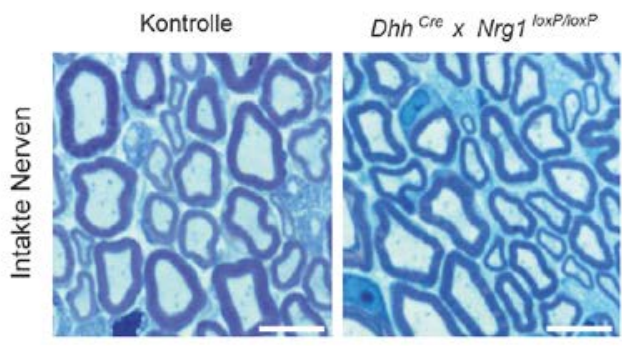

b

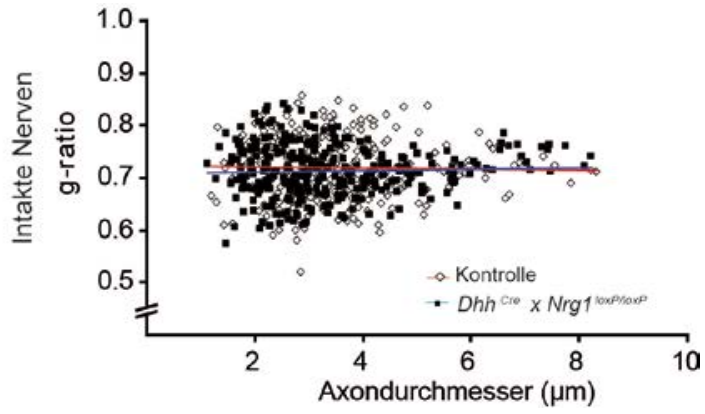

Abb. 8: Schwannzell-NRG1 defiziente Mäuse zeigen eine normale Myelinisierung im PNS.

a: Lichtmikroskopische Aufnahmen von querangeschnittenen $\mathrm{N}$. ischiadici drei Monate alter $D h h^{\mathrm{Cre}} x$ $\mathrm{Nrg} 1^{\text {loxPlloxP }}$ Mäuse und Kontrollen. Messbalken entsprechen $7,5 \mu \mathrm{m}$. b: Quantifizierung von a. Dargestellt ist das g-ratio im Verhältnis zum Axondurchmesser von $\mathrm{n}=3 \mathrm{~N}$.ischiadici pro Gruppe.

Um die Funktion von Schwannzell Neuregulin-1 während der Nervenregeneration und Remyelinisierung zu untersuchen, wurde in $\mathrm{Dhh}^{\mathrm{Cre}} \times \mathrm{Nrg}^{\text {loxP/loxP }}$ Mausmutanten das Nervenkompressionsmodell angewandt. Die Remyelinisierung wurde dabei zunächst vier Wochen nach der Nervenkompression histologisch untersucht (Abb. 9a). Elektronenmikroskopische Aufnahmen der geschädigten Nerven von $D h h^{\mathrm{Cre}} \times \mathrm{Nrg}^{\text {loxP/loxP }}$ Mäusen lassen zahlreiche regenerierte Axone mit einer nur sehr dünnen Myelinschicht erkennen (Abb. 9a). Die g-ratio Analyse vier Wochen nach Nervenkompression ergab, dass Tiere mit einer Deletion von Neuregulin-1 in Schwannzellen eine signifikant stärkere Hypomyelinisierung des distalen $\mathrm{N}$. ischiadicus aufweisen als entsprechende Kontrollmäuse (Abb. 9b). Eine Zunahme der Hypomyelinisierung lässt sich dabei für alle untersuchten Axondurchmesser feststellen, obgleich sie im Bereich grösserer Axonkaliber deutlicher ausgeprägt ist (Abb. 9c). Eine Veränderung der Häufigkeitsverteilung der Axondurchmesser lässt sich in $D h h^{\text {Cre }} \times \mathrm{Nrg}^{\text {loxP/loxP }}$ Mutanten vier Wochen nach Nervenkompression nicht erkennen (Abb. 9d).

Im Folgenden wurde die Anzahl der remyelinisierten Axone im Nervenquerschnitt auf lichtmikroskopischer Ebene vier Wochen nach Nervenkompression quantifiziert (Abb. 9e). Mäuse mit einer Deletion von Neuregulin-1 in Schwannzellen weisen in dieser Analyse eine verringerte Anzahl remyelinisierter Axone im distalen $\mathrm{N}$. ischiadicus im Vergleich zu entsprechenden Kontrollen auf (Abb. 9e). Die Reduktion der myelinisierten Axone in $\mathrm{Dhh}^{\mathrm{Cre}} \mathrm{x}$ $N r g 1^{\text {loxP/loxP }}$ Mutanten könnte dabei sowohl durch eine verschlechterte axonale Regeneration, als auch durch eine fehlende Remyelinisierung regenerierter Axone entstehen. Aus diesem Grund wurden weitere Untersuchungen auf elektronenmikroskopischer Ebene durchgeführt (Abb. 9f). In $D h h^{C r e} \times N r g 1^{\text {loxP/loxP }}$ Mäusen lässt sich eine signifikant höhere Anzahl unmyelinisierter Axone mit einem Durchmesser überhalb von $1 \mu \mathrm{m}$ im Vergleich zu Kontrollmäusen feststellen (Abb. 9f). Normalerweise werden im PNS alle Axone überhalb eines 
Durchmessers von $1 \mu \mathrm{m}$ myelinisiert. Die genauere Analyse der unmyelinisierten Axone grösser $1 \mu \mathrm{m}$ in den $D h h^{C r e} \times \mathrm{Nrg}^{\text {loxP/loxP }}$ Mäusen ergab, dass über zwei Drittel der unmyelinisierten Axone von Schwannzell Zytoplasma umgeben sind (Abb. 9f). Die Reduktion der myelinisierten Axone im Nervenquerschnitt von $D h h^{C r e} \times \mathrm{Nrg}^{\text {loxP/loxP }}$ Mäusen (Abb. 9e) lässt sich somit zumindestens teilweise auf eine fehlende Schwannzellremyelinisierung zurückzuführen (Abb. 9f). Elektrophysiologische Untersuchungen zeigten jedoch auch eine Reduktion des Muskelsummenaktionspotentials (CMAP) in $D h h^{C r e} \times \mathrm{Nrg}^{\text {loxP/loxP }}$ Mäusen vier Wochen nach Nervenkompression, so dass vermutlich zusätzlich auch eine eingeschränkte axonale Regeneration in den Mausmutanten vorliegt (Stassart et al. 2012a).

Die Anzahl der Schwannzellen in einem 1:1 Verhältnis mit Axonen ist in $D h h^{\mathrm{Cre}} \times \mathrm{Nrg}^{\text {loxP/loxP }}$ Mäusen im Vergleich zu Kontrolltieren vier Wochen nach Nervenkompression unverändert (Abb. 9g).

Zusammenfassend zeigen diese Ergebnisse, dass die Expression von Neuregulin-1 in Schwannzellen nach einer Schädigung des peripheren Nervens für eine effiziente und vollständige Remyelinisierung benötigt wird. Ein Verlust von Neuregulin-1 in Schwannzellen (in $D h h^{\text {Cre }} \times \mathrm{Nrg}^{\text {loxPlloxP }}$ Mäusen) führt morphologisch zu einer Hypomyelinisierung und einer reduzierten Anzahl remyelinisierter Axone und schränkt in der Folge die Funktionalität des regenerierten Nerven ein (Abb. 9a-g, Stassart et al. 2012). 
a

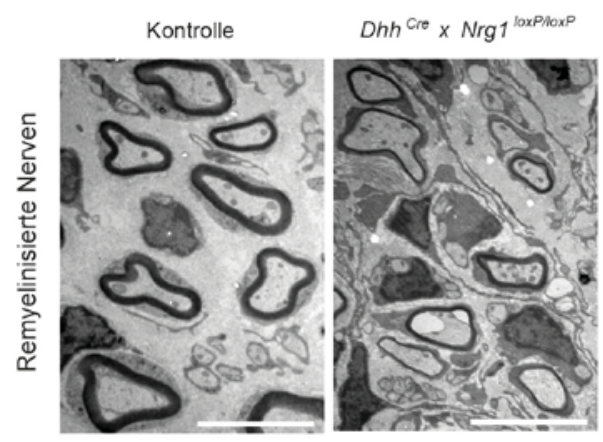

c

Remyelinisierte Nerven

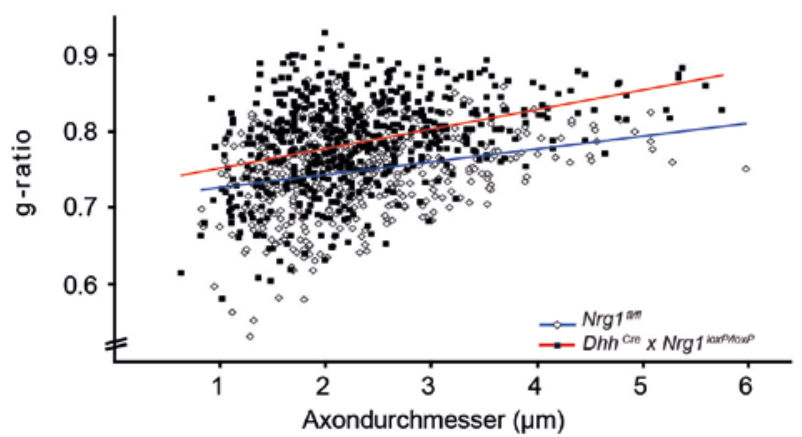

b

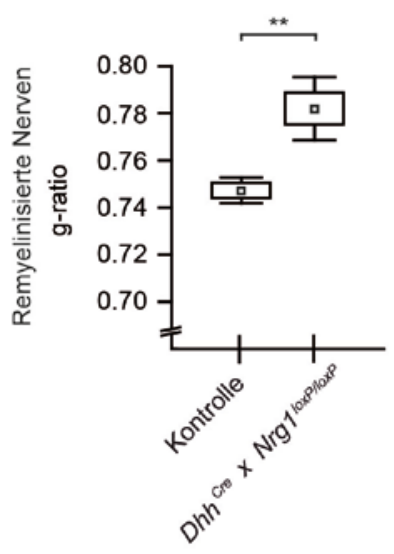

d

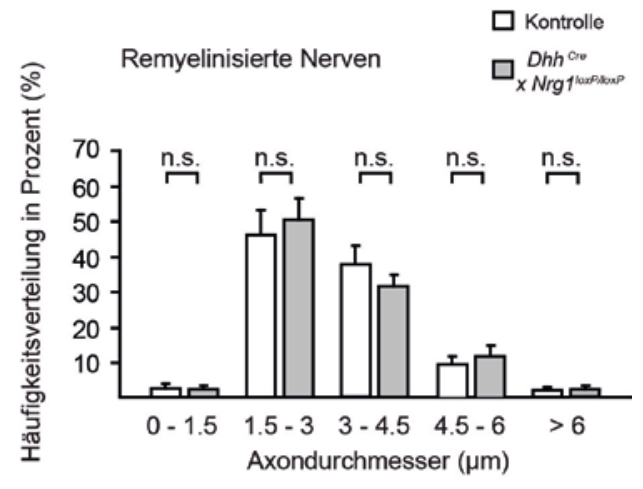

g e

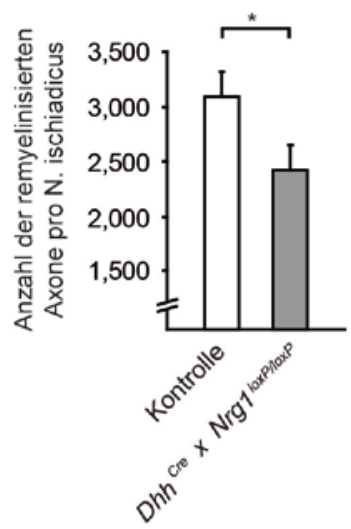

f

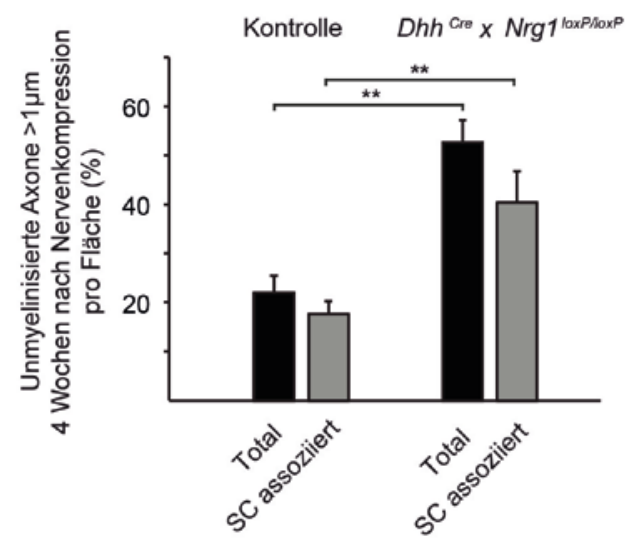

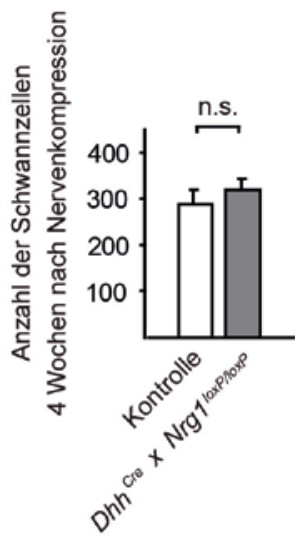

Abb. 9: Die Deletion von NRG1 in Schwannzellen führt zu einer verschlechterten Remyelinisierung vier Wochen nach Nervenkompression. a: Repräsentative elektronenmikroskopische Aufnahmen querangeschnittener $\mathrm{N}$. ischiadici von Kontrollmäusen und $\mathrm{Dhh}^{\mathrm{Cre}} \times \mathrm{Nrg}^{\text {loxP/loxP }}$ Tieren. Die Messbalken entsprechen $5 \mu \mathrm{m}$. b: Die Quantifizierung der Myelindicke mittels g-ratio Analyse zeigt eine Zunahme der Hypomyelinisierung in $D h h^{C r e} \times N_{r g} 1^{\text {loxP/loxP }}$ Mäusen ( $n=3-4$ pro Gruppe). c: Dargestellt ist das g-ratio im Verhältnis zum Axondurchmesser ( $n=3$ pro Gruppe). d: Licht-mikroskopische Analyse der Axondurchmesser in Kontrollen und $D h h^{C r e} \times N r g 1^{\text {loxP/loxP }}$ Mäusen. e: Die Anzahl der remyelinisierten Axone (pro N. ischiadicus Querschnitt) ist in $D h h^{C r e} \times N r g 1^{\text {loxP/loxP }}$ Mäusen reduziert f: Die Anzahl der unmyelinisierten Axone über einem Durchmesser von $1 \mu \mathrm{m}$ pro Fläche. Quantifiziert wurde zum einen die Totalanzahl der Axone sowie diejenigen Axone, die mit Schwannzellen assoziiert, aber nicht remyelinisiert sind. N=3 pro Gruppe. g: Dargestellt ist die Anzahl der Schwannzellen in einem 1:1 Verhältnis mit Axonen pro querangeschnittenem $N$. ischiadicus ( $n=3$ pro Gruppe). (n.s. = nicht signifikant; ${ }^{*} P<0,05 ;{ }^{*} P<0.01$ ). 
Um die Funktion von Schwannzell Neuregulin-1 für die Remyelinisierung und Regeneration des peripheren Nerven besser zu verstehen, wurden weitere Zeitpunkte nach Nervenschädigung in $D h h^{\text {Cre }} \times \mathrm{Nrg}^{\text {loxPlloxP }}$ Mäusen charakterisiert. Dabei wurden die Mausmutanten zunächst vier Tage nach Nervenkompression untersucht, um die Wallerische Degeneration und somit die Dedifferenzierungsphase von Schwannzellen zu analysieren. Ein Teil der Axone ist zu diesem Zeitpunkt bereits vollständig degeneriert, während andere Axone noch relativ gut erhalten sind. Weiterhin lassen sich während dieser Phase zahlreiche kollabierte Myelinscheiden, sogenannte Myelinovoide, feststellen. Diese werden in der Folge von Makrophagen und Schwannzellen selbst phagozytiert.

a

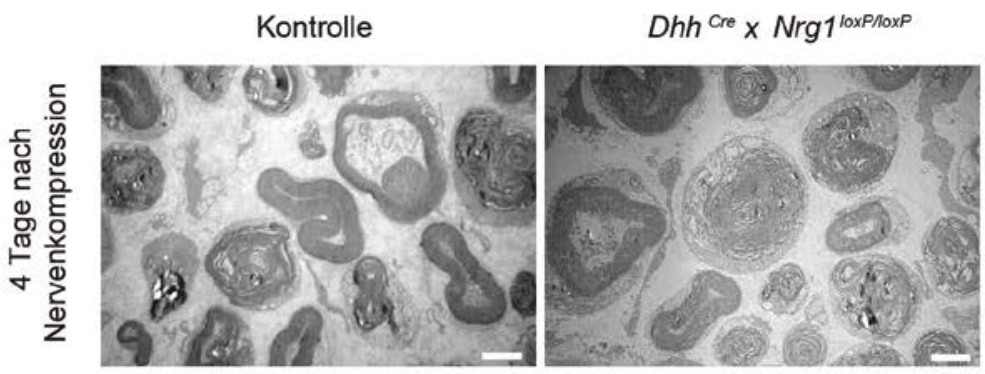

b

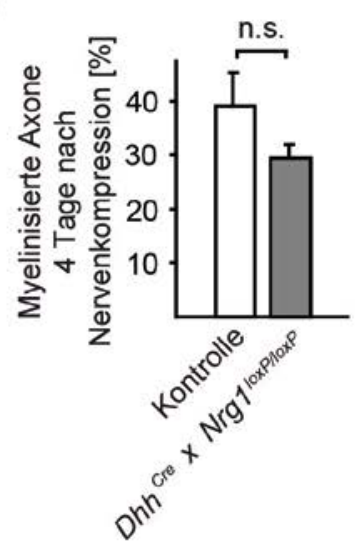

C

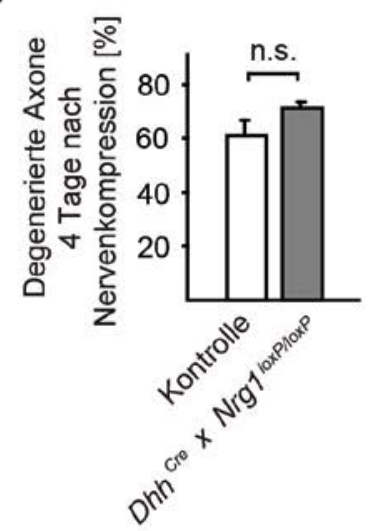

d

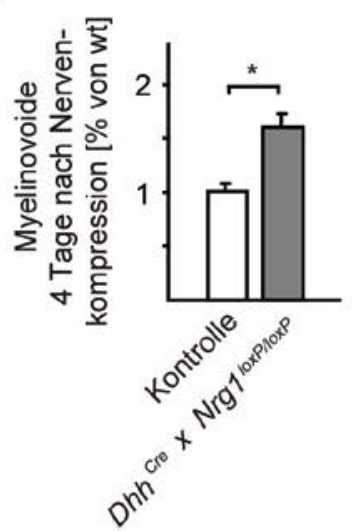

Abb. 10: Der Einfluss von Schwannzell-NRG1 auf die Wallerische Degeneration vier Tage nach Nervenkompression. a: Repräsentative elektronenmikroskopische Aufnahmen des querangeschnittenen $\mathrm{N}$. ischiadicus von Kontrollen und $\mathrm{Dhh}^{\mathrm{Cre}} \times \mathrm{Nrg}^{10 \times P / l o x P}$ Mäusen. Messbalken entspricht $5 \mu \mathrm{m}$. b: Die Anzahl myelinisierter Axone (dargestellt als Prozentsatz der Totalanzahl der Axone (myelinisiert und degeneriert (siehe c)) ist in $D h h^{\text {Cre }} \times \mathrm{Nrg}_{1}{ }^{\text {loxP/loxP }}$ Mäusen im Vergleich zu Kontrollen unverändert. c: Ebenfalls zeigt sich kein Unterschied in der Anzahl der degenerierten Axone zwischen beiden Gruppen d: $D h h^{\mathrm{Cre}} \times \mathrm{Nrg}^{\text {loxPlloxP }}$ Mäuse weisen während der Wallerischen Degeneration eine erhöhte Anzahl an Myelinovoiden im Vergleich zu Kontrolltieren auf. (n.s. = nicht signifikant; ${ }^{\star} \mathrm{P}<0,05$.).

Die Analyse der Wallerischen Degeneration erfolgte auf elektronenmikroskopischer Ebene. Der distale $\mathrm{N}$. ischiadicus von Mäusen mit einer Deletion von Schwannzell Neuregulin-1 weist keinen Unterschied in der Anzahl der myelinisierten, noch nicht degenerierten Axone vier Tage nach Nervenkompression im Vergleich zu Kontrollen auf (Abb. 10a,b). Ebenfalls zeigt sich eine unveränderte Anzahl an Axonen mit Anzeichen einer Degeneration in $D h h^{C r e} \times \mathrm{Nrg}^{\text {loxP/loxP }}$ 
Mäusen (Abb. 10c). Hingegen weisen $D h h^{C r e} \times \mathrm{Nrg}^{\text {loxP/loxP }}$ Mäuse im distalen N. ischiadicus eine erhöhte Anzahl von Myelinovoiden auf (Abb. 10a,d).

Zwei Wochen nach Nervenkompression, d.h. zu Beginn der Remyelinisierung, zeigen $D h h^{C r e} x$ $\mathrm{Nrg1} 1^{\text {loxP/loxP }}$ Mäuse eine reduzierte Anzahl remyelinisierter Axone im Vergleich zu Kontrollmäusen (Stassart et al. 2012a). Zu diesem Zeitpunkt lässt sich zudem eine verringerte Anzahl an Schwannzellen feststellen, die den Transkriptionsfaktor EGR2 exprimieren (Stassart et al. 2012a). Die Schwannzellproliferation und die Anzahl der Schwannzellen sind jedoch auch zwei Wochen nach Nervenkompression unverändert (Stassart et al. 2012a).

\subsection{AXONALES NRG1 TYP I KANN DEN VERLUST VON SCHWANNZELL-NRG1 NICHT KOMPENSIEREN}

Die neuronale Überexpression von Neuregulin-1 Typ I führt zu einer verbesserten Remyelinisierung nach Nervenkompression. Um die Funktionen von axonal und glial exprimiertem Neuregulin-1 besser zu verstehen, wurden im Folgenden Mäuse mit einer neuronalen Überexpression von Neuregulin-1 Typ I mit $D h h^{C r e} x \mathrm{Nrg}^{\text {loxP/loxP }}$ Tieren verpaart. In diesen Doppelmutanten wurde das Nervenkompressionsmodell angewandt, und der $\mathrm{N}$. ischiadicus vier Wochen nach Nervenschädigung untersucht. Elektronenmikroskopische Aufnahmen des distalen $\mathrm{N}$. ischiadicus zu diesem Zeitpunkt lassen erneut die vollständige Wiederherstellung der Myelindicke in Tieren mit einer neuronalen Überexpression von Neuregulin-1 Typ I erkennen. Im Gegensatz dazu weisen Nrg1(I) transgene Tiere verpaart mit $D h h^{C r e} \times \operatorname{Nrg}^{\text {loxPlloxP }}$ Mäusen eine deutlich schlechtere Remyelinisierung auf (Abb. 11a). Die Quantifizierung mittels g-ratio Analyse zeigte entsprechend eine signifikante Reduktion der Myelindicke in den Doppelmutanten $\left(D h h^{C r e} \times \mathrm{Nrg}^{\text {loxP/loxP }} \times \mathrm{Nrg} 1(\mathrm{I}) \mathrm{tg}\right)$ im Vergleich zu Nrg1(I)

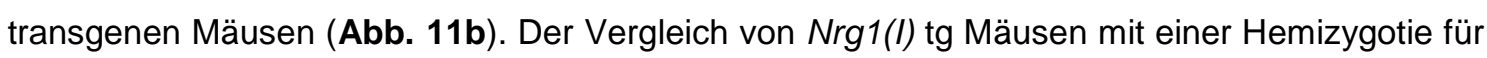
Schwannzell Neuregulin-1 mit Mäusen mit einer homozygoten Deletion von Schwannzell Neuregulin-1 ergab zudem, dass die Reduktion der Myelindicke in diesen Mutanten von der Schwannzell Neuregulin-1 Gendosis abhängig ist (Abb. 11b). Die Hypomyelinisierung in den $D h h^{\text {Cre }} \times \mathrm{Nrg1}^{\text {loxP/loxP }} \times \operatorname{Nrg1}(I)$ tg Mäusen ist unabhängig vom Axondurchmesser, und lässt sich im Bereich aller Axonkaliber beobachten (Abb. 11c). Diese Ergebnisse zeigen zusammenfassend, dass die axonale Überexpression von Neuregulin-1 Typ I eine Deletion von Schwannzell Neuregulin-1 in konditionalen Mausmutanten nach Nervenkompression nicht kompensieren kann. 
a

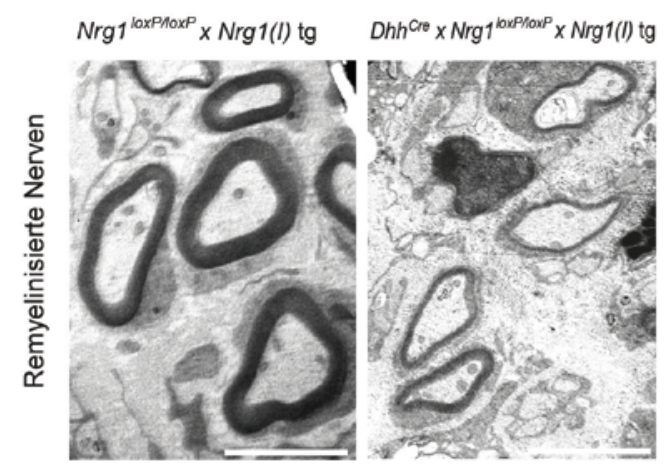

C

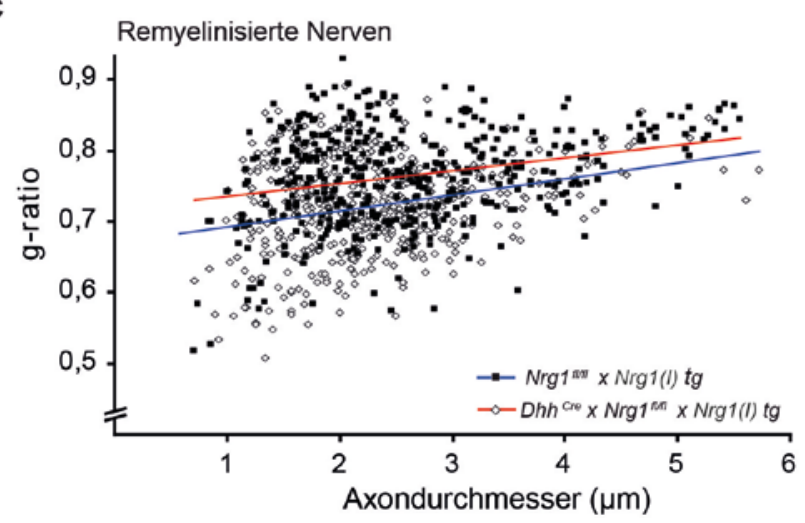

b

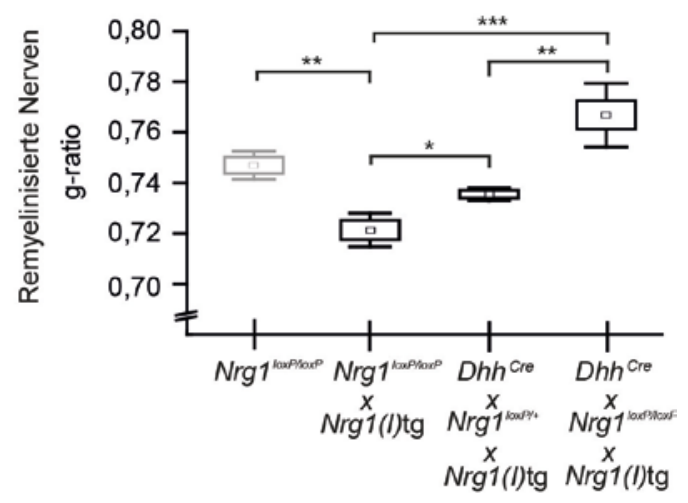

Abb. 11: Die neuronale Überexpression von NRG1 Typ I kann den Verlust von Schwannzell-NRG1 vier Wochen nach Nervenkompression nicht kompensieren. a: Repräsentative elektronenmikroskopische Aufnahmen des quer angeschnittenen $\mathrm{N}$. ischiadicus von Kontrollmäusen mit einer neuronalen Überexpression von Neuregulin-1 Typ I (Nrg1 $\left.1^{\operatorname{loxP} / l o x P} \times \operatorname{Nrg1}(\mathrm{I}) \operatorname{tg}\right)$ sowie $\operatorname{von} \operatorname{Nrg1}(\mathrm{I})$ transgenen Mäusen verpaart mit $D h h^{C r e} \times N r g 1^{\text {loxP/loxP }}$ Tieren. Die Messbalken entsprechen $5 \mu \mathrm{m}$. b: Die Quantifizierung der Myelindicke mittels g-ratio Analyse lässt eine Hypomyelinisierung in $\operatorname{Nrg1}(I)$ transgenen Tieren verpaart mit Mäusen mit einem Verlust von Schwannzell-NRG1 erkennen. Die Myelindicke ist dabei abhängig von der Schwannzell Neuregulin-1 Gendosis (Nrg1 $1^{\text {loxP/loxP }}$ und $\operatorname{Nrg} 1^{\text {loxP/loxP }} \times$

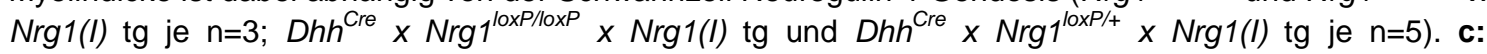
Dargestellt ist das Verhältnis von g-ratio zu Axondurchmesser. Die Reduktion der Myelindicke in den Doppelmutanten lässt sich im Bereich aller Axondurchmesser erkennen ( $n=3$ pro Gruppe); ( $P<0,05$; $\left.{ }^{*} \mathrm{P}<0,01 ;{ }^{* * *} \mathrm{P}<0,001\right)$. 


\section{DISKUSSION}

\subsection{SCHWANNZELLEN REAGIEREN AUCH NACH EINER NERVENSCHÄDIGUNG AUF AXONAL EXPRIMIERTES NEUREGULIN-1}

Die Entwicklung von Schwannzellen im peripheren Nervensystem wird maßgeblich durch die neuronale Expression von Neuregulin-1 Typ III gesteuert (Nave und Salzer 2006). Axonal exprimiertes Neuregulin-1 Typ III kontrolliert zudem die Myelindicke im PNS (Michailov et al. 2004). Obwohl das periphere Nervensystem eine herausragende Plastizität und Regenerationsfähigkeit nach einer Nervenverletzung aufweist, zeigen Schwannzellen häufig nur eine unvollständige Remyelinisierung und die Myelindicke regenerierter Axone erreicht nicht wieder ihren ursprünglichen Wert (Jessen und Mirsky 2008, Schröder 1972, Sherman und Brophy 2005). Verlieren Schwannzellen nach einer Nervenverletzung die Fähigkeit, den Axondurchmesser - d.h. den Surrogatmarker Neuregulin-1 Typ III auf der axonalen Oberfläche - wahrzunehmen? Die vorliegenden Ergebnisse zeigen, dass die neuronale Überexpression von Neuregulin-1 Typ III in transgenen Tieren auch nach einer Nervenschädigung zu einer Hypermyelinisierung führt, die in etwa der Hypermyelinisierung während der Entwicklung entspricht (Michailov et al. 2004). Im Gegensatz zur Entwicklung beeinflusst jedoch nicht nur Neuregulin-1 Typ III, sondern auch Neuregulin-1 Typ I die Remyelinisierung im PNS. Die Überexpression von Neuregulin-1 Typ I führt dabei zu einer Rekonstitution der physiologischen Myelindicke regenerierter Axone.

Redifferenzierte Schwannzellen bleiben demnach auch nach einer Nervenschädigung Neuregulin-1 responsibel. Dies bedeutet, dass Schwannzellen nach einem Nervenschaden die „normale“ Myelindicke wieder herstellen können, wenn ein ausreichendes Angebot an neuronal exprimiertem Neuregulin-1 vorliegt.

Nach einem akuten Nervenschaden degenerieren die Axone distal des Schädigungsortes im Rahmen der Wallerischen Degeneration (Jessen und Mirsky 2008, Chen et al. 2007). Die neu auswachsenden Nervenfasern erreichen erst nach einigen Wochen ihren Zielort (Jessen und Mirsky 2008, Chen et al. 2007). Die Schwannzellen distal der Schädigung verlieren in dieser Zeit den Kontakt zum Axon und sind denerviert. Folglich können Schwannzellen währenddessen nicht durch axonal exprimiertes Neuregulin-1 stimuliert werden. Im Gegensatz zur Entwicklung weisen Schwannzellen nach einer Nervenschädigung somit die Fähigkeit auf, ohne axonalen Kontakt und neuronales Neuregulin-1-Signal die initiale Redifferenzierung (nach abgeschlossener Dedifferenzierungsphase) auszuführen.

\subsection{SCHWANNZELLEN EXPRIMIEREN NEUREGULIN-1 TYP I NACH EINER NERVENVERLETZUNG}

Bisher wurden keine spezifischen Faktoren identifiziert, die die Redifferenzierung von Schwannzellen nach einer Nervenverletzung regulieren. Jedoch wurde schon in früheren 
Studien beobachtet, dass die Expression von Neuregulin-1 im N. ischiadicus nach einer Schädigung induziert wird (Carroll et al. 1997). Neuregulin-1, spezifisch die Typ-I-Isoform, wird dabei insbesondere zwischen dem 1. und 14. Tag, d.h. zu frühen Zeitpunkten nach einer Nervenverletzung heraufreguliert (Stassart et al. 2012a). Schwannzellen exprimieren folglich Neuregulin-1 Typ I, wenn sie den Kontakt zu Axonen, und somit auch zu axonal exprimiertem Neuregulin-1, verloren haben. Im nicht geschädigten Nerven hingegen weisen Schwannzellen nur eine sehr geringe Neuregulin-1-Expression auf.

Wie wird die Neuregulin-1-Expression in Schwannzellen reguliert? Die Behandlung von primären Schwannzellkulturen mit exogenem, rekombinantem Neuregulin-1 inhibiert die Expression von Schwannzell Neuregulin-1 Typ I sowohl auf mRNA als auch auf Proteinebene. Diese Ergebnisse konnten mit verschiedenen weiteren in vitro und in vivo Analysen bestätigt werden (Stassart et al. 2012a). Zudem wurde gezeigt, dass ErbB2/3 Rezeptoren und der MAPK Signalweg die Herrunterregulation der Neuregulin-1-Typ-I-Expression durch exogenes Neuregulin-1 vermitteln (Stassart et al. 2012a).

In der Zusammenschau führten diese Ergebnisse zu dem hypothetischen Modell, dass die axonale Neuregulin-1-Expression im nicht geschädigten Nerven die Expression von Schwannzell Neuregulin-1 über ErbB2/3 Rezeptoren auf der glialen Zellmembran und den MAPK Signalweg inhibiert (Abb.12). Im Fall einer Nervenschädigung wird diese Inhibition durch den Verlust des axonalen Neuregulin-1-Signals aufgehoben, und die denervierte Schwannzelle induziert selbst die Expression von Neuregulin-1 Typ I (Abb. 12). Prinzipiell könnten auch andere Faktoren wie die Demyelinisierung und die Dedifferenzierung von Schwannzellen nach einer Nervenschädigung zu einer Induktion von Schwannzell Neuregulin-1 beitragen. Interessanterweise lässt sich die Heraufregulation von Neuregulin-1 in Schwannzellen jedoch auch in Mausmutanten mit einer Hemizygotie für Neuregulin-1 Typ III ohne zusätzliche Nervenschädigung (und folglich ohne Demyelinisierung und Dedifferenzierung) beobachten (Stassart et al. 2012a). 


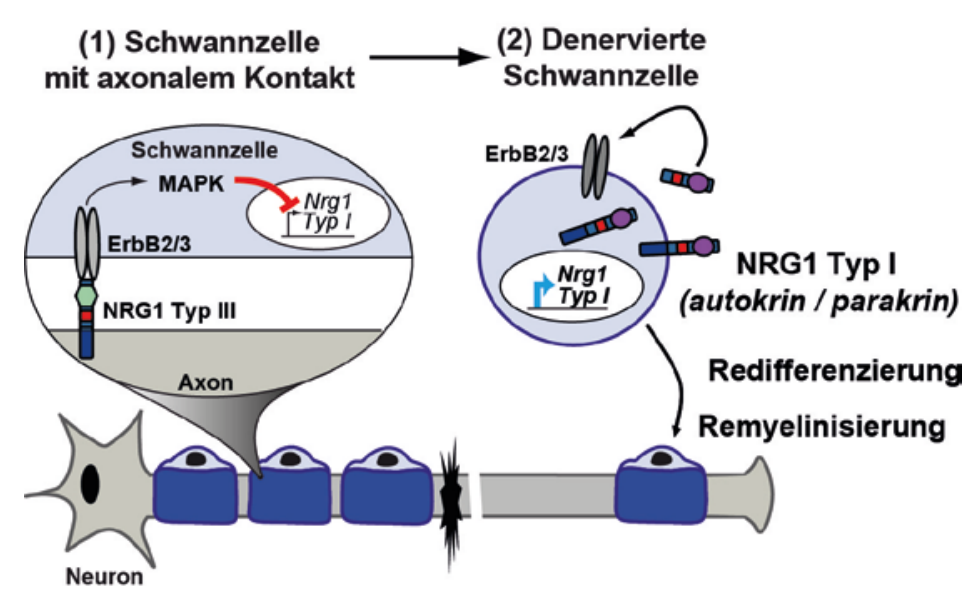

Abb. 12: Modell zur Funktion von NRG1 im intakten Nerv und nach einer Nervenschädigung.

a: In nicht geschädigten, intakten Nerven reguliert Neuregulin-1 Typ III, exprimiert auf der axonalen Oberfläche, die Schwannzellentwicklung und die Myelindicke im PNS. Solange die Schwannzelle Kontakt zum Axon hat, wird die Schwannzell Expression von Neuregulin-1 Typ I über ErbB2/3 Rezeptoren und den MAPK Signalweg inhibiert. Nach einer Nervenschädigung kommt es temporär (aufgrund der Wallerischen Degeneration) zu einem Verlust des axonalen Kontaktes, und die Schwannzellen sind denerviert. Während dieses Zeitraumes empfangen die Schwannzellen kein axonales Neuregulin-1-Signal. Die Inhibition von Schwannzell Neuregulin-1 wird somit aufgehoben, und Schwannzellen synthesieren selbst Neuregulin-1 Typ I. Schwannzell Neuregulin-1 Typ I unterstützt während der Abwesenheit von neuronalem Neuregulin-1 Typ III die Redifferenzierung und Remyelinisierung von Schwannzellen im regenerierten Nerven.

\subsection{SCHWANNZELL-NRG1 BEEINFLUSST DIE SCHWANNZELL-REDIFFERENZIERUNG}

Eine spezifische Deletion von Neuregulin-1 in Schwannzellen (in $D h h^{C r e} \times \mathrm{Nrg}^{\text {loxP/loxP }}$ Mäusen) führt während der Entwicklung des peripheren Nervensystems zu keinen Auffälligkeiten, und die Nerven adulter Mäuse zeigen eine unveränderte Myelindicke. Dass Schwannzell Neuregulin-1 für die Funktion des ungeschädigten peripheren Nerven nicht erforderlich ist, könnte durch die kontinuierliche Stimulation von Schwannzellen mit axonal exprimiertem Neuregulin-1 Typ III während der Entwicklung erklärt werden. Diese Ergebnisse sind somit gut vereinbar mit einer spezifischen Rolle von Schwannzell Neuregulin-1 für Situationen, in denen axonal exprimiertes Neuregulin-1 fehlt.

Tatsächlich zeigen Schwannzell Neuregulin-1 defiziente Mäuse nach einer Nervenschädigung eine verschlechterte Remyelinisierung mit einer verstärkten Hypomyelinisierung sowie einer Reduktion der Anzahl remyelinisierter Axone. Während der Dedifferenzierungsphase ist die Anzahl der degenerierten und noch erhaltenen Axone in $D h h^{C r e} \times \mathrm{Nrg}^{\text {loxP/loxP }}$ Mäusen unverändert. Allerdings zeigen die Mutanten eine erhöhte Anzahl an Myelinovoiden. Diese Ergebnisse weisen darauf hin, dass der Prozess der Wallerischen Degeneration in den Mutanten geringfügig schneller verläuft. Möglicherweise ist Schwannzell Neuregulin-1 an der Feinregulierung der Demyelinisierung und der Dedifferenzierung von Schwannzellen beteiligt, indem es als Differenzierungsfaktor den zeitlichen Ablauf der Wallerischen Degeneration verlangsamt. Um diese Beobachtungen besser zu verstehen, sind zusätzliche Analysen zu verschiedenen Zeitpunkten während der Dedifferenzierungsphase notwendig. 
Im weiteren Verlauf der Nervenregeneration (zwei Wochen nach Nervenkompression) zeigen Mäuse mit einer Deletion von Schwannzell Neuregulin-1 eine eingeschränkte Redifferenzierung mit einer reduzierten Expression des Transkriptionsfaktors EGR2 im Vergleich zu Kontrollmäusen (Stassart et al. 2012a).

Die Induktion der Expression von Neuregulin-1 in Schwannzellen ist demnach notwendig, um die Schwannzellredifferenzierung im richtigen Zeitfenster zu induzieren, und in der Folge eine erfolgreiche Remyelinisierung im peripheren Nervensystem zu gewährleisten (Abb.12). Schwannzell Neuregulin-1 stellt somit einen spezifischen, endogenen ReparaturWachstumsfaktor für Schwannzellen nach einer Nervenschädigung dar. Ob Schwannzell Neuregulin-1 seine Wirkung über einen autokrinen oder einen parakrinen Signalweg vermittelt, muss in weiterführenden Studien untersucht werden.

\subsection{DiE FUNKTION VON GLIALEM UND NEURONALEM NRG1 TYP I WÄHREND DER REMYELINISIERUNG}

Was ist die spezifische Rolle der Typ-I-Isoform von Neuregulin-1 für die Remyelinisierung des peripheren Nervensystems? Die neuronale Überexpression von Neuregulin-1 Typ I in transgenen Mäusen führt zu einer deutlich verbesserten Remyelinisierung mit einer Wiederherstellung der ursprünglichen, physiologischen Myelindicke. In Schwannzellen wird die Expression von Neuregulin-1 Typ I (und nicht von Typ II und III) nach einer Nervenschädigung induziert, und eine Deletion von Neuregulin-1 in Schwannzellen führt zu einer verschlechterten Remyelinisierung im PNS.

Die endogene Expression von Neuregulin-1 Typ I in Motoneuronen und Spinalganglien ist sehr gering (Falls 2003, Loeb et al. 1999), und während der Entwicklung ist Neuregulin-1 Typ I nicht an der Regulation der Myelindicke beteiligt (Michailov et al. 2004). Demnach stellt die neuronale Überexpression eine sehr artifizielle Situation dar und es ist folglich eher unwahrscheinlich, dass die endogene neuronale Expression von Neuregulin-1 Typ I in Neuronen peripherer Axone in vivo während der Remyelinisierung von Bedeutung ist. Neuregulin-1 Typ I wirkt jedoch im Gegensatz zu Neuregulin-1 Typ III als parakrines Signals (Falls 2003). Dies hat insbesondere nach einem Nervenschaden den Vorteil, dass das Neuregulin-1 Typ I Signal denervierte Schwannzellen über eine verhältnismäßig grössere Distanz erreichen kann.

Simuliert nach einem Nervenschaden die neuronale Neuregulin-1 Typ I Überexpression die Induktion von Neuregulin-1 Typ I in Schwannzellen? Interessanterweise zeigen Nrg1 Typ I transgene Tiere, verpaart mit $D h h^{\text {Cre }} \times \mathrm{Nrg}^{\text {loxP/loxP }}$ Mäuse keine verbesserte Remyelinsierung als reine $D h h^{\text {Cre }} \times N r g 1^{\text {loxP/loxP }}$ Tiere. Die neuronale Überexpression von Neuregulin-1 Typ I kann also den Verlust von Schwannzell Neuregulin-1 nicht kompensieren. Neuronales und gliales Neuregulin-1 Typ I müssen sich dennoch funktionell nicht unterscheiden. Vielmehr scheint der zeitliche Verlauf der Remyelinisierung und der Neuregulin-1-Expression in beiden Zelltypen eine wesentliche Rolle zu spielen. Das axonale Neuregulin-1-Signal kann die Schwannzellen erst wieder nach erfolgter axonaler Regeneration erreichen. Dass heisst, auch in Mäusen mit 
einer neuronalen Neuregulin-1 Tyр । Überexpression fehlt denervierten Schwannzellen zunächst das axonale Neuregulin-1 Typ I Signal. In dieser Phase müssen Schwannzellen jedoch dedifferenzieren, proliferieren und die initiale Redifferenzierung beginnen. In dieser Zeit sind Schwannzellen folglich abhängig von selbst exprimierten Wachstumsfaktoren, d.h. sie benötigen endogenes Neuregulin-1 Typ I. Wenn die initiale Redifferenzierung aufgrund der Deletion von Neuregulin-1 in Schwannzellen in diesem Zeitfenster nicht erfolgen kann, kann auch axonales Neuregulin-1 Typ I (welches erst viel später in der Remyelinisierung die Schwannzellen erreicht) den Redifferenzierungsdefekt nicht mehr kompensieren.

Zusammenfassend beeinflusst nach diesem Modell Schwannzell Neuregulin-1 Typ I die frühe Redifferenzierung und Remyelinisierung, während axonal exprimiertes Neuregulin-1 (Typ I und III) die terminale Remyelinisierung und die Myelindicke regenerierter Axone reguliert.

Für das Zeitfenster nach einer Nervenverletzung, in dem Schwannzellen durch Wallerische Degeneration den axonalen Kontakt verlieren, wechselt die für die Regeneration notwendige Neuregulin-1-Expression temporär von Axonen zu Schwannzellen selbst. Dieses Zeitfenster stellt somit einen interessanten Ansatzpunkt für zukünftige therapeutische Strategien zur Verbesserung der Remyelinisierung und Regeneration im PNS dar. 


\section{ZUSAMMENFASSUNG}

Im Gegensatz zu den meisten reifen Geweben weist das periphere Nervensystem eine ausgeprägte Regenerationsfähigkeit nach Verletzungen auf (Jessen und Mirsky 2008). Schwannzellen zeigen während der Nervenregeneration eine erstaunliche Plastizität, indem sie zunächst in proliferierende Vorläuferzellen dedifferenzieren um anschließend in remyelinisierende, reife Schwannzellen zu redifferenzieren (Jessen und Mirsky 2008). Die Myelindicke regenerierter Axone erreicht jedoch nicht wieder den ursprünglichen, physiologischen Durchmesser, und die Nervenfasern bleiben hypomyelinisiert (Schröder 1972, Sherman und Brophy 2005).

Während der Entwicklung des peripheren Nervensystems kontrolliert axonal exprimiertes Neuregulin-1 Typ III alle Stadien der Schwannzellentwicklung und reguliert die Myelindicke (Michailov et al. 2004). Auch nach einer Nervenschädigung bleibt Neuregulin-1 für eine erfolgreiche Remyelinisierung essentiell (Fricker et al. 2011, Stassart et al. 2013), die Rolle von Neuregulin-1 unterscheidet sich jedoch in vieler Hinsicht von der während der Entwicklung. In der vorliegenden Promotionsarbeit konnte gezeigt werden, dass nach einer Nervenverletzung durch die transgene Überexpression von Neuregulin-1 Typ III in Neuronen eine Hypermyelinisierung der regenerierten Axone induziert werden kann. Im Gegensatz zur Entwicklung führt jedoch auch die axonale Überexpression der parakrinen Neuregulin-1 Typ-IIsoform zu einer verbesserten Remyelinisierung, und die Myelindicke erreicht in diesen Tieren ihren ursprünglichen, physiologischen Wert. Schwannzellen verlieren folglich nach einer Nervenverletzung nicht die Fähigkeit auf axonal exprimiertes Neuregulin-1 zu reagieren.

Nach einer Nervenschädigung werden Schwannzellen - im Unterschied zur Nervenentwicklung - nicht kontinuierlich durch axonal exprimiertes Neuregulin-1 stimuliert, da die Axone distal der Schädigung im Rahmen der Wallerischen Degeneration abgebaut werden. Dies bedeutet, dass denervierten Schwannzellen temporär das neuronale Neuregulin-1-Signal fehlt. Während dieses Zeitraumes „wechselt“ die Neuregulin-1-Expression von Axonen zu Schwannzellen, welche innerhalb eines Tages nach einer Nervenschädigung spezifisch die Synthese von Neuregulin-1 Typ I induzieren. Eine erhöhte Schwannzell Neuregulin-1-Typ-I-Expression ist dabei insbesondere während der frühen Remyelinisierung, d.h. in den ersten 14 Tagen nach Nervenschädigung, zu beobachten.

Axonal exprimiertes Neuregulin-1 reguliert die de novo Synthese von Schwannzell Neuregulin-1 Typ I. In vitro Analysen ergaben, dass die Behandlung von primären Schwannzellkulturen mit exogenem, rekombinantem Neuregulin-1 zu einer Inhibition der Schwannzell Neuregulin-1-TypI-Expression führt. Weiterführende Untersuchungen zeigten, dass exogenes (axonales) Neuregulin-1 über ErbB2/3 Rezeptoren und den MAPK Signalweg die Expression von Schwannzell Neuregulin-1 Typ I negativ reguliert (Stassart et al. 2013).

Die in vivo Relevanz der Schwannzell Neuregulin-1-Expression nach einer Nervenschädigung konnte mit Hilfe von Mausmutanten mit einer Deletion von Schwannzell Neuregulin-1 (Dhh ${ }^{\text {Cre }} x$ $N r g 1^{\text {loxP/loxP }}$ Mäuse) nachgewiesen werden. Die Analyse dieser Mutanten ergab, dass 
Schwannzell Neuregulin-1 für die frühe Redifferenzierung und Remyelinisierung nach Nervenschädigung benötigt wird, wohingegen es im intakten Nerven entbehrlich ist.

Die Überexpression von neuronalem Neuregulin-1 Typ I (in Nrg1 Typ I tg Tieren, die eine Rekonstitution der Myelindicke nach Nervenschädigung aufweisen) kann dabei den Verlust von Schwannzell Neuregulin-1 (in einer Verpaarung mit $D h h^{\mathrm{Cre}} \times \mathrm{Nrg}^{\text {loxP/loxP }}$ Mäusen) nicht kompensieren. Die Funktionen von glialem und neuronalem Neuregulin-1 sind demnach im zeitlichen Verlauf der Remyelinisierung verschieden.

Zusammenfassend ist die Funktion von Neuregulin-1 nach einer Nervenschädigung wesentlich komplexer als während der Entwicklung, und umfasst sowohl axonal als auch glial exprimiertes Neuregulin-1. Gliales Neuregulin-1 Typ I wird induziert, wenn Schwannzellen den Kontakt zu Axonen und axonal exprimiertem Neuregulin-1 Typ III verloren haben. Schwannzell Neuregulin1 dient dabei als endogener Wachstumsfaktor, welcher spezifisch die initiale Redifferenzierungs- und Remyelinisierungsphase von Schwannzellen beeinflusst. Neuronal exprimiertes Neuregulin-1 (Typ I und III) reguliert hingegen die terminale Redifferenzierung und die Myelindicke nach einer Nervenschädigung im PNS. 


\section{ABBILDUNGSVERZEICHNIS}

Abbildung 1: Die Entwicklung von Schwannzellen im peripheren Nerv

Abbildung 2: Die Struktur der Neuregulin-1-Isoformen Typ I-III

Abbildung 3: Die neuronale Überexpression von NRG1 Typ III führt zu einer Hypermyelinisierung nach Nervenkompression

Abbildung 4: Neuronales NRG1 Typ I verbessert die Remyelinisierung im PNS

Abbildung 5: Die Schwannzellproliferation und Differenzierung ist nach Nervenkompression in Nrg1 Typ I transgenen Tieren unverändert

Abbildung 6: Schwannzellen exprimieren Neuregulin-1 nach Nervenkompression im PNS

Abbildung 7: Die Behandlung von primären Schwannzellkulturen mit rekombinantem NRG1 inhibiert die NRG1 Expression in Schwannzellen

Abbildung 8: Schwannzell Neuregulin-1 defiziente Mäuse zeigen eine normale Myelinisierung im PNS

Abbildung 9: Die Deletion von Neuregulin-1 in Schwannzellen führt zu einer verschlechterten Remyelinisierung vier Wochen nach Nervenkompression

Abbildung 10: Der Einfluss von Schwannzell Neuregulin-1 auf die Wallerische Degeneration vier Tage nach Nervenkompression

Abbildung 11: Die neuronale Überexpression von Neuregulin-1 Typ I kann den Verlust von Schwannzell Neuregulin-1 vier Wochen nach Nervenkompression nicht kompensieren

Abbildung 12: Model zur Funktion von Neuregulin-1 im intakten Nerv und nach einer Nervenschädigung 


\section{LITERATURVERZEICHNIS}

Arthur-Farraj PJ et al. (2012): c-Jun reprograms Schwann cells of injured nerves to generate a repair cell essential for regeneration. Neuron 75 (4), 633-647

Atanasoski S, Scherer SS, Sirkowski E, Leone D, Garrat AN, Birchmeier C, Suter U (2006): ErbB2 signaling in Schwann cells is mostly dispensable for maintenance of myelinated peripheral nerves and proliferation of adult Schwann cells after injury. J Neurosci 26 (7), 2124-2131

Bähr M, Frotscher M, Küker W: Duus' Neurologisch-topische Diagnostik. 8., komplett überarbeitete Auflage; Georg Thieme Verlag, Stuttgart 2003

Bermingham-McDonogh O, Xu YT, Marchionni MA, Scherer SS (1997): Neuregulin expression in PNS neurons: isoforms and regulation by target interactions. Mol Cell Neurosci 10(3-4), 184-195

Birchmeier C, Nave KA (2008): Neuregulin-1, a key axonal signal that drives Schwann cell growth and differentiation. Glia 56 (14), 1491-1497

Bosse F (2012): Extrinsic cellular and molecular mediators of peripheral axonal regeneration. Cell Tissue Res $\underline{349(1)}, 5-14$

Brinkmann BG et al. (2008): Neuregulin-1/ErbB signaling serves distinct function in myelination of the peripheral and central nervous system. Neuron 59 (4), 581-595

Carroll SL, Miller ML, Frohnert PW, Kim SS, Corbett JA (1997): Expression of neuregulins and their putative receptors, ErbB2 and ErbB3, is induced during Wallerian degeneration. J Neurosci 17(5), 16421659

Campbell NA, Reece JB: Biologie. 6. Auflage; Spektrum Akademischer Verlag GmbH, Heidelberg 2003

Chen ZL, Yu WM, Strickland S (2007): Peripheral regeneration. Annu Rev Neurosci 30, 209-233

Eckert R, Burggren W, French K, Randall D: Tierphysiologie. 4. Auflage; Georg Thieme Verlag, Stuttgart 2002

Emery B (2010): Transcriptional and post-transcriptional control of CNS myelination. Curr Opin Neurobiol $20(5), 601-607$

Emery B (2010a): Regulation of oligodendrocyte differentiation and myelination. Science 330 (6005), 779782

Falls DL (2003): Neuregulins: functions, forms, and signaling strategies. Exp Cell Res 284 (1), 14-30

Friede RL, Bischhausen R (1982): How are sheath dimensions affected by axon caliber and internode length. Brain Res 235 (2), 335-350

Fricker FR et al. (2011): Axonally derived neuregulin-1 is required for remyelination and regeneration after nerve injury in adulthood. J Neurosci 31 (9), 3225-3333

Fricker FR, Bennett DL (2011): The role of neuregulin-1 in the response to nerve injury. Future Neurol $\underline{6}$ (6), 809-822

Frostick SF, Yin Q, Kemp GJ (1998): Schwann cells, neurotrophic factors, and peripheral nerve regeneration. Microsurgery $\underline{18(7)}, 397-405$

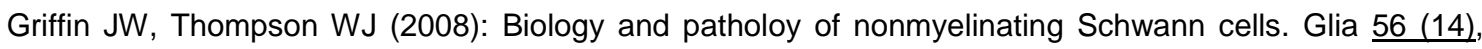
1518-1531

Haberland C: Clinical Neuropatholoy. Demos Medical Publishing, New York 2007

Hanisch UK, Kettenmann H (2007): Microglia: active sensor and versatile effector cells in the normal and pathogenic brain. Nat Neurosci 10 (11), 1387-1394 
Hellemans J, Mortier G, De Paepe A, Speleman F, Vandesompele J (2007): qBase relative quantification framework and software for management and automated analysis of real-time quantitative PCR data. Genome Biol 8(2), R19

Jaegle M, Ghazvini M, Mandemakers W, Piirsoo M, Driegen S, Levavasseur F, Raghoenath S, Grosveld F, Meijer D (2003): The POU proteins Brn-2 and Oct-6 share important functions in Schwann cell development. Genes Dev 17(11), 1380-1391

Jessen KR, Mirsky R (2005): The origin and development of glial cells in peripheral nerves. Nat Rev Neurosci 6 (9), 671-682

Jessen KR, Mirsky R (2008): Negative regulation of myelination: relevance for development, injury, and demyelinating disease. Glia 56 (14): 1552-1565

Kao SC, Wu H, Xie J, Chang CP, Ranish JA, Graef IA, Crabtree GR (2009): Calcineurin/NFAT signaling is

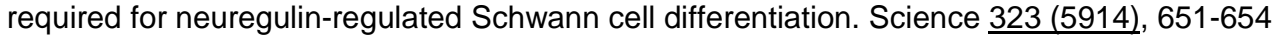

Karnovsky MJ (1965): A formaldehyde-glutaraldehyde fixative of high osmolality for electron microscopy. J Cell Biol 27, 137-138

Laemmli UK (1970): Cleavage of structural proteins during the assembly of the head of bacteriophage T4. Nature $\underline{15}, 680-685$

Li L, Cleary S, Mandarano MA, Long W, Birchmeier C, Jones FE (2002): The breast proto-oncogene, HRGalpha regulates epithelial proliferation and lobuloalveolar development in the mouse mammary gland. Oncogene 21(32), 4900-4907

Loeb JA, Khurana TS, Robbins JT, Yee AG, Fischbach GD (1999): Expression patterns of transmembrane and released forms of neuregulin during spinal cord and neuromuscular synapse development. Development 126(4), 781-791

Luft JH (1961): Improvements in epoxy resin embedding methods. J Biophys Biochem Cytol $\underline{9}$, 409-414.

Michailov GV, Sereda MW, Brinkmann BG, Fischer TM, Haug B, Birchmeier C, Role L, Lai C, Schwab MH, Nave KA (2004): Axonal neuregulin-1 regulates myelin sheath thickness. Science 304 (5671), 700-703

Mirsky R, Woodhoo A, Parkinson DB, Arthur-Farraj P, Bhaskaran A, Jessen KR (2008): Novel signals controlling embryonic Schwann cell development, myelination and dedifferentiation. J Peripher Nerv Syst $\underline{13(2)}, 122-135$

Mullis K, Faloona F, Scharf S, Saiki R, Horn G, Erlich H (1986): Specific enzymatic amplification of DNA in vitro: the polymerase chain reaction. Cold Spring Harb Symp Quant Biol 51(1), 263-273

Napoli I et al. (2012): A central role for the ERK-signaling pathway in controlling Schwann cell plasticity and peripheral nerve regeneration in vivo. Neuron $\underline{73}(4), 729-742$

Nave KA, Salzer JL (2006): Axonal regulation of myelination by neuregulin 1. Curr Opin Neurobiol $\underline{16}$ (5), 492-500

Nave KA (2010): Myelination and support of axonal integrity by glia. Nature 468 (7321), 244-252

Newbern J, Birchmeier C (2010): Nrg1/ErbB signaling networks in Schwann cell development and myelination. Semin Cell Dev Biol 21 (9), 922-928

Newbern J et al. (2011): Specific functions for ERK/MAPK signaling during PNS development. Neuron $\underline{69}$ (1), 91-105

Oberheim NA, Goldman SA, Nedergaard M (2012): Heterogeneity of astrocytic form and function. Methods Mol Biol $\underline{814}, 23-45$

Ohno $\mathrm{M}$ et al. (2009): Nardilysin regulates axonal maturation and myelination in the central and peripheral nervous system. Nat Neurosci $\underline{12}, 1506-1513$

Peters A, Palay SL, deF Webster H: The fine structure of the nervous system. 3. Auflage; Oxford University Press, New York 1991

Pertusa M, Morenilla-Palao C, Carteron C, Viana F, Cabedo H (2007): Transcriptional control of cholesterol biosynthesis in Schwann cells by axonal Neuregulin-1. J Biol Chem 282(39), 28768-28778 
Quarles RH, Macklin WB, Morell P: Myelin Formation, Structure and Biochemistry; in: Basic Neurochemistry: Molecular, Cellular and Medical Aspects.; hrsg. Von Siegel G, Albers RW, Brady S, Price D; Band 1; Elsevier Academic Press, London 2006, 51-71

Reynolds ES (1963): The use of lead citrate at high $\mathrm{pH}$ as an electron-opaque stain in electron microscopy. J Cell Biol 17, 208-212

Richardson KC, Jarett L, Finke EH: Embedding in epoxy resins for ultrathin sectioning in electron microscopy. Stain Technol 1960, 35, 313-323

Rivest S (2009): Regulation of innate immune responses in the brain. Nat Rev Immunol 9 (6), 429-439

Sandrock AW Jr, Dryer SE, Rosen KM, Gozani SN, Kramer R, Theill LE, Fischbach GD (1997): Maintenance of acetylcholine receptor number by neuregulins at the neuromuscular junction in vivo. Science 276 (5312), 599-603

Schröder JM (1972): Altered ratio between axon diameter and myelin sheath thickness in regenerated nerve fibers. Brain Res 45 (1), 49-65

Sherman DL, Brophy PJ (2005): Mechanisms of axon ensheathment and myelin growth. Nat Rev Neurosci $\underline{6(9)}, 683-690$

Simons M, Trotter J (2007): Wrapping it up: the cell biology of myelination. Curr Opin Neurobiol $\underline{17(5)}$, 533-540

Stassart RM, Goebbels S, Nave KA: Factors controlling myelin formation; in Neuroglia; Kettenmann $\mathrm{H}$ und Ransom B. 3. Auflage, Oxford University Press, New York 2012, Kapitel 44.

Stassart RM, Fledrich R, Velanac V, Brinkmann BG, Schwab MH, Meijer D, Sereda MW, Nave KA (2013): A role for Schwann cell-derived neuregulin-1 in remyelination. Nat Neurosci 16(1), 48-54

Stoll G, Müller HW (1999): Nerve injury, axonal degeneration and neural regeneration: basic insights. Brain Pathol 9 (2), 313-325

Taveggia C et al. (2005): Neuregulin-1 type III determines the ensheathment fate of axons. Neuron $\underline{47(5)}$, 681-694

Taveggia C, Feltri ML, Wrabetz L (2010): Signals to promote myelin formation and repair. Nat Rev Neurol $\underline{6(5)}, 276-287$

Trepel M: Neuroanatomie Struktur und Funktion. 2. überarbeitete Auflage; Urban und Fischer Verlag, München 1999

Velanac V et al. (2012): Bace1 processing of NRG1 type III produces a myelin-inducing signal but is not essential for the stimulation of myelination. Glia $\underline{60(2)}, 203-217$

Welsch U: Lehrbuch Histologie. 1. Auflage; Urban und Fischer Verlag, München 2003

Wolpowitz D, Mason TB, Dietrich P, Mendelsohn M, Talmage DA, Role LW (2000): Cysteine-rich domain isoforms of the neuregulin-1 gene are required for maintenance of peripheral synapses. Neuron 25 (1), 79 91 


\section{DANKSAGUNG}

Ich danke Prof. Klaus-Armin Nave, PhD für die Möglichkeit, in seiner Abteilung die Promotionsarbeit durchzuführen. Insbesondere möchte ich mich bei Ihm für die umfassende Unterstützung, sein Vertrauen sowie die vielen wissenschaftlichen Diskussionen und zahreichen wissenschaftlichen Anregungen während vieler Jahre bedanken.

Ich möchte mich bei Prof. Dr. med. Michael W. Sereda bedanken, in dessen Arbeitsgruppe die Arbeit durchgeführt wurde. Ich danke inm für die lange gute Zusammenarbeit, die Betreuung und die Möglichkeit, selbstständig und frei alle Projekte und Ideen verfolgen zu können. Ich möchte mich insbesondere für die jahrelange Unterstützung und für seine Fähigkeit, immer motivierend und positiv auch während schwieriger Zeiten zu wirken, bedanken.

Ich möchte der Arbeitsgruppe von Prof. Dr. med. Michael W. Sereda wie auch der gesamten Abteilung für Neurogenetik für die tolle und offene Arbeitsatmosphäre danken. Besonders danke ich in diesem Zusammenhang Robert Fledrich, Bastian Brinkmann, Gerd Meyer zu Hörste, Theresa Kungl und Susanne Quintes. Weiterhin möchte ich Markus Schwab, Celia Kassmann und Sandra Goebbels für viele Diskussionen danken.

Mein besonderer Dank gilt Robert Fledrich, mit dem dieses Projekt zusammen durchgeführt wurde. Ich möchte mich sehr für die tolle und fruchtbare Zusammenarbeit, die unzähligen Diskussionen und die ständige, unverzichtbare Unterstützung bedanken, ohne die dieses Projekt so nicht zustande gekommen wäre. Zudem möchte ich mich bei Ihm für seine Hilfe in allen Lebenslagen während der letzten Jahre bedanken.

Ich danke Tanja Freerck für die Betreuung meiner Mauslinien sowie Tarik Durkaya für seine Unterstützung bei der Genotypisierung der Tiere. Zudem danke ich Annette Fahrenholz für ihre Hilfe bei der Immunhistochemie.

Weiterhin möchte ich mich bei Prof. Dr. med. Wolfgang Brück für die Möglichkeit bedanken, in der Abteilung für Neuropathologie meine Facharztausbildung absolvieren zu können, sowie für seine Unterstützung, parallel meine wissenschaftlichen Projekte durchführen zu können.

Mein grösster Dank gilt meiner Familie, ohne die das alles nicht möglich gewesen wäre. 